Schriften des Forschungszentrums Jülich

Reihe Energie \& Umwelt / Energy \& Environment

Band / Volume 215 

Forschungszentrum Jülich $\mathrm{GmbH}$

Institut für Energie- und Klimaforschung (IEK)

Werkstoffstruktur und -eigenschaften (IEK-2)

\section{Micro- and Macro-Mechanical Testing of Transparent $\mathrm{MgAl}_{2} \mathrm{O}_{4}$ Spinel}

Oleg Tokariev

Schriften des Forschungszentrums Jülich 
Bibliographic information published by the Deutsche Nationalbibliothek. The Deutsche Nationalbibliothek lists this publication in the Deutsche Nationalbibliografie; detailed bibliographic data are available in the Internet at http://dnb.d-nb.de.

Publisher and Forschungszentrum Jülich $\mathrm{GmbH}$

Distributor: Zentralbibliothek 52425 Jülich

Tel: $\quad+49246161-5368$

Fax: $\quad+49246161-6103$

Email: zb-publikation@fz-juelich.de www.fz-juelich.de/zb

Cover Design: $\quad$ Grafische Medien, Forschungszentrum Jülich $\mathrm{GmbH}$

Printer: $\quad$ Grafische Medien, Forschungszentrum Jülich $\mathrm{GmbH}$

Copyright: $\quad$ Forschungszentrum Jülich 2014

Schriften des Forschungszentrums Jülich

Reihe Energie \& Umwelt / Energy \& Environment, Band / Volume 215

D 82 (Diss., RWTH Aachen University, 2013)

ISSN 1866-1793

ISBN 978-3-89336-960-7

The complete volume is freely available on the Internet on the Jülicher Open Access Server (JUWEL) at www.fz-juelich.de/zb/juwel

Neither this book nor any part of it may be reproduced or transmitted in any form or by any means, electronic or mechanical, including photocopying, microfilming, and recording, or by any information storage and retrieval system, without permission in writing from the publisher. 


\section{ABSTRACT}

The mechanical properties and reliability aspects of advanced transparent fineand coarse-grained $\mathrm{MgAl}_{2} \mathrm{O}_{4}$ spinel have been characterized at ambient and high temperature. The studies were based on a combination of micro- and macro-mechanical methods to assess Young's modulus, hardness, fracture toughness, strength and crack growth kinetics. The results and reliability aspects are discussed in terms of linear elastic fracture mechanics. Strength was analyzed using two- and three-parameter Weibull statistics. The experimental limits of Young's modulus determination using standard ringon-ring testing are highlighted, and an approach is outlined to correct the measured apparent values. Experimentally obtained strength data as a function of loading rate are used to assess the potential effect of subcritical crack growth, yielding the failure time under static loading, via a strength/probability/time plot for a lifetime prediction. Furthermore, the Brinell indentation showed potential for local strength measurement and the data supported a strength-loaded area relationship that was based on the ring-on-ring test data. Novel experimental methods were implemented for fracture determination and strain detection. Particular attention was directed to the effect of defects and associated local strain fields, as assessed using polarized light in photoelastic measurements. Complementary fractography by optical, confocal and scanning electron microscopy provided a correlation between failure initiating defect size and fracture stress. 


\section{KURZFASSUNG}

Mechanische Eigenschaften und Zuverlässigkeitsaspekte fortschrittlicher transparenter fein und grobkörniger $\mathrm{MgAl}_{2} \mathrm{O}_{4}$ Spinelmaterialien wurden bei Raumtemperatur und erhöhten Temperaturen untersucht. Die Untersuchungen basierten auf einer Kombination mikro- und makromechanischer Methoden zur Bestimmung von Young's Modul, Härte, Risszähigkeit, Festigkeit und Risswachstumskinetik. Resultate und Zuverlässigkeit wurden unter Berücksichtigung der linear elastischen Bruchmechanik diskutiert. Die Analyse der Festigkeiten basierte auf Zwei- und Dreiparamter-Weibullstatistiken. Die experimentellen Grenzen der Young's Modul Ermittlung im Fall eines Standard Doppelring-Biegetests werden hervorgehoben und eine Korrekturmethode der scheinbaren experimentellen Werte ist beschrieben. Experimentell als Funktion der Lastrate ermittelte Festigkeitsdaten wurden zur Beurteilung des potenziellen Effekts des unterkritischen Risswachstums verwendet und erlaubten eine Lebensdauervorhersage anhand von Festigkeits - Wahrscheinlichkeits - Zeit Graphen. Weiterhin wurde das Potential der Brinell Härteeindrucksmethode zur Messung der lokalen Festigkeit gezeigt und berechnete Daten stimmten mit einer auf Doppelringmessungen basierten Gleichung des Zusammenhangs Festigkeit - belastete Fläche überein. Neuartige experimentelle Methoden wurden zur Festigkeits- und Dehnungsdetektion eingesetzt. Besondere Aufmerksamkeit wurde auf den Effekt von Defekten und dem damit im Zusammenhang stehenden lokalen Dehnungsfeld gerichtet, wobei Untersuchungen auf photoelastischen Messungen beruhten. Komplementäre fraktographische Untersuchungen mittel optischer, konfokaler und Rasterelektronen Mikroskopie ergaben einen klaren Zusammenhang zwischen versagensrelevanten Defekten und Bruchspannung. 


\section{TABLE OF CONTENTS}

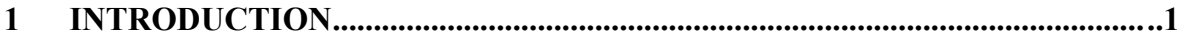

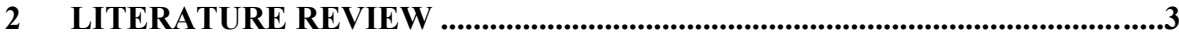

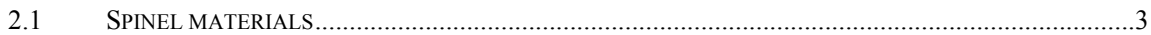

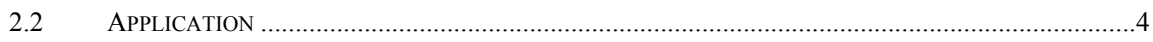

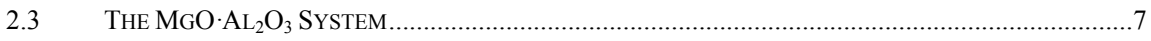

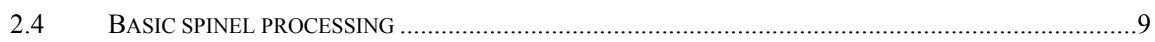

2.5 PHYSICAL, CHEMICAL AND MECHANICAL PROPERTIES ........................................................10

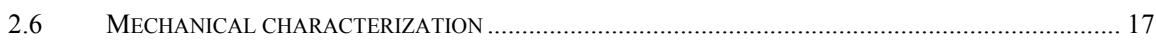

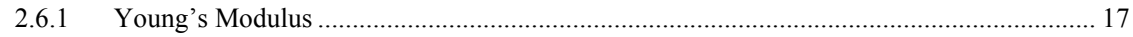

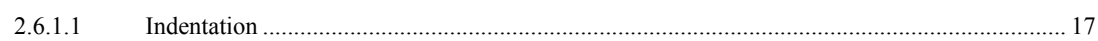

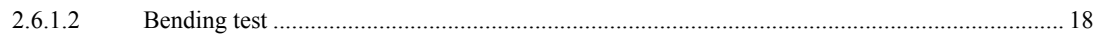

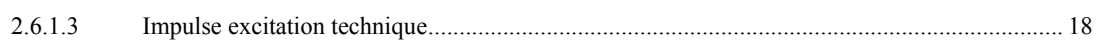

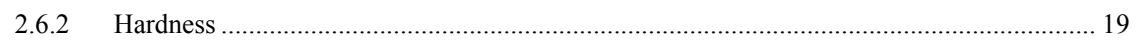

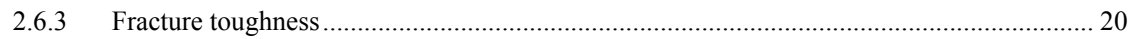

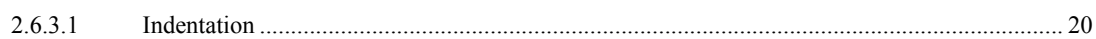

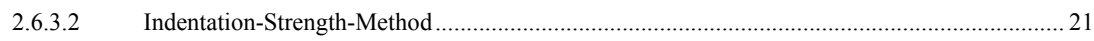

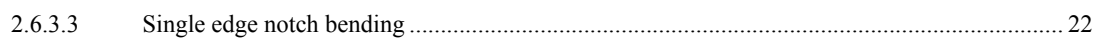

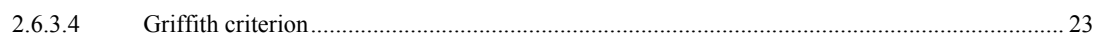

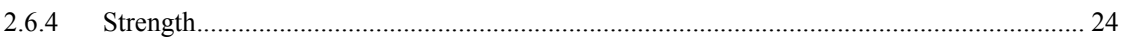

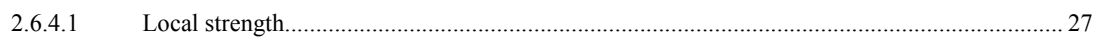

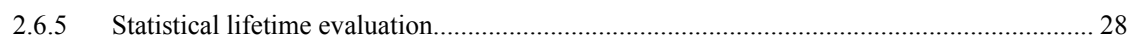

2.6.5.1 Slow crack growth and Strength-Probability-Time (SPT) prediction ................................28

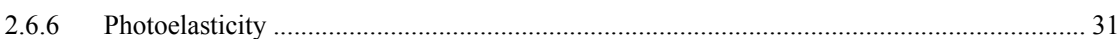

3 INVESTIGATED MATERIALS AND EXPERIMENTAL METHODS........... 32

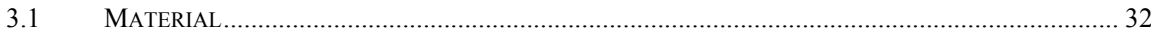

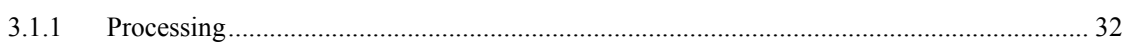

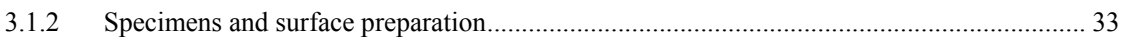

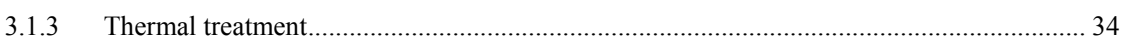

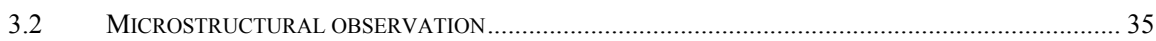

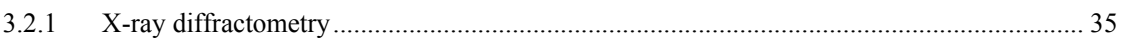




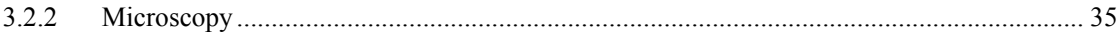

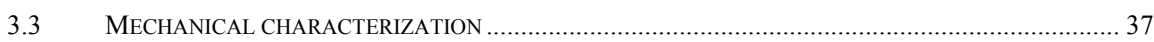

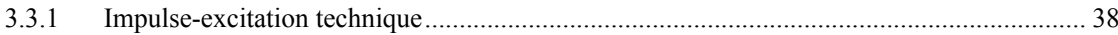

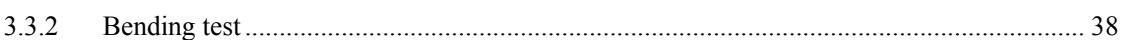

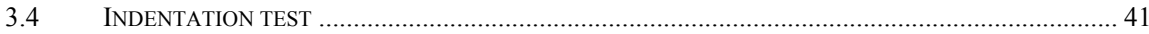

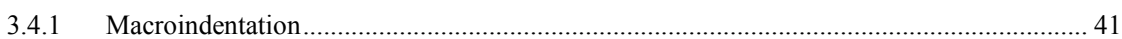

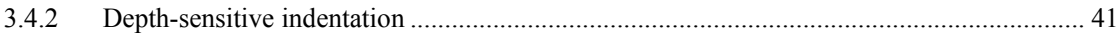

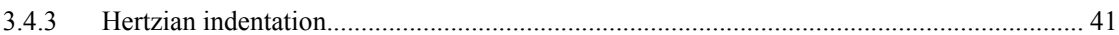

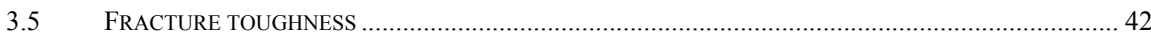

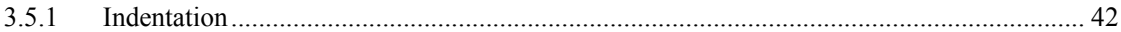

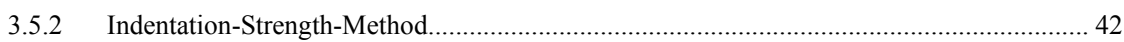

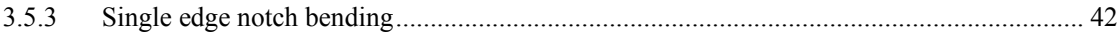

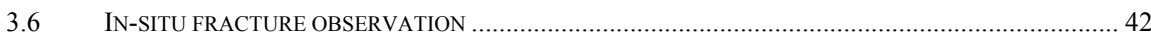

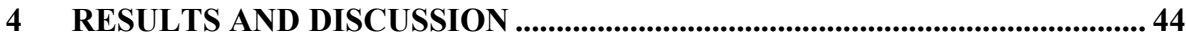

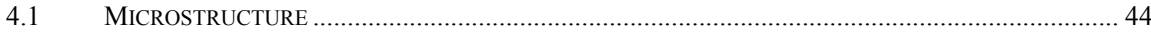

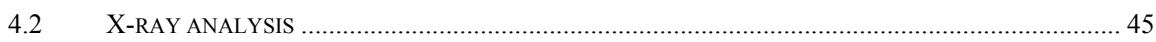

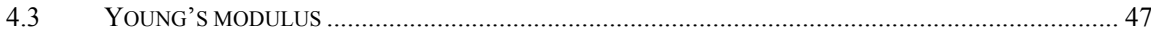

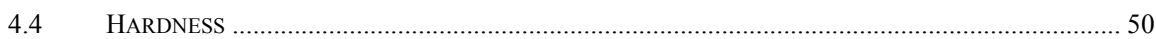

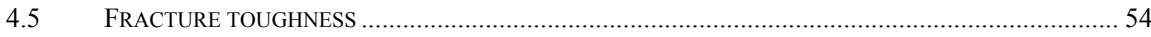

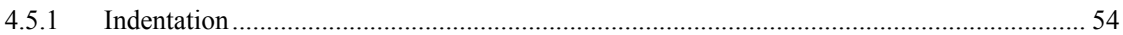

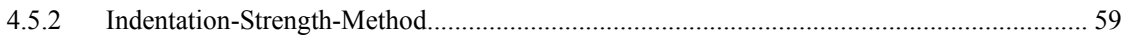

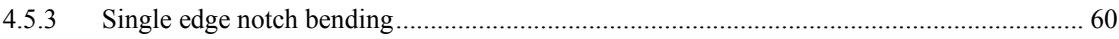

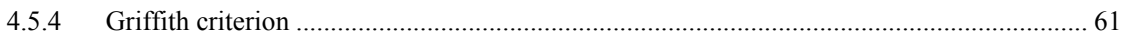

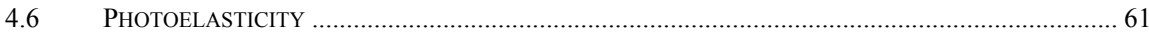

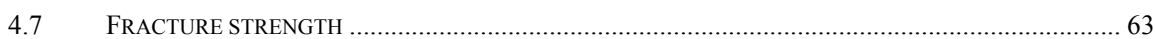

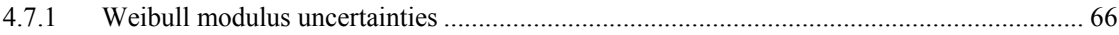

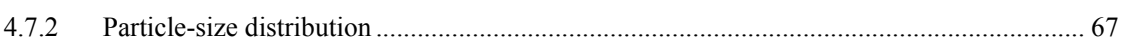

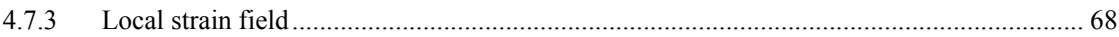

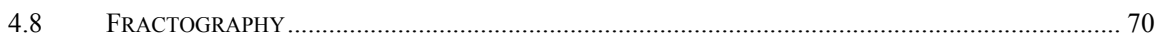

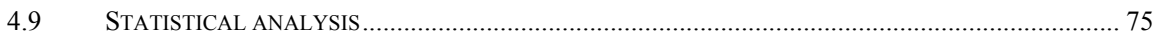

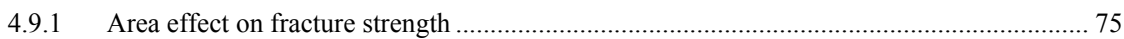

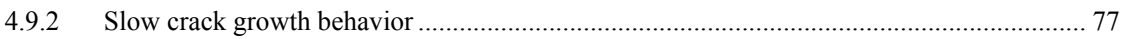

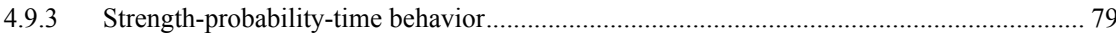

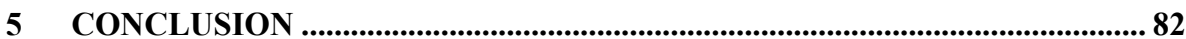

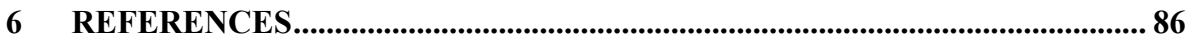




\section{INTRODUCTION}

Ceramics are increasingly utilized in a variety of technical applications, where either specific functional or structural properties (or both) are needed $\left.{ }^{1}\right]$. In particular, transparent ceramics have gained importance in technical window applications $\left[{ }^{2}\right]$. Spinel is a transparent oxide ceramic currently under consideration for such applications. One of the industrial development targets is to produce highly reliable transparent ceramics at low cost. Magnesia spinel $\left(\mathrm{MgAl}_{2} \mathrm{O}_{4}\right)$ appears promising for attaining the envisioned goals by modifying materials and improving the fabrication process. In general, for such functional applications, the mechanical properties must be sufficient to warrant the structural integrity of the component. Therefore, in addition to detailed characterization of the mechanical properties (strength and hardness in particular), analyzing failure origins is a critical aspect.

Results obtained from mechanical measurements and microstructural characterizations in this study are presented for the considered $\mathrm{MgAl}_{2} \mathrm{O}_{4}$ material. In addition, a main focus of this study is to evaluate different micro- and macro-mechanical characterization methods, particularly the utilization and verification of macroscopically non-destructive characterization approaches, and the correlation of results with microstructural features (i.e., grain size, defects). As a novel experimental approach, an indentation testing device developed in-house and permitted in-situ through thickness fracture observation and photoelastic measurements was used for this transparent material to obtain information on the variation of local stress fields.

Elastic modulus, fracture toughness, and fracture strength as important basic materials properties have been characterized thoroughly. In addition, the effect of environmentally assisted subcritical crack growth and its implication on long-term reliability via a strength/probability/time plot was considered.

Of equal importance to the statistical data for materials development and improvement is the knowledge of failure-relevant defects, particularly the effect of imperfections and associated local stress fields. Here, fractographic analysis based on the 
combination of confocal and scanning electron microscopy with advanced software packages provides important information. 


\section{LITERATURE REVIEW}

\subsection{Spinel materials}

The name "spinel" is used for the ternary oxide compound $\mathrm{MgAl}_{2} \mathrm{O}_{4}\left[{ }^{3}\right]$ and also as a name of a group of chemical compounds with an identical crystallographic structure and the general formula $-\mathrm{AB}_{2} \mathrm{O}_{4}$, where $A$ is a divalent charged atom such as $\mathrm{Mg}^{+2}, \mathrm{Fe}^{+2}$, $\mathrm{Mn}^{+2}, \mathrm{Zn}^{+2}$, and $B$ is a trivalent charged atom such as $\mathrm{Al}^{+3}, \mathrm{Fe}^{+3}, \mathrm{Cr}^{+3}, \mathrm{~Pb}^{+3}$. Due to its chemical compatibility with alumina, zirconia and mullite, spinel is also considered to be an attractive matrix for ceramic matrix composites $\left[{ }^{4}\right]$. Some typical examples of the spinel group are aluminates $\left(\mathrm{MgAl}_{2} \mathrm{O}_{4}\right)$, ferrites $\left(\mathrm{MgFe}_{2} \mathrm{O}_{4}\right)$, chromites $\left(\mathrm{FeCr}_{2} \mathrm{O}_{4}\right)$, franklinites $\left(\mathrm{ZnFe}_{2} \mathrm{O}_{4}\right)$, gahnites $\left(\mathrm{ZnAl}_{2} \mathrm{O}_{4}\right)$, magnetites $\left(\mathrm{Fe}_{3} \mathrm{O}_{4}\right)$ and miniumes $\left(\mathrm{Pb}_{2} \mathrm{PbO}_{4}\right)$. The physical and chemical properties of spinel are governed by the $A$ and $B$ compounds as well as by the distribution of cations located at the different crystallographic sites $\left.{ }^{5}\right]$. The $f c c$ cubic spinel crystal structure $(F d 3 m)$ is a close-packed array of oxygen ions with the general formula $\mathrm{AB}_{2} \mathrm{O}_{4}$, in which $\mathrm{Mg}^{+2}$ cations occupy 8 of the 64 tetrahedral interstices and $\mathrm{Al}^{+3}$ cations occupy 16 of the 32 octahedral interstices $\left[{ }^{6},{ }^{7}\right]$ (Fig. 2). The lattice parameter $A_{o}$ of stoichiometric spinel is $0.80832 \mathrm{~nm}\left[{ }^{8}\right]$.

Property optimization motivates continuing efforts to produce new materials, extend phase fields and improve homogeneity $\left[{ }^{9},{ }^{10},{ }^{11}\right]$. This, in turn, provides the impulse to develop new synthesis and processing approaches.

The basic procedures to produce spinel materials have been known since 1905 [ $\left.{ }^{12}\right]$ and the system $\mathrm{MgO} \cdot \mathrm{Al}_{2} \mathrm{O}_{3}$ was defined in $1916\left[{ }^{13}\right]$ and has essentially remained unchanged since then. Already since the 1930s, attempts have been made to apply magnesium aluminate spinels and use them instead of magnesia chromite products, even though the latter have a lower price and are simpler to manufacture. This is due to an increasing awareness of the toxicity of the $\mathrm{Cr}^{+6}$ formed by $\mathrm{Cr}_{2} \mathrm{O}_{3}$ under alkaline conditions, as well as stricter regulations for the use and waste disposals of refractories 
containing chromium species $\left[{ }^{14}\right]$. The awareness of toxicity increased the industrial importance of aluminates $\left(\mathrm{MgAl}_{2} \mathrm{O}_{4}\right)$ and ferrites $\left(\mathrm{MgFe}_{2} \mathrm{O}_{4}\right)$.

In the 1960's, spinel was already recognized for its high hardness, strength and optical transparency $\left[{ }^{15},{ }^{16}\right]$. Transparent polycrystalline spinel was initially developed as a transparent armor material in $1969\left[{ }^{17}\right]$. It was fabricated using classic ceramic technologies: preparing high purity ultrafine spinel powder, pressing the powder into pellets and finally sintering.

Spinel still did not reach much commercial success until the middle 1980s, mainly due to its complex processing. Many studies exist on the effect of processing parameters on the properties of spinel and its composites, both stoichiometric and non-stoichiometric (magnesia or alumina rich compounds) $\left[{ }^{18}\right]$. At the beginning of the $1980 \mathrm{~s}$, polycrystalline spinel was produced by hot-pressing spinel powder, resulting in optical properties equivalent to that of single crystals $\left[{ }^{19}\right]$; starting around the same time, metal oxide spinels have been synthesized by various methods based on the mechanical oxide and/or salt mixtures calcination $\left[{ }^{20},{ }^{21},{ }^{22}\right]$. Recently, micron-grained and sub-microngrained spinels have been produced by means of extremely homogenous slip-casting with acceptable mechanical properties, as well as high transparency in the visible and infrared spectral range $\left[{ }^{23}\right]$. Currently, micron-, submicron- and nano-grained spinels ceramics are under development, and already show many processing and property advantages over conventional coarse-grained spinel $\left[{ }^{24}\right]$. In particular, many methods have been developed to synthesize high quality powders as ingot material $\left[{ }^{25},{ }^{26}\right]$. However, the lack of suitable, well-developed and low-cost preparation methods still limits spinels' application as highperformance transparent ceramics.

\subsection{Application}

In general, spinel compounds are of interest since they exhibit a wide range of novel and adjustable properties, making the material useable for electronic, magnetic, catalytic, photonic and structural applications $\left[{ }^{27},{ }^{28}\right]$.

In particular, the high melting point of the magnesium aluminate spinel $\left(2135^{\circ} \mathrm{C}\right)$, high mechanical strength at ambient and elevated temperatures, good thermal shock resistance and chemical inertness are an important combination of properties, which has 
already led to the application of magnesium aluminate spinels in metallurgy, electrochemistry and chemical industry $\left[{ }^{29}, 30,31\right]$, mainly:

- Refractories

The high melting point and excellent thermal and chemical resistance makes spinel, here as a major component in an alumina-or magnesia-rich matrix, useable for refractory applications. Due to large tensile hoop stresses, the thermal expansion mismatch between periclase and spinel phases in certain areas of phase diagram (20wt.\%, see Fig. 1) leads to micro-crack development around the periclase grains in the spinel matrix if a certain grain size is exceeded. This decreases strength and stiffness, but also can reduce the probability of crack propagation in thermal shock loading $\left[{ }^{32}\right]$. The major application areas of spinel refractories are transition and burning zones of cement rotary kilns, sidewalls and bottoms of steel ladles, because they are resistant to corrosion by slag $\left[{ }^{33}\right]$. Ordinary ceramic refractory materials typically show a heterogeneous porous microstructure, which consists of large (max. grain size is typically $3-5 \mathrm{~mm}$ ) and fine grains, which form the matrix. Although magnesium aluminate spinels are known to present an attractive combination of physical and mechanical properties, their technological application is, due to the difficulties in sintering and quality issues, still limited to magnesia clinkers used for the construction of furnaces $\left[{ }^{34}\right]$.

- Optical Devices

Sintered polycrystalline fine-grained spinel with its high refractive index, low scatter and random orientation of small crystallites, is optically completely isotropic. In the visible wavelength range $(380-750 \mathrm{~nm})$, it exhibits a similar optical transmission as the single crystalline material (>80\%), with some differences at short ultraviolet (UV) wavelengths $(230-400 \mathrm{~nm})$. Transparent ceramics have attracted great attention for their use in a wide range of optical applications: high-power lasers, electro-optic devices and lenses. They also have been considered to be an optical material for infrared sensors $\left[{ }^{35},{ }^{23}\right]$. UV-transparent materials also attract significant interest as laser lenses in the microelectronic chip industry $\left[{ }^{1}\right]$. Markets for portable digital devices have shown strong growth potential, requiring the use of compact lenses, light sensors and protective transparent shields. Frequently, a compact and small lens systems design is necessary for use in cell phones and cameras, and gives rise to the development of new transparent 
materials with a high refractive index and high Abbé number, since this enables downsizing of optical systems $\left[{ }^{36}\right]$. In addition to the refractive index, dispersion value is also important for optical components. Particularly for camera lenses, low dispersion materials are preferred in the correction of chromatic aberration $\left[{ }^{37}\right]$.

- Armor materials

Transparent armor is a system of functionally-integrated transparent materials whose main role is to provide blast/ballistic protection of windshields and side windows, while retaining the structural integrity and optical transparency of the component $\left[{ }^{38}\right]$. Armor systems are traditionally laminates of soda-lime glass layers. A means to reduce weight and dimensions is the partial replacement of glass by transparent ceramics, since the ceramic has higher hardness, Young's modulus and fracture toughness. Armor performance has not been successfully correlated to a single material property to date, due to the dynamic nature of the ballistic event. However, several fundamental material properties have been used to rank ceramics for screening purposes, with hardness appearing to be the main parameter.

- Energy technology applications

Highly porous magnesium aluminate spinel is considered a suitable inert substrate in some solid oxide fuel cell (SOFC) designs $\left[{ }^{39}\right]$. For employing spinel material as SOFC substrate, the material must be porous, to allow access of gases to the electrodes. Here, high strength (even in the porous state) and chemical inertness are important prerequisites. An additional advantage for this application is that its coefficient of thermal expansion can be varied by changing the amounts of the constituent phases, which limits thermally-induced stresses.

- Other areas where spinel application is considered are: insulating material for fusion reactors and nuclear waste containers; dental implants; tribological applications; gas purging cones; ceramic gas nozzles for welding and plasma cutting; and refractory lances $\left[{ }^{1},{ }^{28},{ }^{40}\right]$. 


\subsection{The $\mathrm{MgO} \cdot \mathrm{Al}_{2} \mathrm{O}_{3}$ System}

Spinel $\left(\mathrm{MgAl}_{2} \mathrm{O}_{4}\right)$ is a stable intermediate compound in the binary phase diagram $\mathrm{MgO}-\mathrm{Al}_{2} \mathrm{O}_{3}\left[{ }^{6}\right]$. The limits of the diagram are $\mathrm{MgO}$ and $\mathrm{Al}_{2} \mathrm{O}_{3}$, which have rather high melting temperatures of $2800{ }^{\circ} \mathrm{C}$ and $2020^{\circ} \mathrm{C}$, respectively (Fig. 1).

The solid-state reaction between $\mathrm{MgO}$ and $\mathrm{Al}_{2} \mathrm{O}_{3}$ is governed by counter-diffusion of $\mathrm{Al}^{+3}$ and $\mathrm{Mg}^{+2}$ ions through the oxygen lattice of the spinel phase. The diffusion of three $\mathrm{Mg}^{+2}$ ions is compensated by two $\mathrm{Al}^{+3}$ ions in the opposite direction and, therefore, three moles of spinel are formed at the $\mathrm{Al}_{2} \mathrm{O}_{3}-\mathrm{MgAl}_{2} \mathrm{O}_{4}$ interface for every mole formed at the $\mathrm{MgO}-\mathrm{MgAl}_{2} \mathrm{O}_{4}$ interface $\left[{ }^{41},{ }^{42}\right]$. As a result, if a stoichiometric initial composition of $\mathrm{MgO}$ and $\mathrm{Al}_{2} \mathrm{O}_{3}$ is used by slowly heating and cooling down, at the peritectic point a pure spinel is obtained. In many cases, the compound $\mathrm{MgO}-n \mathrm{Al}_{2} \mathrm{O}_{3}$ is non-stoichiometric, i.e., $n$ is not equal to 1 and can range from 1 to 7.3 , since excess $\mathrm{Al}^{+3}$ ions occupy tetrahedral sites, substituting $\mathrm{Mg}^{+2}$ ions. This causes a proportional decrease of the lattice parameter due to the smaller diameter of $\mathrm{Al}^{+3}\left[{ }^{43}\right]$. Pure spinel has a volume expansion of $5-7 \%\left[{ }^{44}\right]$ and melts at $2135{ }^{\circ} \mathrm{C}$, with a eutectic point at $1995{ }^{\circ} \mathrm{C}$. Maximum periclase solid solution was found to correspond to $9.5 \mathrm{wt} \% \mathrm{Al}$ ions and the maximum spinel solid solution to $6 \mathrm{wt} \% \mathrm{Mg}$ ions $\left[{ }^{45}\right]$.

The spinel divides the phase diagram into two eutectic systems $\mathrm{MgO}-\mathrm{MgAl}_{2} \mathrm{O}_{4}$ and $\mathrm{MgAl}_{2} \mathrm{O}_{4}-\mathrm{Al}_{2} \mathrm{O}_{4}$ (Fig. 1). Adjustment of sintering temperature and chemical composition can change the material from a solid solution to a two-phase structure, which improves strength, hardness and crack resistance $\left[{ }^{46}\right]$. However, low-purity magnesium aluminate spinel contains considerable amount of impurities like silica and soda. These impurities can form low-temperature eutectics, facilitate liquid-phase sintering and make the spinel structure less homogeneous, with considerable amount of clusters, voids and agglomerations.

In general there are two types of spinel: normal and inverted (reverse). In normal spinels all $A$ ions are located in tetrahedral sites and all $B$ ions in octahedral coordination. When the structure is inverted, the divalent $A$ ions and half of the trivalent $B$ ions are located in the octahedral sites, while the remaining $B$ ions have tetrahedral coordination. Both normal and inverted spinels have the same cubic $F d 3 m$ - structure $\left[{ }^{47}\right]$. For an 
excellent review of the normal and inverted spinel structures and their mechanical properties see Shukla et al $\left[{ }^{48}\right]$.

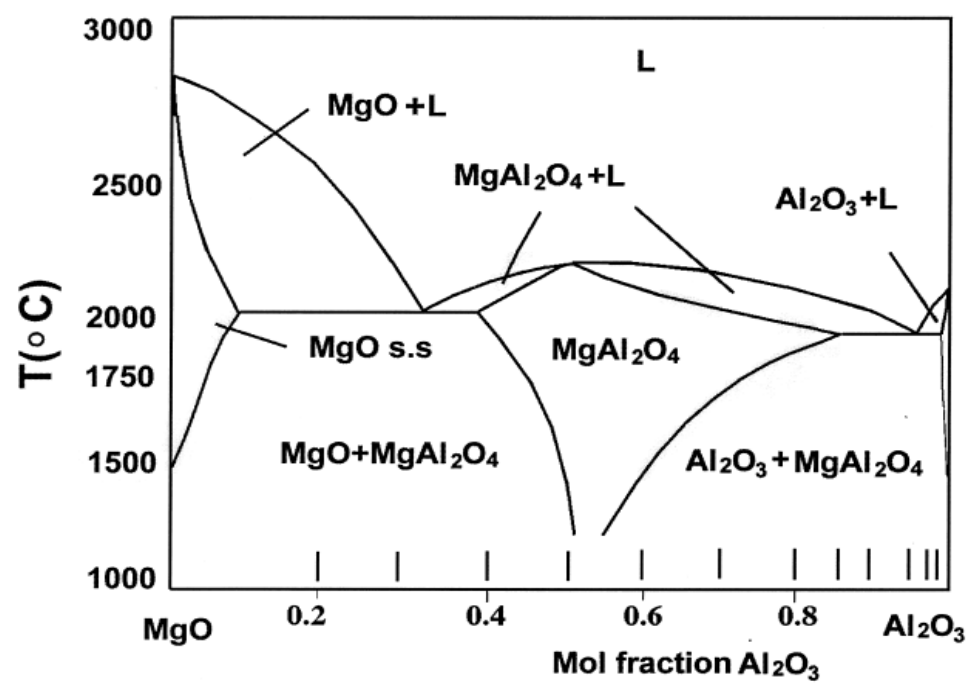

Fig. 1: $\mathrm{MgO}-\mathrm{Al}_{2} \mathrm{O}_{3}$ binary phase diagram $\left[{ }^{49}\right]$.

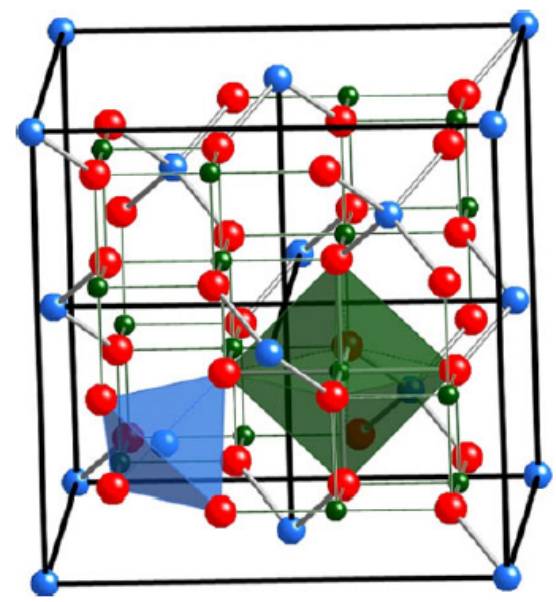

Fig. 2: Tetrahedral cubic $\mathrm{MgAl}_{2} \mathrm{O}_{4}$ spinel unit cell with $\mathrm{Mg}$ (blue), $\mathrm{Al}$ (green) and $\mathrm{O}$ (red) atoms. The unit cell is divided into eight subunits with $\mathrm{Mg}$ in tetrahedral (blue) and Al in octahedral (green) coordination in alternating sub-cells $\left.{ }^{48}\right]$. 


\subsection{Basic spinel processing}

Spinel components are usually fabricated starting from phase-pure spinel powder. In order to enhance sinterability, the powder must be very fine (less than $0.5 \mu \mathrm{m}$ in diameter) and have high specific surface area, typically higher than $15 \mathrm{~m}^{2} / \mathrm{g}$. Such very fine powders are difficult to process. They tend to have very low bulk density and are difficult to disperse in a liquid medium to facilitate forming processes $\left[{ }^{50}\right]$.

The first step in spinel powder processing is to spray the powder dry into a denser, more flowable powder containing organic processing aids. Very careful selection of organic additives and mixing methodology are required to successfully disperse a high quantity of powder while retaining sufficient fluidity of the resulting slurry.

Following the spray drying, the powder is molded and pressed, typically using isostatic pressure. This fabrication method is suitable for small to moderate numbers of components ranging in size from small coupons to large plates, and geometries that can include tubes or even domes. Careful control of the process is required to provide sufficient densification in order to minimize shrinkage stresses occurring in later thermal processing $\left[{ }^{51}\right]$.

Pressed parts must be prefired to remove the organic additives prior to sintering. When done incorrectly, this process can lead to the fracture of the pressed part. Consequently, this step of the process requires the longest cycle time of any spinel fabrication process steps.

The sintering process step follows debinding, and the part is densified up to at least $95 \%$. Despite removal of organics in the prior processing step, a relatively long cycle is still required for sintering in order to remove any residual organics, as well as any adsorbed water bound to the very high surface area particles $\left[{ }^{52}\right]$.

Hot isostatic pressing (HIP) is used to pressurize the parts during a thermal cycle at temperatures similar to the sintering temperature. Under these conditions, the residual porosity is forced to shrink and ultimately removed as the material densifies further $\left[{ }^{50}\right]$. 


\subsection{Physical, chemical and mechanical properties}

The basic properties of spinel are governed by the types of atoms present, their bonds and their order. Magnesium aluminate spinel material is based on ionic bonds, and at room temperature fracture occurs without any plastic deformation, which is reflected in a limited tensile strength and toughness $\left[{ }^{53}\right]$. Pores and other imperfections can lead to stress concentrations, further decreasing strength and toughness. Due to the ionic bounding, dislocation slip generally does not occur at room temperature $\left[{ }^{54}\right]$.

Spinel's optical properties are comparable to polycrystalline alumina and, since it has a cubic structure (i.e. no birefringence), it can transmit light with wavelengths from 0.25 to $5.5 \mu \mathrm{m}$ without optical distortion $\left[{ }^{55}\right]$. Light transmission through polycrystalline transparent ceramics is influenced by absorption, scattering by pores and additionally decreased by losses due to birefringent splitting of the beam at grain boundaries (Fig. 3). Transmission of light is attained by low porosities $(<0.05 \%)$ along with rather small grain sizes $(<1 \mu \mathrm{m})\left[{ }^{56}\right]$. In fact, only $0.1 \%$ residual porosity can completely impair transparency, and large grains increase light scattering $\left[{ }^{57}\right] . \mathrm{MgAl}_{2} \mathrm{O}_{4}$ spinel is one of the cubic oxides where high transmission values can be obtained even at larger grain sizes due to the absence of birefringent scattering $\left[{ }^{23}\right]$.

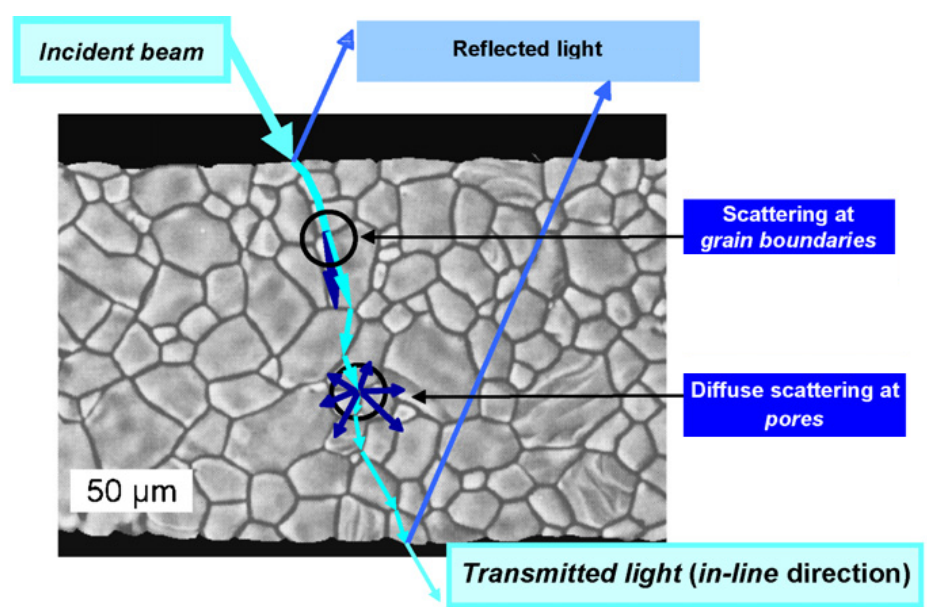

Fig. 3: Light transmission through a polycrystalline translucent ceramic $\left[{ }^{23}\right]$. 
Mechanical properties of transparent polycrystalline spinels have been reported at room temperature (hardness: 14 - $17 \mathrm{GPa}$ - where applied loads are not always specified, Young's Modulus: 260 - $280 \mathrm{GPa}$, flexural strength: 185 - $300 \mathrm{MPa}$ and fracture toughness: $\left.1.5-2.2 \mathrm{MPa} \cdot \mathrm{m}^{0.5}\right)\left[{ }^{1}, 4658,59,60,61\right]$. Limited data exist for elevated temperature $\left[{ }^{62},{ }^{63},{ }^{64},{ }^{65},{ }^{66}\right]$. Fracture toughness and Young's modulus of magnesium aluminate spinel as a function of temperature are depicted in Fig. 4. The reduction of elastic modulus and fracture toughness with increasing temperature is typical for many sintered ceramics, especially in cases where the behavior may be governed by a second-phase sintering aid $\left[{ }^{63},{ }^{67}\right]$. Since for this group of materials such behavior typically coincides with softening of the grain boundaries, a monotonous decrease of mechanical properties with temperature can be expected.

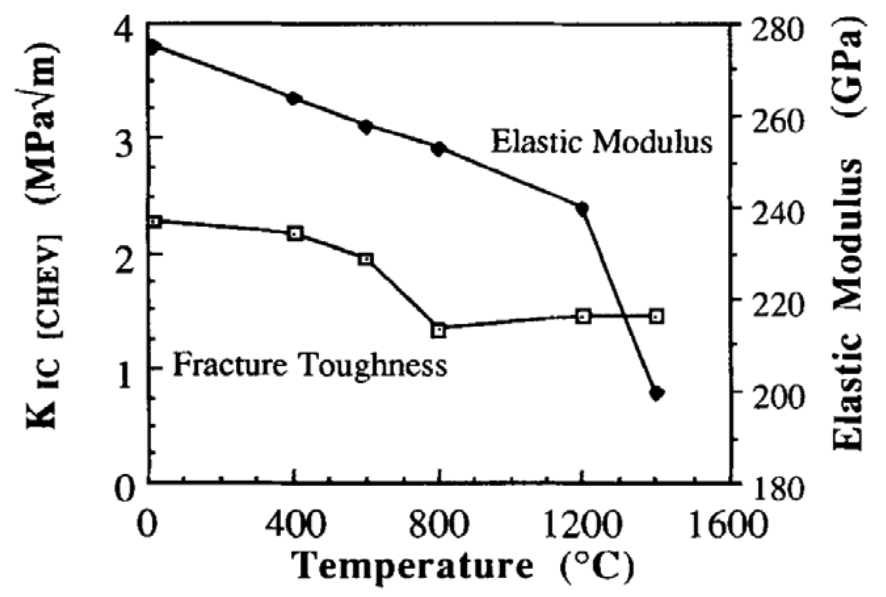

Fig. 4: Fracture toughness and Young's modulus of $\mathrm{MgAl}_{2} \mathrm{O}_{4}$ spinel as a function of temperature $\left[{ }^{67}\right]$.

Contrary to Young's modulus and fracture toughness, the hardness of spinel (see section 4.4) is usually load-dependent. However, typically data are only reported for one particular (rather high) load value $\left[{ }^{68}\right]$. When a very low indentation load is used, the measured hardness is usually higher. With an increase in test load, the measured hardness decreases (Fig. 5); a behavior often observed for ceramic material, which is known as 
indentation size effect (ISE) $\left[{ }^{69},{ }^{70},{ }^{71},{ }^{72},{ }^{73}\right]$. The ISE makes it difficult to define hardness by a single number. Many research works have been devoted to the origin of the ISE and several possible explanations have been proposed. In addition to explanations that concern experimental errors $\left[{ }^{74}\right]$, elastic recovery work, hardening during indentation, dislocation and twin activities and (especially for ceramic materials), the onset of local damage have been considered $\left[{ }^{75}\right]$.

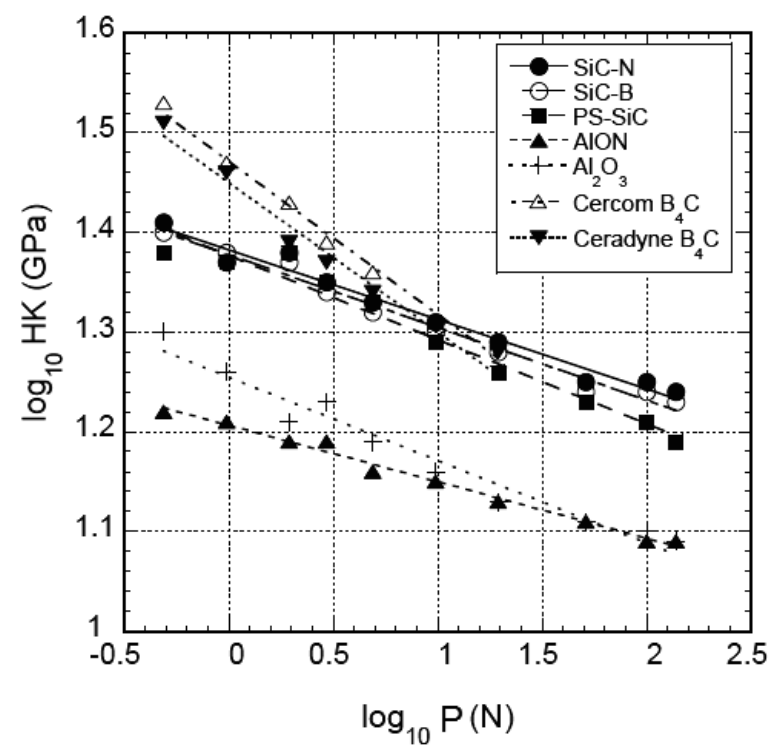

Fig. 5: Knoop hardness-load data for some ceramic materials $\left[{ }^{76}\right]$.

Many works have been devoted to improving the mechanical properties of transparent $\mathrm{MgAl}_{2} \mathrm{O}_{4}$ spinels $\left[{ }^{51,77},{ }^{78},{ }^{79}\right]$. Parameters such as non-stoichiometry coefficient $n$ and powder composition, as well as the sintering and hot-isostatic pressing (HIP) parameters, significantly changed the mechanical behavior of sintered ceramics $\left[{ }^{46},{ }^{80}\right]$. As illustrated in Fig. 6 , the grain size increased from $290 \mathrm{~nm}\left(1150{ }^{\circ} \mathrm{C}\right)$ to $9.8 \mu \mathrm{m}$ $\left(1550{ }^{\circ} \mathrm{C}\right)$ with increasing sintering temperature, while at the same time the porosity slightly decreased. 
A variation of the HIP conditions (Table 1) revealed that Young's modulus and fracture toughness are rather insensitive to the grain size. However, increasing HIP temperature and pressure resulted in a decrease of the optical extinction $\left[{ }^{81}\right]$.

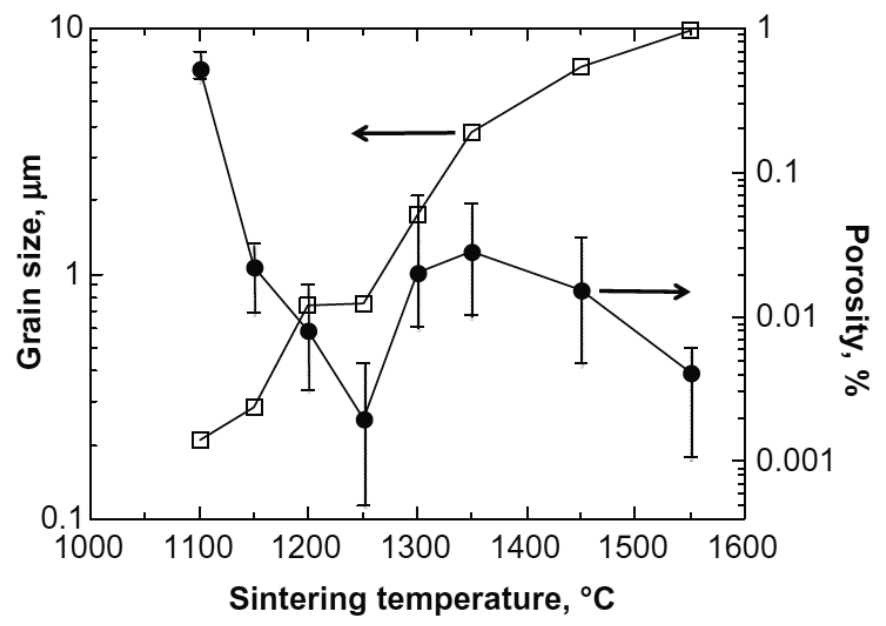

Fig. 6: Dependence of grain size and porosity of $\mathrm{MgAl}_{2} \mathrm{O}_{4}$ spinel on the sintering temperature $\left[{ }^{80}\right]$.

Table 1. Basic mechanical properties of $\mathrm{MgAl}_{2} \mathrm{O}_{4}$ spinel as a function of grain size obtained using different processing conditions [ $\left.^{82}\right]$.

\begin{tabular}{|c|c|c|c|c|c|c|}
\hline Material & $\begin{array}{c}\text { Average } \\
\text { grain size }\end{array}$ & $\begin{array}{c}\text { Young's } \\
\text { Modulus } \\
(\mathrm{GPa})\end{array}$ & $\begin{array}{c}\text { Hardness } \\
\mathrm{HV} \mathrm{10} \\
(\mathrm{GPa})\end{array}$ & $\begin{array}{c}\mathrm{K}_{\mathrm{IC}} \\
(\mathrm{MPa} \cdot \sqrt{\mathrm{m}})\end{array}$ & $\begin{array}{c}\text { 4-point } \\
\text { bending } \\
\text { strength } \\
(\mathrm{MPa})\end{array}$ & $\begin{array}{c}\text { Compressive strength } \\
\text { static }- \text { dynamic } \\
(\mathrm{MPa})\end{array}$ \\
\hline & $0.35 \mu \mathrm{m}$ & $272 \pm 0$ & $14.7 \pm 0.2$ & $1.7 \pm 0.1$ & $274 \pm 40$ & \\
Spinel ceramics & $0.55 \mu \mathrm{m}$ & $270 \pm 2$ & $14.3 \pm 0.2$ & $1.7 \pm 0.1$ & $284 \pm 18$ & $883-3497$ \\
(all transparent) & $1.4 \mu \mathrm{m}$ & $270 \pm 3$ & $13.6 \pm 0.1$ & $2.0 \pm 0.1$ & $270 \pm 57$ & $879-3569$ \\
& $13 \mu \mathrm{m}(5-50 \mu \mathrm{m})$ & $275 \pm 1$ & $12.7 \pm 0.2$ & $1.8 \pm 0.1$ & $210 \pm 13$ & $757-3510$ \\
& $36 \mu \mathrm{m}(10-75 \mu \mathrm{m})$ & $273 \pm 1$ & $12.0-13.0$ & $1.8 \pm 0.1$ & $153-193$ & $643-3550$ \\
\hline
\end{tabular}

Most mechanical properties of non-stoichiometric spinel appear to be superior compared to stoichiometric spinel. However, the flexural strength first increases at lower $n$ and then decreases at higher $n$, whereas hardness and fracture toughness increase uniformly with increasing $n$ (Fig. 7) $\left.{ }^{46}\right]$. 

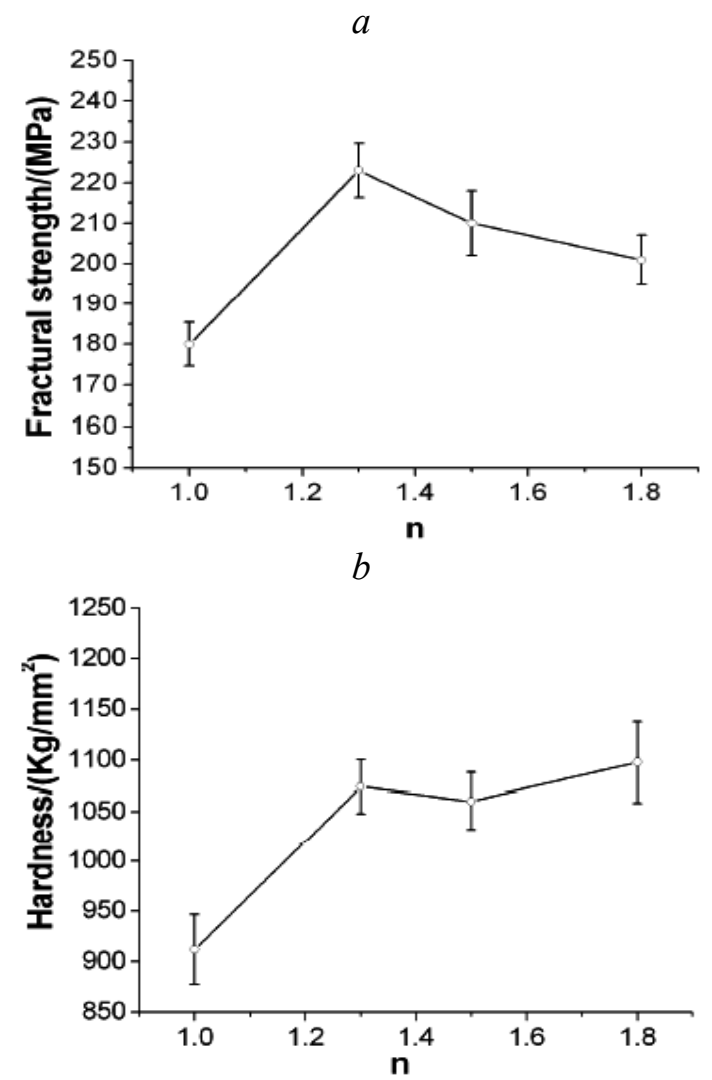

$c$

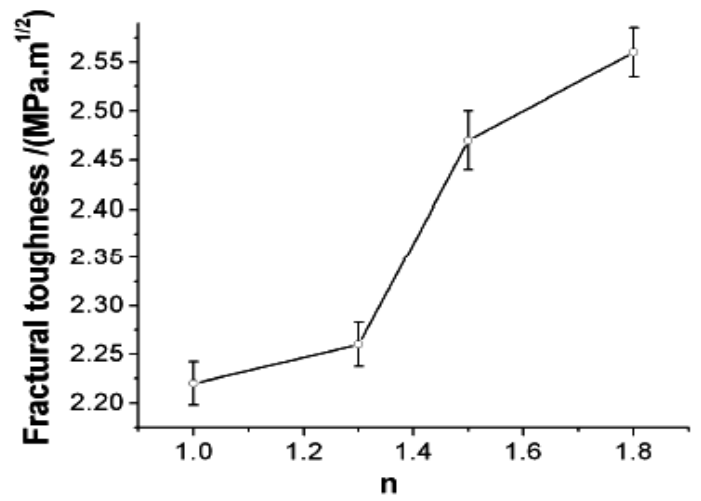

Fig. 7: Mechanical properties of transparent spinel ceramics prepared from $\mathrm{MgO}-n$ $\mathrm{Al}_{2} \mathrm{O}_{3}$ powders as a function of non-stoichiometry n, (a) flexural strength, (b) hardness and (c) fracture toughness $\left[^{46}\right]$. 
The increase of strength might be attributed to better densification related to the enhanced sintering capability of non-stoichiometric ceramics, due to spinel lattice defects induced by deviation from stoichiometry of $\mathrm{MgO} \cdot n \mathrm{Al}_{2} \mathrm{O}_{4}$ powders grains and by corundum grains segregating from spinel grains during cooling. The corundum grains usually improve in strength due to their high elastic modulus and stronger bonding with spinel grains in comparison with the stoichiometric spinel grains $\left[{ }^{83},{ }^{84}\right]$. Hardness increases with increasing $n$ due to $\mathrm{Al}_{2} \mathrm{O}_{3}$ grain separation and the densification of spinel grains $\left[{ }^{85}\right]$. Toughening effects are supposed to be increased by dispersed rigid $\mathrm{Al}_{2} \mathrm{O}_{3}$ particles and non-stoichiometric spinel grains. Rigid $\mathrm{Al}_{2} \mathrm{O}_{3}$ particles are furthermore able to resist crack expansion and consume energy, thereby improving toughness $\left[{ }^{46}\right]$.

Furthermore, a clear effect of the porosity on the mechanical properties $\left[{ }^{39}\right]$ has been verified (Table 2).

Table 2. Effect of porosity on the mechanical properties of spinel

\begin{tabular}{lcccc}
\hline Property & Units & Dense MMA (6\% porosity) & Porous (18.3\%) & Porous (24.5\%) \\
\hline Young's modulus, $E$ & $\mathrm{GPa}$ & $192 \pm 8$ & $100 \pm 10$ & $70 \pm 7$ \\
Poisson's ratio, $v$ & $\mathrm{MPa} \cdot \mathrm{m}^{1 / 2}$ & $2.1 \pm 0.2$ & 0.21 & $1.2 \pm 0.09$ \\
Fracture toughness, $K_{I c}$ & $\mathrm{MPa}$ & 22 & 14 & $0.63 \pm 0.08$ \\
Fracture energy, $G_{c}$ & $\mathrm{MPa}$ & $151 \pm 14$ & $51 \pm 6$ & 5.3 \\
Mean flexural strength, $\sigma_{\mathrm{f}}$ & & 157 & 54 & $30 \pm 3$ \\
Weibull's stress, $\sigma_{0}$ & $\mathrm{~m}$ & 10.8 & $5.5 \times 10^{-4}$ & 9.3 \\
Weibull modulus, $m$ & $\mathrm{GPa}$ & $1.9 \times 10^{-4}$ & & $4.4 \times 10^{-4}$ \\
$c \cong\left(\frac{K_{\mathrm{Ic}}}{\sigma_{\mathrm{f}}}\right)^{2}$ & & $6.3 \pm 0.3$ & & \\
Vickers hardness & & & \\
\hline
\end{tabular}

$\left(\mathrm{MMA}\right.$ is $\left.\mathrm{MgO}+\mathrm{MgAl}_{2} \mathrm{O}_{4}\right)$

In comparison with other industrially used transparent ceramics, spinel can be ranked between sapphire and fused silica (Table 3 ) $\left[{ }^{86}\right]$ with regard to its key mechanical properties. 


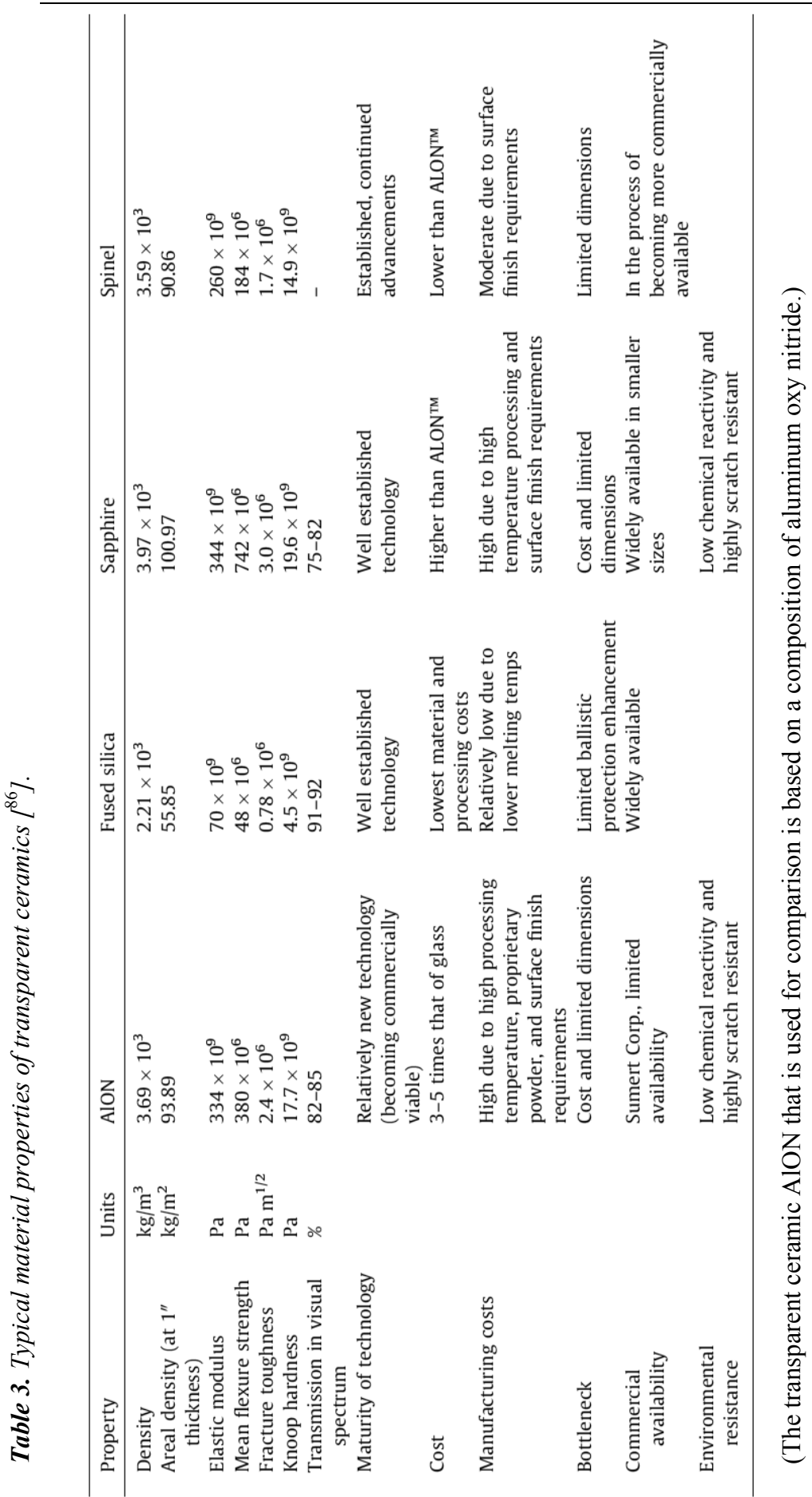




\subsection{Mechanical characterization}

\subsubsection{Young's Modulus}

\subsubsection{Indentation}

In contrast to traditional hardness testing, instrumented depth sensitive indentation permits the measurement of the penetration depth of the indentation tip into the material $h$ as a function of force $P$ (Fig. 9). For indentation testing a Vickers tip is most commonly used. The Vickers indenter geometry corresponds to a square pyramid, with an angle of $136^{\circ}$ between the triangle faces. Indentation load-displacement curves can be used to determine mechanical characteristics, according to DIN 50359-1 $\left[{ }^{87}\right]$ (Fig. 8).
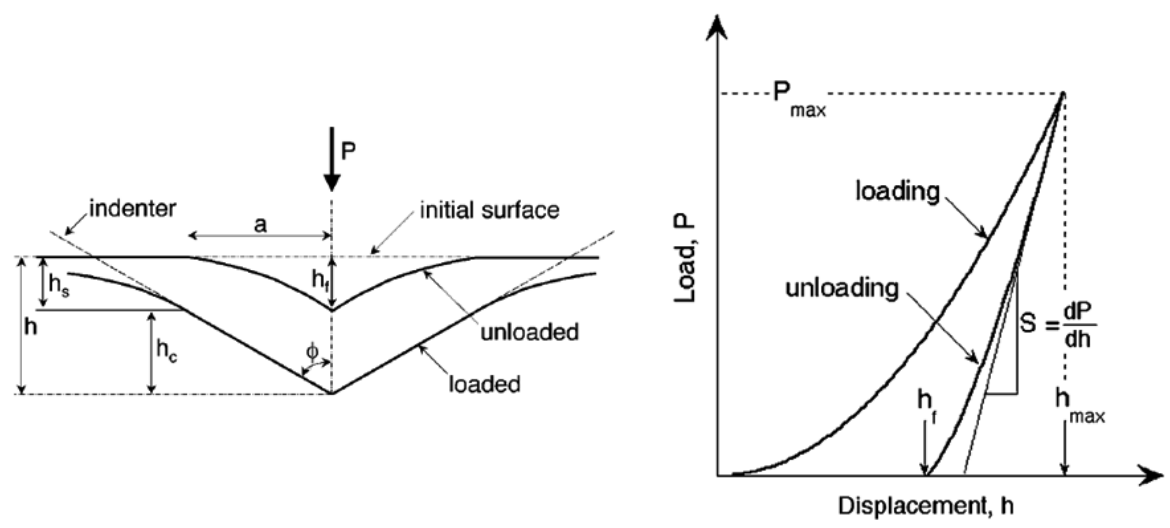

Fig. 8: Instrumented indentation: a) main parameters describing the impression, b) schematic representation of load - displacement curve obtained during indentation $\left[{ }^{88}\right]$.

The reduced Young's modulus can then be calculated from the indentation loaddisplacement curve $\left[{ }^{88}\right]$ :

$E_{r}=\beta \frac{\sqrt{\pi}}{2} \cdot \frac{S}{\sqrt{A_{C}}}$

Eq. 1 
where $\beta$ is a correction factor for the Vickers indenter (1.0124); $S$ is the unloading slope $\mathrm{d} P / \mathrm{d} h$ and $A_{\mathrm{c}}$ is the projected contact area predetermined via calibration of the indentation system. The indentation Young's modulus can then be calculated as $\left[{ }^{88}\right]$ :

$$
E_{I T}=\frac{1-v^{2}}{\frac{1}{E_{r}}-\frac{1-v_{i}^{2}}{E_{i}}}
$$

where $E_{i}$ is Young's modulus of the indenter, and $v$ and $v_{i}$ are Poisson's ratios of the tested material and indenter, respectively.

\subsubsection{Bending test}

In the case of a bi-axial ring-on-ring bending test, the Young's modulus is calculated from the linear part of the load-displacement curve after ASTM C1499-05 $\left[{ }^{89}\right]$ :

$E_{R O R}=\frac{3 \cdot\left(1-v^{2}\right) \cdot r_{1}^{2} \cdot \Delta P}{2 \pi \cdot \Delta f \cdot h^{3}} \times\left[\left(\frac{r_{2}}{r_{1}}\right)^{2}-1-\ln \left(\frac{r_{2}}{r_{1}}\right)+\frac{1}{2}\left(\frac{1-v}{1+v}\right) \times\left(\frac{r_{2}^{2}-r_{1}^{2}}{r_{3}^{2}}\right) \times\left(\frac{r_{2}^{2}}{r_{1}^{2}}\right)\right]$ Eq. 3

where $v$ is Poisson's ratio, $\Delta P$ is the difference in force, and $\Delta f$ is the corresponding change in displacement, $h$ is the specimen thickness, and $r_{1}, r_{2}$ and $r_{3}$ are radii of load ring, support ring and specimen, respectively.

\subsubsection{Impulse excitation technique}

The impulse excitation technique (IET) is a non-destructive method to determine the Young's modulus, with widespread use in science and industry. This method is based on an actuator that hits the surface of the sample, resulting in a free vibration with a material-specific and geometry-dependent resonance frequency. Since every sample has its own resonance frequency and the geometry is fixed, the resonance frequency is only 
related to density and the Young's modulus $\left[{ }^{90}\right]$. Often the entire oscillation waveform after excitation is recorded, as illustrated in Fig. 16. Afterwards, the fundamental frequency $f$ of the flexural resonance is extracted automatically.

The Young's modulus is often calculated from resonance frequency, using automatized software based on the relevant relationships for disc- and bar-shaped specimens given in ASTM E1876 - 01.

This method's advantage lies not only in the simplicity of the experimental setup, but also in high measurement accuracy. In fact, it has been verified for glass that the Young's modulus measured by bending tests is usually $\sim 7 \%$ lower than that obtained using IET, due to system error and contact displacement $\left[{ }^{91}\right]$. IET results have excellent stability, while results of Vickers indentation show bigger scatter and are influenced by sample surface and inhomogeniety effects $\left[{ }^{91}\right]$.

\subsubsection{Hardness}

Additionally, the depth-sensitive indentation technique permits the determination of indentation hardness $\left(H_{I T}\right)$ by the ratio of maximum load to residual contact area $\left[{ }^{87}\right]$ :

$H_{I T}=\frac{P_{\text {max }}}{A_{C}}$

whereas the Vickers hardness can be determined as:

$H V=\frac{2 P \sin \frac{136^{\circ}}{2}}{d^{2}} \approx 1,854 \frac{P}{d^{2}}$

where $d$ is the arithmetic mean of the two diagonals. 


\subsubsection{Fracture toughness}

Fracture toughness $\left(K_{I C}\right)$ is the material resistance to instable crack growth. Fracture toughness can be tested by different methods, e.g., single edge notch bending, indentation and indentation-strength-in-bending tests $\left[{ }^{40}\right]$, and by means of the Griffith criterion. The following sections give details on these methods.

\subsubsection{Indentation}

The local contact of a sharp tip with the surface of brittle materials can result in damage by crack formation at the edges of the indenter tip. The size of the impression and cracks is related to the elastic/plastic stress field under the indenter. If a material shows indentation cracking, the fracture toughness can be determined, defined here as the indentation toughness $\left(K_{I N D}\right)$. Different relationships exist to determine indentation toughness, depending on the crack types generated during the impression. Evans and Charles $\left[{ }^{92}\right]$, Niihara et al. $\left[{ }^{93}\right]$, Anstis et al. $\left[{ }^{94}\right]$ and Lawn et al. $\left[{ }^{95}\right]$ have been pioneers in determining fracture toughness by Vickers indentation. The fracture toughness is computed from the length of the indentation-induced cracks, taking into account applied load, hardness, Young's modulus and calibration geometry factor $\left[{ }^{94},{ }^{95},{ }^{96}\right]$. Due to the small size of indents and cracks, this method is a macroscopically rather nondestructive characterization. However, the obtained values need careful interpretation. Mistakes in crack length observation and irregular fracture behavior can result in errors of up to $50 \%$ $\left[{ }^{97}\right]$. The typical crack pattern after Vickers indentation is given in Fig. 9.
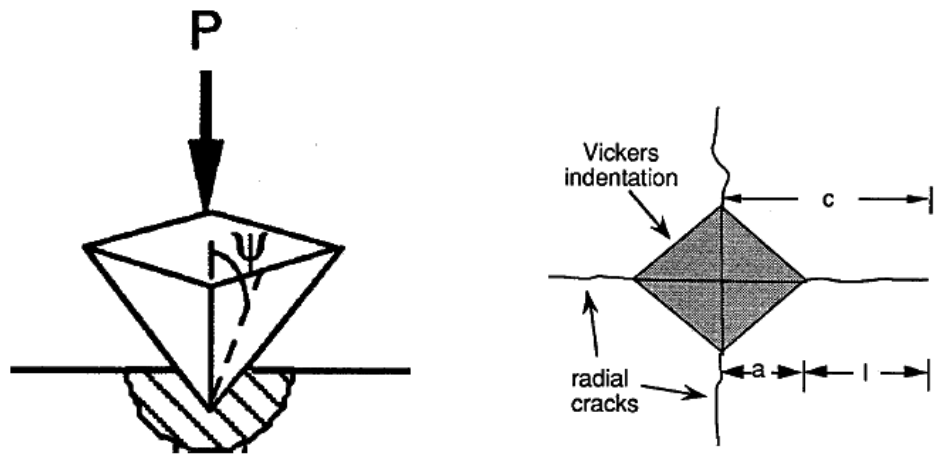

Fig. 9: Radial crack system (right) after Vickers indentation (left) $\left[^{98}\right]$. 
In the present study, the widely used relationships for a half-penny crack system proposed by Lankford $\left[{ }^{99}\right]$, Niihara $\left[{ }^{93}\right]$ and Anstis $\left[{ }^{94}\right]$ were applied for indentation toughness determination.

Lankford equation $\left[{ }^{99}\right]$ : $(c / a>2)$

$$
K_{\text {ind }}=0.0363 \cdot(E / H)^{2 / 5} \cdot\left(P / a^{1.5}\right) \cdot(a / c)^{1.56}
$$

Eq. 6

Niihara equation $\left[{ }^{93}\right]$ :

$(c / a>2.5)$

$$
K_{\text {ind }}=0.067 H \sqrt{a} \cdot(E / H)^{0.4} \cdot(c / a)^{-1.5}
$$

Anstis equation $\left[{ }^{94}\right]$ :

$(c \geq 2 a)$

$$
K_{\text {ind }}=0.016 \cdot(E / H)^{0.5} \cdot\left(P / c^{1.5}\right)
$$

where: $a$ - half of imprint's diagonal length, $c$ - crack length (measured from the end of imprint) and $P$ - applied load.

\subsubsection{Indentation-Strength-Method}

An additional method of determining fracture toughness is the IndentationStrength-in-Bending method (ISM). This method is based on the fracture of pre-indented specimens. Consequently, well-defined defects are used to determine the fracture toughness from the fracture load obtained in a bending test. The fracture toughness $\left(K_{I S M}\right)$ can be calculated using $\left[{ }^{96}\right]$ :

$$
K_{I S B}=A \cdot\left(\frac{E}{H}\right)^{1 / 8} \cdot\left(\sigma \cdot P^{1 / 3}\right)^{3 / 4}
$$

During the bending experiment, the indentation induced residual stress field results in subcritical (stable) growth of the indentation-induced crack. This effect is considered by the geometrical constant $A=0.59 \pm 0.12\left[{ }^{94}, 96\right]$, which is determined as $A=\left[(256 / 27) \cdot(\pi \cdot \Omega)^{3 / 2} \cdot \varphi\right]^{1 / 4}$, where $\Omega$ is a crack-geometry factor considering freesurface effects (ellipticity and crack interaction) $\left[{ }^{96},{ }^{100}\right]$, and $\varphi=0.016 \pm 0.004$ is a 
material independent "calibration" constant for radial cracks at Vickers indents, which was obtained by averaging over the data for structured ceramics $\left[{ }^{94}, 95\right]$. This calibration value is calculated from the ratio between the maximal crack length after stable crack growth $c_{m}$ (just before catastrophic specimen failure) and the initial indentation-induced crack length $c_{0}$ which was $\Omega \sim\left(c_{m} / c_{0}\right)^{3 / 8}=1.12$. The calibration value needs to be verified experimentally for any material and if necessary $A$ needs to be re-calibrated.

\subsubsection{Single edge notch bending}

Fracture toughness of ceramics is often determined by SENB tests, according to ISO $13586\left[{ }^{101}\right]$. This method, based on a notched bending specimen, is one of the simplest and most reliable methods for determining fracture toughness $\left[{ }^{40}\right]$.

As illustrated in Fig. 10, an edge crack of depth $c$ that is pre-introduced by cutting and sharpened with a razor blade, is extended from the tensile surface when a critical load is reached. In case of four-point bending of rectangular bar-shaped specimens, the critical stress intensity factor (fracture toughness) is then given by $\left[{ }^{102}\right]$ :

$$
K_{S E N B}=\frac{P_{C}}{B \sqrt{W}} \cdot \frac{S_{1}-S_{2}}{W} \cdot \frac{3 \Gamma_{M} \sqrt{\alpha}}{2(1-\alpha)^{3 / 2}}
$$

where $P_{c}$ is the critical fracture load, $B$ is a thickness, $W$ is a height, $S_{2}$ inner and $S_{1}$ outer roller span, and $\Gamma_{M}$ is numerical factor:

$\Gamma_{M}=1.1215 \sqrt{\pi} \cdot\left[\frac{5}{8}-\frac{5}{12} \alpha+\frac{1}{8} \alpha^{2}+5 \alpha^{2} \beta^{6}+\frac{3}{8} \exp \left(-6.1342 \frac{\alpha}{\beta}\right)\right]$

where $\alpha=a / W \approx 0.5$ and $\beta=1-\alpha$. 


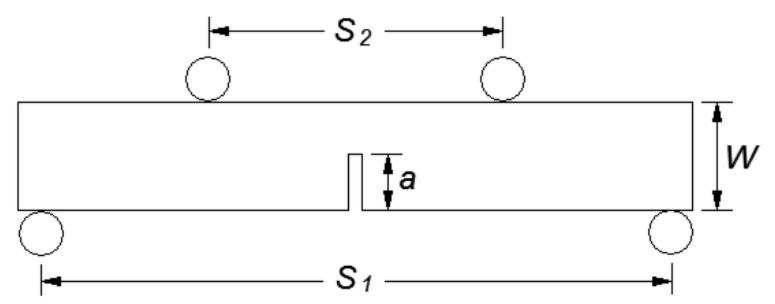

Fig. 10: Four-point bending test with edge-notched specimen $\left[{ }^{40}\right]$.

\subsubsection{Griffith criterion}

In bending tests, failure will occur from pre-existing flaws. Therefore, fracture toughness determination is possible if these flaws are identified and their size is measured. If enough fracture energy is available, which is usually the case for finite-sized specimens in a bending test, fracture occurs when a critical applied tensile stress is exceeded. In this case the stress intensity factor exceeds the fracture toughness and unstable crack growth starts $\left[{ }^{103},{ }^{104},{ }^{105}\right]$. The major types of fracture-initiating defects in ceramics are machining flaws, microstructural inhomogeneities, inclusions and pores. Fracture toughness is related to the critical stress and defect size $c$ via:

$K_{I C . G r i f i t h}=(Y / Z) \cdot \sigma \cdot \sqrt{c}$ Eq. 12

where $Y$ is a geometry factor dependent on the loading conditions, specimen shape and defect size, and $Z$ is a shape factor for the defect. For flaws in a uniform stress field, $Y$ is independent of $c$ and given by: $Y=\sqrt{\pi}$ - for volume flaws, and $Y=1.12 \cdot \sqrt{\pi}$ - for surface flaws. If the defect has a linear crack front, the shape factor is $Z=1$, whereas for a circular or penny-shaped flaw, $Z=\frac{\pi}{2}\left[{ }^{98}\right]$.

Therefore, an estimation of fracture toughness is possible based on experimental observations of fracture origins using fractography. 


\subsubsection{Strength}

Fracture stress is determined in the case of ring-on-ring bending tests from the maximum load at failure $P$ (see section 3.3.2), according to ASTM C1499-05 $\left[{ }^{89}\right]$ :

$$
\sigma=\frac{3(1+v) P}{2 \pi \cdot h^{2}} \times\left[\ln \frac{r_{2}}{r_{1}}+\frac{(1-v)}{(1+v)} \times \frac{r_{2}^{2}-r_{1}^{2}}{2 \cdot r_{3}^{2}}\right]
$$

where $v$ is Poisson's ratio, $h$ is the specimen thickness, and $r_{1}, r_{2}$ and $r_{3}$ are radius of load ring, support ring, and specimen radius, respectively.

Fracture stress of ceramics typically displays a considerable scatter that depends on the defect size distribution. Strength characterization is therefore usually performed using statistical approaches. In particular, Weibull statistics are widely used to assess the inherent scatter $\left[{ }^{106},{ }^{107}\right]$. Based on the "weakest link hypothesis", it is assumed that the most serious (largest) flaw controls the strength $\left[{ }^{108},{ }^{109}\right]$. In general, the critical parameters for predicting the fracture strength of a component are the specific dimensions, characteristic strength, Weibull modulus and threshold strength.

According to the Weibull statistics that are widely accepted for brittle materials $\left[{ }^{108}\right]$, the cumulative failure probability of a component made of brittle material with specified dimension $P(\sigma)$, subjected to stress $\sigma$, is given by:

$$
P(\sigma)=1-\exp \left[-\left(\frac{\sigma-\sigma_{u}}{\sigma_{0}}\right)^{m}\right]
$$

where $\sigma_{0}$ is the characteristic fracture strength, $\sigma_{u}$ is the threshold stress, below which no failure will occur, and $m$ is the Weibull modulus, being a measure of strength distribution.

The characteristic strength corresponds to a failure probability of $63.2 \%$, and therefore is only a weak criterion for assessing the reliability of brittle materials. Only the knowledge of characteristic strength, Weibull modulus and threshold strength permits complete characterization of a material for a given specimen dimension and an estimation 
of the probability of failure for a particular stress level. Often $\sigma_{u}$ is assumed to be zero, yielding a two-parameter relationship. In fact, numerical simulations and experimental data have verified that as long as sample data are limited in number $(\sim 30)$ and the threshold stress is not too large, a two-parameter Weibull distribution should be used $\left[{ }^{110},{ }^{111}\right]$. It has also been demonstrated that when a two-parameter distribution is used, an underestimation is more likely than an overestimation. Hence, it can be considered the more conservative approach $\left[{ }^{112}\right]$. The statistical parameters of the Weibull distribution are most frequently assessed using linear regression (LR) or the maximum likelihood method (ML) $\left.{ }^{113}\right]$. In the present study, the LR method is used for simplicity, since it has been verified that the differences in the resulting parameters obtained using the different methods is rather small $\left[{ }^{114}\right]$. Obviously the Weibull parameters are subject to uncertainties and, for design purposes, it is necessary to give appropriate confidence intervals for example based on ASTM C1239-06A [ $\left.{ }^{115}\right]$.

In the linear regression analysis (LR) the least-square fitting of a two-parameter Weibull distribution, which takes twice the double logarithm of Eq. 14, permits to determine $m$ as the slope, and $\sigma_{0}$ as the y-intercept:

$\ln \ln \left(\frac{1}{1-P_{f}}\right)=m \cdot\left(\ln (\sigma)-\ln \left(\sigma_{0}\right)\right)$

Eq. 15

where $P_{f}$ is the failure probability. In the LR method, the stress values are ranked with respect to their individual probability according to $\left[{ }^{116}\right]$ :

$P_{i}(\sigma)=(i-0.5) / N$

Eq. 16

Since the characteristic strength is a rather inappropriate parameter to assess the reliability of a brittle component (given the failure probability of $63.2 \%$ ), usually fracture stresses for failure probabilities of $10^{-6}$ or $10^{-3}$ should not be exceeded to warrant structural integrity. Furthermore, the decrease of fracture stress due to larger deformed volumes in real application should be considered.

In addition to the two-parameter distribution, a three-parameter Weibull distribution can also be used to analyze the data $\left[{ }^{117}\right]$. In order to carry out the linear 
regression analysis, a threshold stress is chosen and the parameters are optimized based on the uncertainty of the regression slope.

The standard deviation of Weibull modulus $s(m)$ and characteristic strength $s\left(\sigma_{0}\right)$ can be estimated for a particular number of tests $g$ via $\left[{ }^{118}\right]$ :

$$
\begin{aligned}
& \frac{s(m)}{m}=\frac{1}{\sqrt{g}} \\
& \frac{s\left(\sigma_{0}\right)}{\sigma_{0}}=\frac{1}{m \cdot \sqrt{g}}
\end{aligned}
$$

The statistical bias errors in the estimated Weibull parameters and calculation of confidence bounds have to be calculated from the available data set $\left[{ }^{119}\right]$. Depending on the number of specimens in a given batch, the estimate of Weibull modulus $m$ may exhibit significant statistical bias. An unbiased estimate of the Weibull modulus $m_{U}$ is obtained by multiplying the biased estimate by an appropriate unbiasing factor (listed in ASTM C1239-06A). For this procedure, an unbiasing factor of $1-1.593145 N^{-1.046958}$ suggested in $\left[{ }^{116}\right]$ can also be applied, yielding a negligible difference of $\sim 2 \%$, compared with the tabulated ASTM values for a data set of at least 10 specimens.

The equations for the upper $m_{U P P}=m_{B I A S} / m_{5 \%}$ and lower $m_{L O W}=m_{B I A S} / m_{95} \%$ confidence intervals, respectively, describe how the different limiting values are calculated for a $90 \%$ confidence level. The values for $m_{5} \%$ and $m_{95} \%$ are listed in ASTM C1239-06A $\left[{ }^{115},{ }^{120}\right]$.

The strength values obtained using ring-on-ring specimens vary with test specimen size. Characteristic strength values can be scaled to other specimen geometries using the area relationship (Eq. 19). The effective area under tensile stress in a ring-onring test is $\left[{ }^{121},{ }^{122}\right]$

$$
A_{\text {eff } \cdot R O R}=\frac{\pi}{2} D_{L}^{2}\left\{1+\left[\frac{44(1+v)}{3(1+m)}\right] \cdot\left[\frac{5+m}{2+m}\right] \cdot\left(\frac{D_{S}-D_{L}}{D_{S} D}\right)^{2}\left[\frac{2 D^{2}(1+v)+\left(D_{S}-D_{L}\right)^{2}(1-v)}{(3+v) \cdot(1+3 v)}\right]\right\} \text { Eq. } 19
$$


Comparison of Eq. 19 to numerical computations indicates that for $m \geq 5, v \geq 0.17$ and $D_{S} / D_{L}=0.5$, the error is less than $3 \%$ compared to a full integration of the stress field, but for $D_{S} / D_{L}=0.2$, the estimates are better than 5\%. The use of Eq. 19 requires that fracture origins are clearly defined as surface defects $\left[{ }^{121}\right]$.

Since the strength of ceramics depends on the surface area or volume under stress, the characteristic strength needs to be rescaled from the size (effective area) of the test specimen to the actual component via $\left[{ }^{123}\right]$ :

$\left(\frac{\sigma_{0, G 1}-\sigma_{u}}{\sigma_{0, G 2}-\sigma_{u}}\right)=\left(\frac{A_{1}}{A_{2}}\right)^{-1 / m}$

Similar relationships can be derived for volume defects.

\subsubsection{Local strength}

Hertzian (spherical) indentation of brittle materials is a feasible way to test the contact damage that may occur in application. An advantage of Hertzian indentation is that the material first responds linear-elastically before permanent contact damage (fracture) starts. Ring cracking is caused by the radial tensile stress occurring on the edge of the circular contact area, between the indenter and investigated material (Fig. 11).

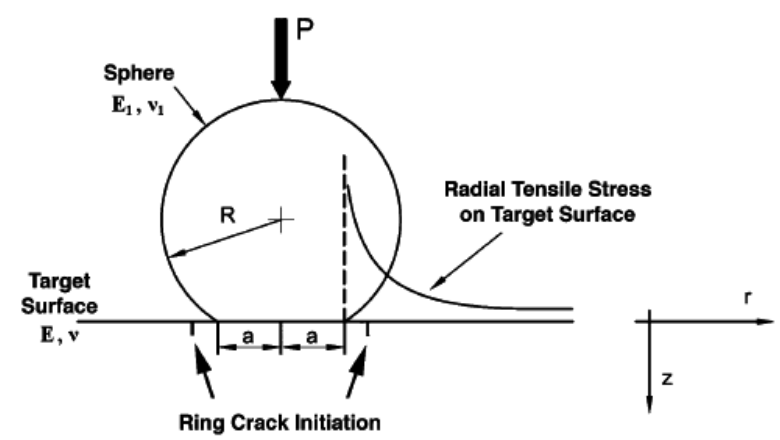

Fig. 11: Schematic diagram for Hertzian indentation and ring crack initiation $\left[{ }^{124}\right]$. 
When a hard sphere (radius $R$ and elastic constants $E_{1}, v_{1}$ ) is pressed with a load $P$ on to a flat substrate (elastic constants $E_{2}, v_{2}$ ), the contact radius $a$ is given by [ $\left.{ }^{125}\right]$ :

$a=\sqrt[3]{4 k P \cdot r / 3 E}$ Eq. 21

where

$k=(9 / 16) \cdot\left[\left(1-v_{1}^{2}\right)+\left(1-v_{2}^{2}\right) \cdot E_{1} / E_{2}\right]$ Eq. 22

Considering the average stress criterion as a good indicator of material strength, the following relation has been proposed for calculating the local fracture strength $\left[{ }^{125}\right]$ :

$\sigma_{\text {Hertzian }}=\left[-0.1373 a_{c}{ }^{2}+0.2862 a_{c}+0.0236\right] \cdot\left(\frac{3 E}{4 k}\right)^{2 / 3} \cdot \frac{1}{\pi} \cdot\left(\frac{P_{c}}{r^{2}}\right)^{1 / 3}$

where $a_{c}$ can be determined by Eq. 21 with $P=P_{c}$.

The effective area $\left(A_{\text {eff.Hertzian }}\right)$ is located at the specimen surface, where $z=0$ and corresponds to the region where tensile surface stresses occur. This region is located outside the contact area. $A_{\text {eff.Hertzian }}$ is derived for the conditions: $r \geq a$ and $z=0\left[{ }^{124}\right]$ (see Fig. 11).

$A_{\text {eff }} \cdot$ Hertzian $=\frac{\pi}{m-1} \cdot\left(\frac{4 k P R}{3 E}\right)^{2 / 3}$

Eq. 24

\subsubsection{Statistical lifetime evaluation}

\subsubsection{Slow crack growth and Strength-Probability-Time (SPT) prediction}

A ceramic component must be designed not only with respect to the applied load, but also to sustain a certain lifetime. For this reason, knowledge of the relationship between strength and operation time is necessary. Existing cracks may grow slowly, depending on the atmosphere, especially humidity. This behavior is known as subcritical 
crack growth (SCG). If SCG is described quantitatively, the lifetime of the component can be predicted using a strength-probability-time (SPT) diagram. Accordingly, an SPT diagram is a link between strength, probability of failure, and lifetime.

The experimental determination of an SPT diagram can be based on measurement of strength as a function of the loading rate, since a slower loading rate permits cracks to grow during loading, resulting in lower apparent strength. The fracture strength is in then correlated with the stress rate $\dot{\sigma}$ via $\left[{ }^{113}\right]$ :

$\log \sigma_{0}=\frac{1}{n+1} \log \dot{\sigma}+\log D$

where $n$ and $D$ (in $\mathrm{MPa} / \mathrm{s}$ ) are the SCG parameters.

To apply the SPT method, fracture stresses for a monotonous loading need to be known as a function of loading rate and these stresses are condensed to the equivalent stress $\sigma_{1 s}$. The characteristic strength $\sigma_{0}$, measured at a certain stress rate of $\dot{\sigma}$, is in this case converted into an equivalent stress that would have caused the sample to fail in a time of $1 \mathrm{~s}$ with a fracture probability of $P_{f}=63.2 \%\left[{ }^{126},{ }^{127}\right]$ :

$\sigma_{1 s}=\sigma_{0}\left(\frac{\sigma_{0}}{\dot{\sigma}(n+1)}\right)^{\frac{1}{n}}$

Eq. 26

The combination of this stress and the failure probability of $63.2 \%$ results in a first data point on the SPT diagram. The $1 \mathrm{~s}$ line crosses the $\sigma_{l s}$ data point and has a slope equal to the Weibull modulus $m$. The prediction of different lifetimes can be performed using the relation:

$$
\frac{t_{2}}{t_{1}}=\left(\frac{\sigma_{1}}{\sigma_{2}}\right)^{n}
$$

Therefore, a series of lines can be drawn, with spacing between the lines equal to $(\ln 10) / n$. In this case, each line represents a one-decade increase in lifetime. Eq. 2 can 
then be used to assess failure probability as a function of stress for a given geometry. To analyze the influence of the specimen or component size on the allowable stress, Eq. 20 should be used.

The SPT diagram consists of a series of failure lines representing equivalent times of failure at different stresses. An example for yttria-stabilized zirconia (YSZ) is given in Fig. $12\left[{ }^{128}\right]$.

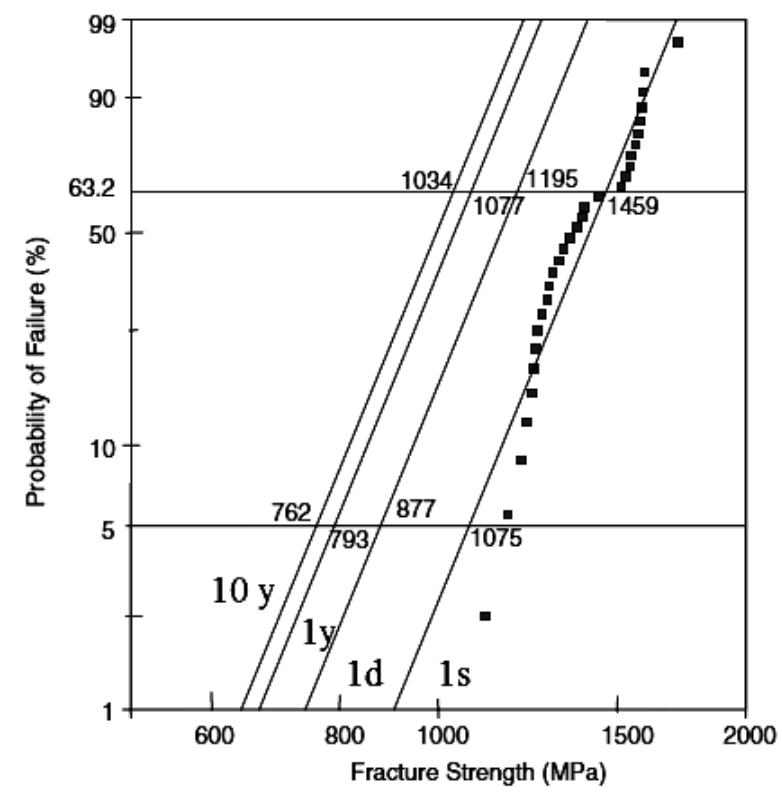

Fig. 12: Strength-probability-time diagram for YSZ [28]

It can be seen that for a given failure probability, YSZ survives for a longer period at lower stresses. For example, for a lifetime of $1 \mathrm{~s}$ with a survival probability of $63.2 \%$, the stress should not exceed $\sim 1460 \mathrm{MPa}$, whereas for a lifetime of 10 years with the same survival probability, the applied stress should not exceed $\sim 1030 \mathrm{MPa}$.

It has to be emphasized that the SPT diagram is only valid for the actual environmental conditions under which the specimens are tested $\left[{ }^{129}\right]$. 


\subsubsection{Photoelasticity}

Photoelasticity is a non-destructive experimental method used primarily for two dimensional plain strain state analysis, which uses optical effects to determine strain distribution. Photoelastic analysis provides qualitative assessment of highly strained areas and peak strain at the surface and in the interior of the structure. It also distinguishes areas of low strain level where the material is less utilized. Almost all transparent isotropic materials (such as glass, polycrystalline ceramics, as well as many transparent synthetic resins and polymers) exhibit a double refracting effect on a beam of light, when they are subjected to strain $\left[{ }^{130}\right]$.

When the material is strained and a ray of light enters along one of the directions of principal strain, the light splits into two component waves - each with its plane of polarization parallel to one of the remaining two principal planes (planes on which shear stress is zero). Furthermore, the light travels along these two paths with different velocities, which depend on the magnitudes of the remaining two principal strains in the material. The incident light is resolved into components having polarization planes parallel to the directions of the principal strains $\sigma_{l}$ and $\sigma_{2}$ (Fig. 13). Since these waves intersect the body with different velocities, the waves appear with a phase relationship, or relative retardation. Quantitative determination of the strain values is usually not possible and the method is used only qualitatively $\left[{ }^{131}\right]$.

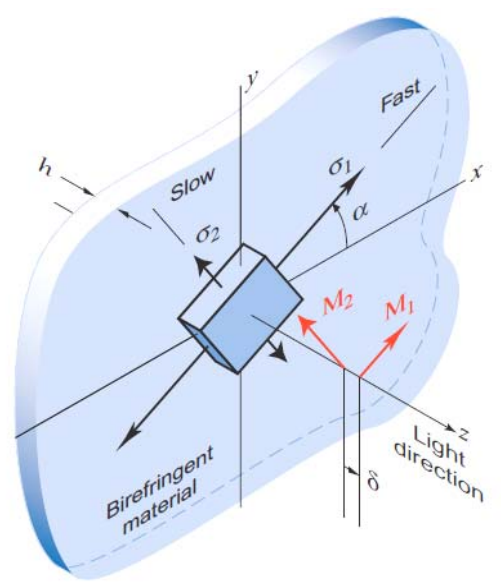

Fig. 13: Birefringent effect [131] 


\section{INVESTIGATED MATERIALS AND EXPERIMENTAL METHODS}

\subsection{Material}

\subsubsection{Processing}

The material was developed, produced and supplied by CeramTec-ETEC, Lohmar. A nano-sized $\mathrm{MgAl}_{2} \mathrm{O}_{4}$ spinel powder with a specific surface area BET of 30 $\mathrm{m}^{2} / \mathrm{g}$, average particle size $70 \mathrm{~nm}$ and purity of more than $99.9 \%$ was used as raw material. This powder was dispersed with a stirred media mill in water to form a slurry with 50 wt.-\% solid material. Polyvinyl alcohol and Ammonium stearate were used as plasticifiers. The slurry was spray dried and then uniaxially pressed on a Herzog HP40 laboratory press. Thereafter, the green samples were debindered, sintered in a Nabertherm HT40 furnace and afterwards hot isostatically pressed in an EPSI Hot Isostatic Pressing. A detailed description of the fine- and coarse-grained spinel production is given in Table 4 .

Table 4. Spinel production

\begin{tabular}{|l|l|}
\hline \multicolumn{1}{|c|}{ Fine-grained spinel } & \multicolumn{1}{c|}{ Coarse-grained spinel } \\
\hline $\begin{array}{l}\text { Mixing water, powder }(50 \mathrm{wt}-\%), \\
\text { dispersant, sintering aid }\end{array}$ & $\begin{array}{l}\text { Mixing water, powder }(50 \mathrm{wt}-\%), \\
\text { dispersant, sintering aid }\end{array}$ \\
\hline Ball milling $(2 \mathrm{~h})$ & Ball milling $(2 \mathrm{~h})$ \\
\hline Spray drying $(100-200 \mu \mathrm{m})$ & Freeze drying $(100-200 \mu \mathrm{m})$ \\
\hline Molding & Hot pressing $\left(1700{ }^{\circ} \mathrm{C}, 1 \mathrm{~h}\right)$ \\
\hline Debindering $\left(24 \mathrm{~h} / 800{ }^{\circ} \mathrm{C}\right)$ & $\begin{array}{l}\text { Hot isostatic pressing } \\
\left(1600{ }^{\circ} \mathrm{C}, 200 \mathrm{MPa}, 2 \mathrm{~h}\right)\end{array}$ \\
\hline Sintering $\left(1600^{\circ} \mathrm{C} / 2 \mathrm{~h}\right)$ & \\
\hline $\begin{array}{l}\text { Hot isostatic pressing } \\
\left(1600{ }^{\circ} \mathrm{C}, 200 \mathrm{MPa}, 2 \mathrm{~h}\right)\end{array}$ & \\
\hline
\end{tabular}




\subsubsection{Specimens and surface preparation}

The transparent spinel was produced as $100 \mathrm{~mm} \times 100 \mathrm{~mm}$ plates, with a thickness of $6.2 \mathrm{~mm}$. Disk shaped specimens were cut out of the spinel plates by wire cutting (Fig. 14) for mechanical testing.
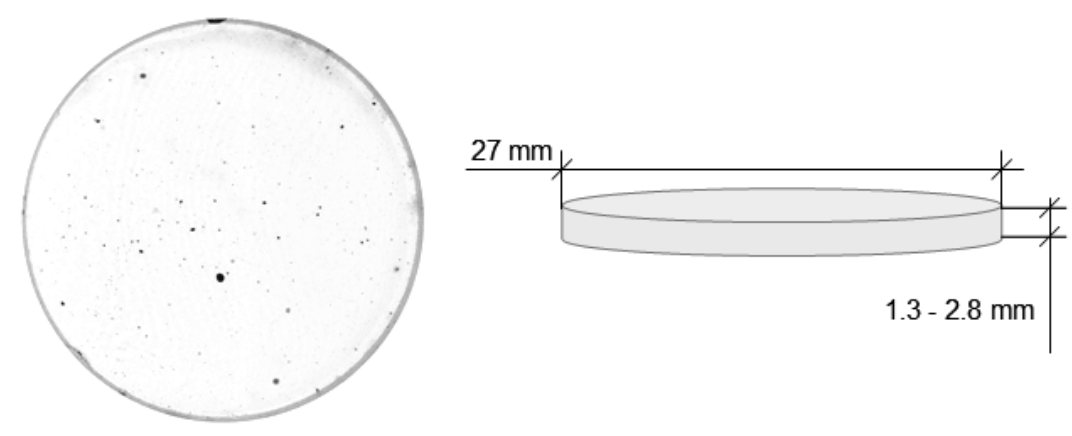

Fig. 14: Disk shaped specimens

Grinding conditions were chosen according to initial results of batches grinded under the different conditions: $54 \mu \mathrm{m}$ diamond abrasive wheel ( $1 \mathrm{~min}), 18 \mu \mathrm{m}$ diamond abrasive wheel ( $3 \mathrm{~min}$ ) and final polishing using $6 \mu \mathrm{m}$ diamond suspension (30 $\mathrm{min}$ ). The optimal polishing condition $(6 \mu \mathrm{m})$ was selected by CeramTec-ETEC to obtain the required optical properties, whereas the optimal grinding condition $(18 \mu \mathrm{m})$ was chosen after macromechanical measurements (see section 4.7). These specimens were investigated by ring-on-ring bending and impulse excitation. The samples were polished (Minimet 1000) using diamond paste $(1 \mu \mathrm{m})$ and silica slurry $(0.2-0.5 \mu \mathrm{m})$ for microscopic analysis and indentation testing.

The fine- and coarse-grained spinel specimens investigated by various methods at room (RT) and high temperature (HT) (see section 3.1.3) are given in Table 5. 
Table 5. Spinel specimens tested in this work

\begin{tabular}{|c|c|c|c|c|}
\hline \multirow{2}{*}{ Method } & \multicolumn{2}{|c|}{$\begin{array}{c}\text { Fine-grained spinel } \\
\text { (number of specimens) }\end{array}$} & \multicolumn{2}{|c|}{$\begin{array}{l}\text { Coarse-grained spinel } \\
\text { (number of specimens) }\end{array}$} \\
\hline & $\begin{array}{c}\text { Room } \\
\text { temperature }\end{array}$ & $\begin{array}{l}\text { High } \\
\text { temperature }\end{array}$ & $\begin{array}{c}\text { Room } \\
\text { temperature }\end{array}$ & $\begin{array}{l}\text { High } \\
\text { temperature }\end{array}$ \\
\hline $\begin{array}{l}\text { Fractography and } \\
\text { microstructure observation }\end{array}$ & 45 & $\begin{array}{c}11 \\
\text { (etched) }\end{array}$ & 13 & $\begin{array}{c}4 \\
\text { (etched) }\end{array}$ \\
\hline Photoelasticity & 16 & $\begin{array}{c}2 \\
\text { (annealed) }\end{array}$ & & \\
\hline $\begin{array}{l}\text { In-situ fracture observation in } \\
\text { light microscopy }\end{array}$ & 1 & & & \\
\hline $\begin{array}{l}\text { Determination of volume and } \\
\text { agglomeration-size distribution }\end{array}$ & 25 & & & \\
\hline $\mathrm{X}$-ray analysis & 1 & & 1 & \\
\hline Ring-on-ring bending test & 170 & & 52 & \\
\hline $\begin{array}{l}\text { Micro- and macro-indentation } \\
\text { testing }\end{array}$ & 17 & $\begin{array}{c}3 \\
\text { (annealed) }\end{array}$ & 14 & $\begin{array}{c}2 \\
\text { (annealed) }\end{array}$ \\
\hline Impulse excitation testing & 3 & 1 & 3 & 1 \\
\hline $\begin{array}{l}\text { Indentation }\left(\mathrm{K}_{\mathrm{IND}}\right) \text { toughness } \\
\text { evaluation }\end{array}$ & 9 & & 3 & \\
\hline $\begin{array}{l}\text { Single edge notch bending } \\
\left(\mathrm{K}_{\mathrm{SENB}}\right) \text { toughness evaluation }\end{array}$ & 5 & & 3 & \\
\hline $\begin{array}{l}\text { Indentation strength in bending } \\
\left(\mathrm{K}_{\mathrm{ISM}}\right) \text { toughness evaluation }\end{array}$ & 4 & & & \\
\hline
\end{tabular}

\subsubsection{Thermal treatment}

The heat treatments of specimens used for microscopic investigations are summarized in Table 6.

Table 6. Application of the heat treatment regimes.

\begin{tabular}{|l|c|c|c|}
\hline \multicolumn{1}{|c|}{ Investigation } & Applied methods & Heat treatment & Samples \\
\hline $\begin{array}{l}\text { Effect of annealing on } \\
\text { local strains }\end{array}$ & Photoelasticity & $\begin{array}{c}\text { annealing in air } \\
\left(1000^{\circ} \mathrm{C}, 60 \mathrm{~min}\right)\end{array}$ & $\begin{array}{c}\text { disk-shaped, } \\
\text { fragments }\end{array}$ \\
\hline Structural observation & $\begin{array}{c}\text { Light and scanning } \\
\text { electron microscopy }\end{array}$ & $\begin{array}{c}\text { etching in air } \\
\left(1500^{\circ} \mathrm{C}, 30-120 \mathrm{~min}\right)\end{array}$ & fragments \\
\hline $\begin{array}{l}\text { Effect of annealing on } \\
\text { mechanical properties }\end{array}$ & Bending, indentation & $\begin{array}{c}\text { annealing in air } \\
\left(1000^{\circ} \mathrm{C}, 60 \mathrm{~min}\right)\end{array}$ & $\begin{array}{c}\text { disk-shaped, } \\
\text { fragments }\end{array}$ \\
\hline
\end{tabular}

* heating rate $3 \mathrm{~K} / \mathrm{min}$, cooling rate $5 \mathrm{~K} / \mathrm{min}$. 
Annealing conditions were chosen to retain transparency of fine- and coarsegrained spinel samples.

Thermal etching was carried out in order to examine the grain structure. Since sintering was carried out at a temperature of $1600{ }^{\circ} \mathrm{C}$, a temperature $1500{ }^{\circ} \mathrm{C}$ was chosen for thermal etching as suggested by the manufacturer. The spinel structures showed different grain size-dependent etching rates. Therefore, exposure times of 30 and $120 \mathrm{~min}$ were used for the fine- and coarse-grained spinels, respectively.

\subsection{Microstructural observation}

\subsubsection{X-ray diffractometry}

The phase composition was determined by X-ray diffraction using a Siemens D5000 diffractometer, equipped with an X-ray tube with copper anode $(\lambda=1.5418 \AA)$, powered with an accelerating voltage of $40 \mathrm{kV}$ and a current of $40 \mathrm{~mA}$.

\subsubsection{Microscopy}

Microstructure investigations were performed by light microscopy (LM: Zeiss Axiomat), confocal laser scanning microscope (CM: Keyence VK-9500) and scanning electron microscopy (SEM: LEO 440) on polished, ceramographically prepared crosssections. Specimens were embedded in epoxy resin and ground on silicon carbide abrasive papers with stepwise decreasing size of abrasive particles (400 up to 4000 grit). For subsequent polishing, diamond pastes and suspensions with grain sizes from 3 , through 1 to $1 / 4 \mu \mathrm{m}$ were used. When visibility of the grain structure was required, the epoxy resin was removed and the polished ceramographic sections were thermally etched (Table 6).

Image analysis (grain size, porosity and phase content estimation) was carried out using the "AnalySIS" software, provided by Olympus., Since thermal etching did not appear to influence the grain structure, grain size analysis was performed on thermally etched specimens (although a local influence on the phase composition could not be ruled out). The latter, however, is not critical for grain size analysis. Grain sizes were 
determined from light and scanning electron micrographs. The planimetric method was applied involving automated measurement of the grain area for grain size determination, and was performed by the AnalySIS software. The results were then recalculated into the diameter of a circle with an identical area as the measured grain, and are given in the following as an equivalent circular diameter (ECD). The average grain size of the samples was calculated, assuming spherical grains, from the linear intercept on a twodimensional cross-section using the following relation $\left[{ }^{132}\right]$ :

$D=1.56 \cdot D_{1}$

Eq. 28

where $D$ is the corrected grain size and $D_{1}$ is the average grain size obtained from the linear intercept method.

A light microscope (Leica DMLM) with a magnification of 63 was used at CeramTec-ETEC for analyzing intrinsic agglomerates, as well as providing agglomerate dimensions and distribution. In order to determine sizes and volume of the particles (Fig. 45), an automatical recalculation into white/black images was obtained by digital images taken from the center of the specimen $\left(\sim 200 \mathrm{~mm}^{2}\right)$, as well as carried out by singlepurpose software.

To reveal fracture mode and crack shape of the fine- and coarse-grained spinels, a line of Vickers indents was introduced into the surfaces of some samples under a load of $49 \mathrm{~N}$, with a distance of $\sim 20 \mu \mathrm{m}$ between the radial crack tips. Subsequently, the specimen was manually broken and observed via light microscopy.

Fractographic analysis was performed on specimens fractured in bending tests. Fracture origins were identified by a stereo-zoom microscope (Olympus SZH10) and SEM (LEO 440), as well as by a confocal laser-scanning microscope (Keyence VK9500). The SEM in combination with Energy Dispersive X-ray spectroscopy (EDX) at high resolution $(1 \mu \mathrm{m})$ permitted to analyze the elemental composition.

Transmission electron microscopy (TEM: Philips CM 200 and JEOL 200CX) was conducted on thin foils prepared by $\mathrm{Ga}^{+}$- focused ion beam technique (FIB: Zeiss Neon 40EsB CrossBeam). Critical microstructural details were investigated by means of highresolution TEM. 
The photoelastic observation was carried out with the aid of a circular polariscope in dark field configuration (Zeiss Axioskop $40 \mathrm{Pol}$ ). The set-up consists of a light source, a polarizer, a quarter-wave plate oriented at $45^{\circ}$ with respect to the polarizer, the specimen, a second quarter-wave plate, and an analyzer (Fig. 15).

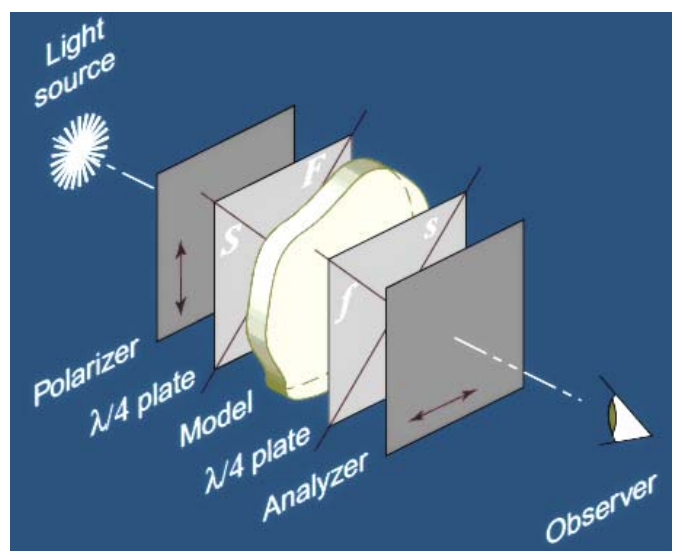

Fig. 15: Working scheme of circular polariscope (dark field) $\left.{ }^{131}\right]$

\subsection{Mechanical characterization}

Various testing methods were applied to obtain mechanical properties of the $\mathrm{MgAl}_{2} \mathrm{O}_{4}$ spinel. In particular, bending tests were used to determine fracture strength and Young's modulus, which was additionally determined using a resonance-based method and depth-sensitive indentation. Fracture strength data were statistically evaluated; fractured specimens were used to assess the failure origin. The depth-sensitive indentation method was also used to measure the hardness of the material. Fracture toughness was evaluated by three methods: the length of indentation cracks, the indentation strength method and from a direct measurement of the defect size in combination with the Griffith criterion. 


\subsubsection{Impulse-excitation technique}

The measurements at room temperature were carried out on disk-shaped specimens with a $27 \mathrm{~mm}$ diameter and thicknesses between 1.3 and $2.8 \mathrm{~mm}$ (see section 3.1.2), using a commercial resonance system (GrindoSonic, Lemmens KG, Belgium) (Fig. 16a) based on ASTM E1876-01 $\left[{ }^{133}\right]$. However, for high temperature measurement the use of rectangular bars was required by the test setup $(25 \mathrm{~mm} \times 6 \mathrm{~mm} \times 2 \mathrm{~mm})$; the bars were wire cut out of disk shaped specimens.

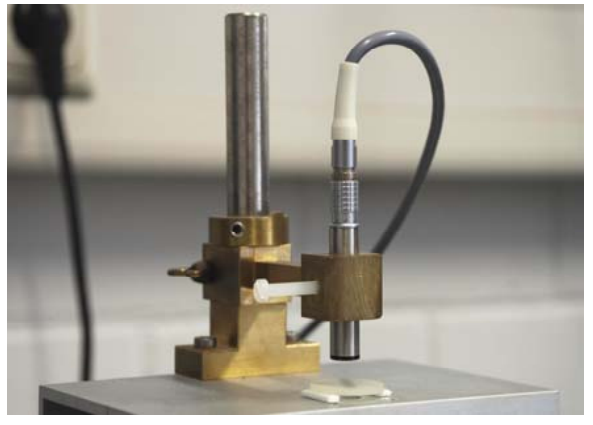

$a$

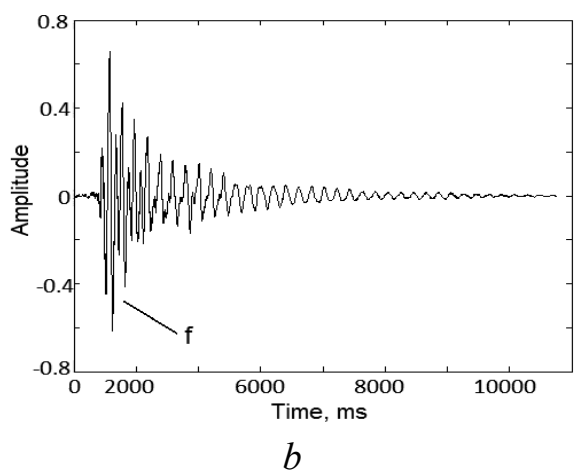

$b$

Fig. 16: a) Set-up for impulse excitation tests in air; b) typical resonance signal of the specimen induced by push rod.

\subsubsection{Bending test}

Bending experiments were carried out using the electromechanical testing machine Instron 1362 (Fig. 17a). Specimens for strength characterization were investigated in a ring-on-ring configuration, which avoids edge effects, and failure initiates within the loading ring. A limited number of specimens have been machined to carry out the single edge notch bending (SENB) test after ISO 13586 (see section 3.5.3) to assess the fracture toughness. 


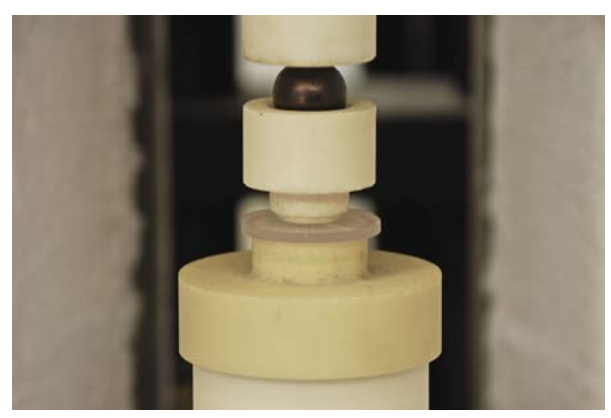

$a$

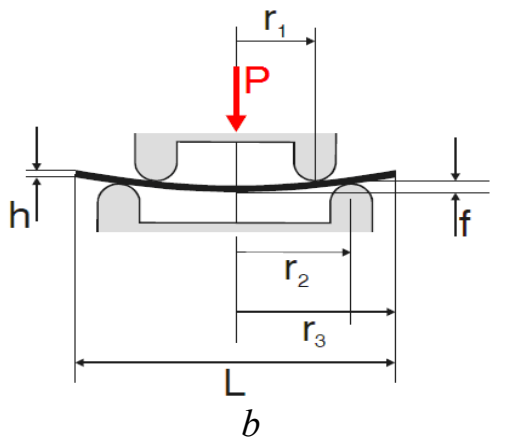

Fig. 17: a) Ring-on-ring testing set-up; b) Schematic sketch of load and support ring with specimen.

Biaxial ring-on-ring bending test, according to the procedure given in ISO 1288

$\left[{ }^{134}\right]$, permits a simultaneous assessment of Young's modulus and fracture stress for thin plates. The specimens were mounted between a loading (top) and support ring (bottom), both made of alumina. Alumina ceramics were also used for the upper pushing rod and the lower tubular support piston. The arrangement provided high temperature stability, stiffness, and good alignment of the load train. The displacement was measured in the center of the specimen with a ceramic extension rod attached to a linear variable differential transformer (Sangamo, LVDT, range $\pm 1 \mathrm{~mm}$, precision $1.25 \mu \mathrm{m}$ ). The load was determined with a $10 \mathrm{kN}$ load cell (Interface $1210 \mathrm{ACK}$ ). The temperature was monitored during the test close to the outer specimen surface with a thermocouple. All tests were carried out with support and load ring diameters of $D_{s}=19 \mathrm{~mm}$ and $D_{L}=9.4$ $\mathrm{mm}$, respectively. Young's modulus was measured at specimens with thicknesses ranging from $0.5 \mathrm{~mm}$ to $3 \mathrm{~mm}$. In order to determine fracture stress, $3 \mathrm{~mm}$ thick specimens were used.

To determine inert strength, a loading rate of $100 \mathrm{~N} / \mathrm{min}$ was chosen in order to minimize slow crack growth effects. Ten tests per rate at stress rates of $3.6 \cdot 10^{-2}, 3.6 \cdot 10^{-1}$, and 19 tests at $3.6 \mathrm{MPa} / \mathrm{s}$ were performed to analyze slow crack growth.

Limitations for the use of the ring-on-ring test are provided in the literature $\left[{ }^{89},{ }^{121}\right]$. The linear theory is valid as long as the deflection of the specimen does not exceed a certain value, which depends on the diameter ratio of the loading and the supporting ring, and is $\sim 1 / 2$ of the specimen thickness for a ratio of $1 / 2$ and $\sim 3$ for a ratio 
of $1 / 5\left[{ }^{135},{ }^{136},{ }^{137}\right]$. In order to avoid non-linearity in the load-stress curve related with large deflection, the thickness has to be:

$t \geq \sqrt{8 \sigma \cdot r_{1}^{2} / 3 E}$

Since the largest measured fracture stress was $\sim 240 \mathrm{MPa}$, the calculated value $t \geq$ $230 \mu \mathrm{m}$ was well below the thickness of the specimens (for strength measurement $0.5-$ $2.8 \mathrm{~mm}$ ). Specimen diameter, as well as thickness, also may affect the overall stress state. The stress state on the tensile surface inside the loading ring is, in theory, equibiaxial and constant. In practice, contact stresses are present under the loading ring. For round samples with $D_{s} / t$ between 10 and 30, and $\left(D-D_{s}\right) / t$ between 1 and 6 , (where $D$ and $D_{s}$ are diameters of the sample and support ring, respectively) the stresses within the loading ring are estimated to be constant within 2\% $\left[{ }^{138}\right]$. According to DIN $51105\left[{ }^{139}\right]$, the ratio $D_{L} / D_{S}$ should be between 0.2 and 0.5 (where $D_{L}$ is a diameter of loading ring). Taking the thickness range of the investigated spinel plates and the geometry of the bending set-up, following allowable ratios can be determined: $6.8<D_{s} / t<38 ; 2.9<$ $\left(D-D_{s}\right) / t<16 ; D_{L} / D_{S}=0.5$. Both criteria are fulfilled (Fig. 18) for a thickness between 1.35 and 1.9 .

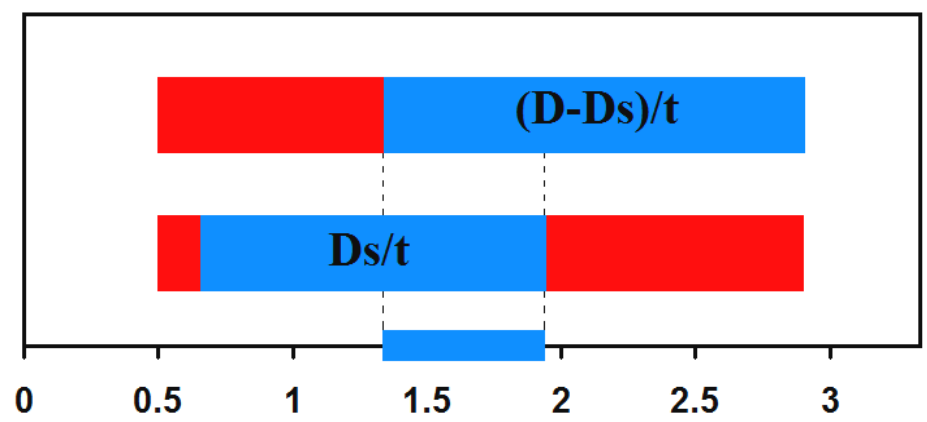

Fig. 18: The suitable thickness range of the specimens (in blue) for the ring-on-ring bending test. 
The load-displacement curves were corrected for the compliance-related deformation of the set-up. To consider the machine compliance, a $25 \mathrm{~mm}$-thick alumina specimen was subjected to loading using the configuration described above; up to the maximum force was used in the fracture tests of spinel specimens.

The actual machine deformation for a particular load was subtracted from the deformation obtained in the bending tests of the spinels in order to obtain an unbiased Young's modulus.

\subsection{Indentation test}

\subsubsection{Macroindentation}

Loads of 9.8, 49 and $98 \mathrm{~N}$ were applied for macrohardness determination (see sections 2.6.2, 4.4) by means of the hardness tester Buehler Met 10.

\subsubsection{Depth-sensitive indentation}

Experiments were carried out using both a Fischer HC100 indentation system and a combined nano-micro indentation set-up (CSM). Indentations were performed using loads between 0.1 and $20 \mathrm{~N}$. Surface and cross-sections of the specimens were indented at low loads with the number of indents $\sim 25$, whereas for higher loads a sufficient statistical analysis could be obtained from 5 measurements. The available optical microscope system permits evaluation of the microstructural changes, as well as the crack lengths, for calculation of indentation fracture toughness (see section 2.6.3.1).

\subsubsection{Hertzian indentation}

Based on the Hertzian indentation method (see section 2.6.4.1), the local strength was estimated for the fine-grained material using spherical indenters with a radius of 0.5 and $2.5 \mathrm{~mm}$, respectively. Impressions were made in the load range from 30 to $245 \mathrm{~N}$, with load steps of $49 \mathrm{~N}$. The critical load for the formation of cone cracks was estimated visually after the impression using an optical microscope. 


\subsection{Fracture toughness}

\subsubsection{Indentation}

Using a macroindenter Buehler Met 10 and a microindenter Fischer HC100, the impressions were introduced into the spinel surface under different loads, ranging from 3 to $98 \mathrm{~N}$ (see section 2.6.3.1).

\subsubsection{Indentation-Strength-Method}

For ISM testing, typically up to four impressions were placed with an identical load $(9.8 \mathrm{~N})$ at the tensile specimen surface inside the loading ring area. This permits a clear determination of crack origin and an estimate of crack extension during the bending test before failure since fracture will typically only occur by crack extension starting from one of the pre-indentations. It was verified fractographically on every sample that failure in the subsequently carried out ring-on-ring bending test (see section 2.6.3.2) always occurred from one of the impression cracks.

\subsubsection{Single edge notch bending}

The measurements were carried out using an electromechanical testing machine (Instron 1362). The bending supports had an inner span of $S_{2}=7.5 \mathrm{~mm}$, and an outer span of $S_{l}=15 \mathrm{~mm}$. Due to limited availability of materials, only a small number of tests could be carried out with a specimen geometry of $4 \times 5 \times 25 \mathrm{~mm}$ and $1.7 \times 3 \times 25 \mathrm{~mm}$ for fine- and coarse-grained spinel specimens, respectively (see Table 5). Prior to the tests, the bar-shaped specimens were pre-notched following ASTM C1421 [ $\left.{ }^{140}\right]$.

\subsection{In-situ fracture observation}

In addition to fracture mode and crack shape estimation, which are critical parameters for fracture toughness determination $\left(K_{I N D}\right)$, it is necessary to know if indentation cracks and delaminations form during loading or unloading. Therefore, an indentation device with in-situ observation has been developed and applied (Fig. 19). 


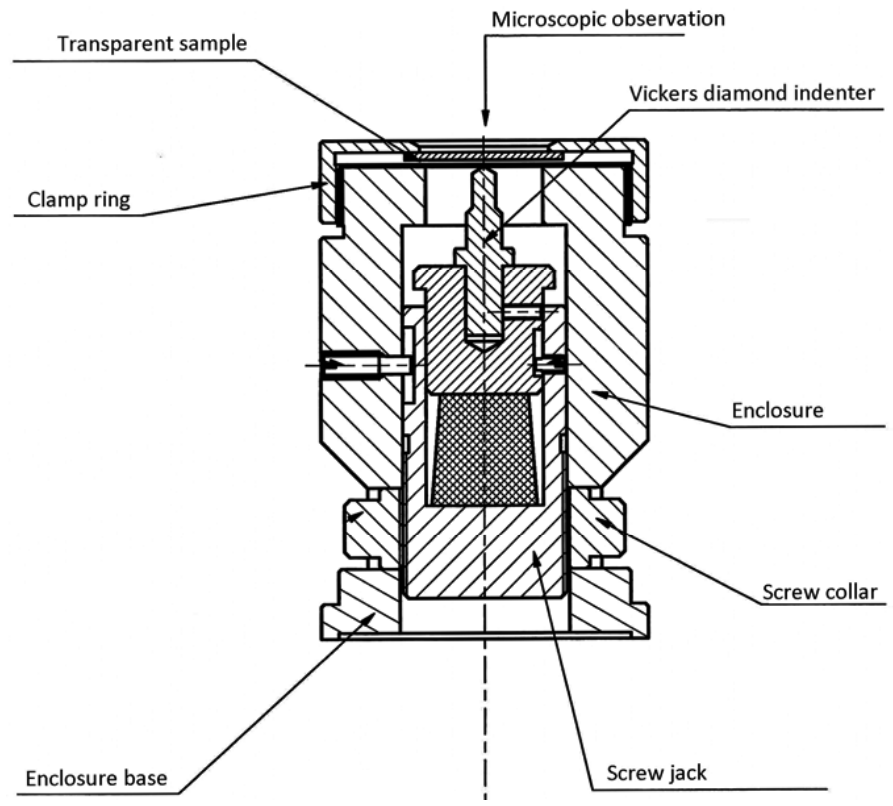

Fig. 19: Indentation device for in-situ fracture observation.

The specimen to be tested is fixed between a clamp ring and enclosure in order to avoid displacement of the specimen during loading. The gradual rotation of a screw collar moves the Vickers indenter to the contact surface, introducing the indentation mark and associated local fracture. A light microscope, Zeiss Axiomat, positioned above the specimen, permitted to observe the indentation process. 


\section{RESULTS AND DISCUSSION}

\subsection{Microstructure}

The etched fine-grained and coarse-grained spinels were investigated via light microscope. Following the procedure outlined above (see section 3.2.2), the grain size was determined for both spinels, yielding an average grain size of $\sim 5 \mu \mathrm{m}$ varying from $0.2 \mu \mathrm{m}$ to up to $50 \mu \mathrm{m}$ for fine-grained transparent spinel (Fig. 20a), and an average grain size $60 \mu \mathrm{m}$, with a size variety from $5 \mu \mathrm{m}$ up to $170 \mu \mathrm{m}$ for the coarse-grained transparent spinel. The microstructure of both spinels is inhomogeneous, and partially consists of zones with relatively coarse and fine grains (Fig. 20).
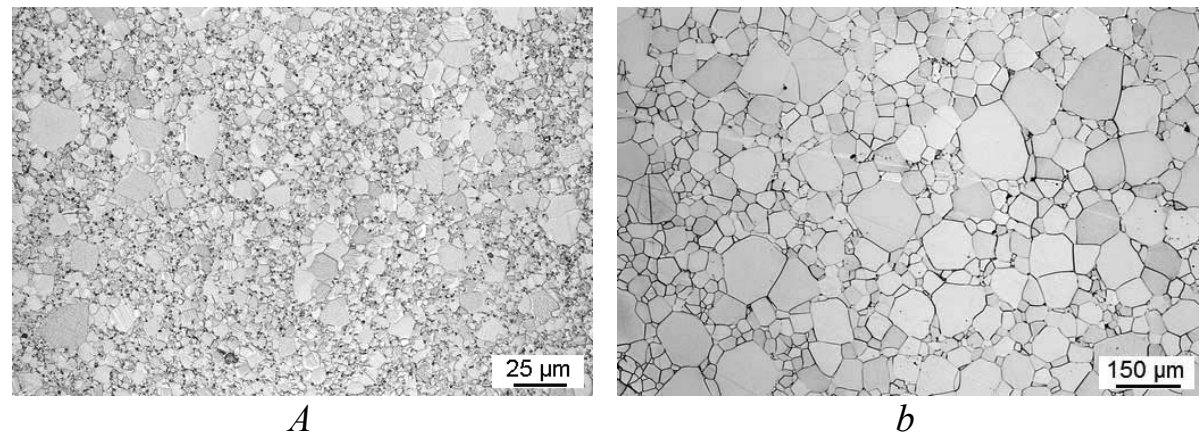

Fig. 20: Thermally etched structures of fine-grained (a) and coarse-grained (b) spinel.

In addition, a thin lamella was extracted by FIB from the fine-grained material and then characterized by TEM, confirming the existence of nanometer-sized grains and well-defined grain boundaries (Fig. 21a). A complementary EDX element analysis verified that the material consists locally only of aluminum, magnesium and oxygen (Fig. $21 \mathrm{~b}$ ). The presence of copper and carbon in the spectrum is caused by the material of the specimen holder and the carbon coating deposited to enhance electrical conductivity, respectively. 
TEM investigation was applied for analyzing the element composition between fine- and coarse-grained areas in fine-grained spinel.
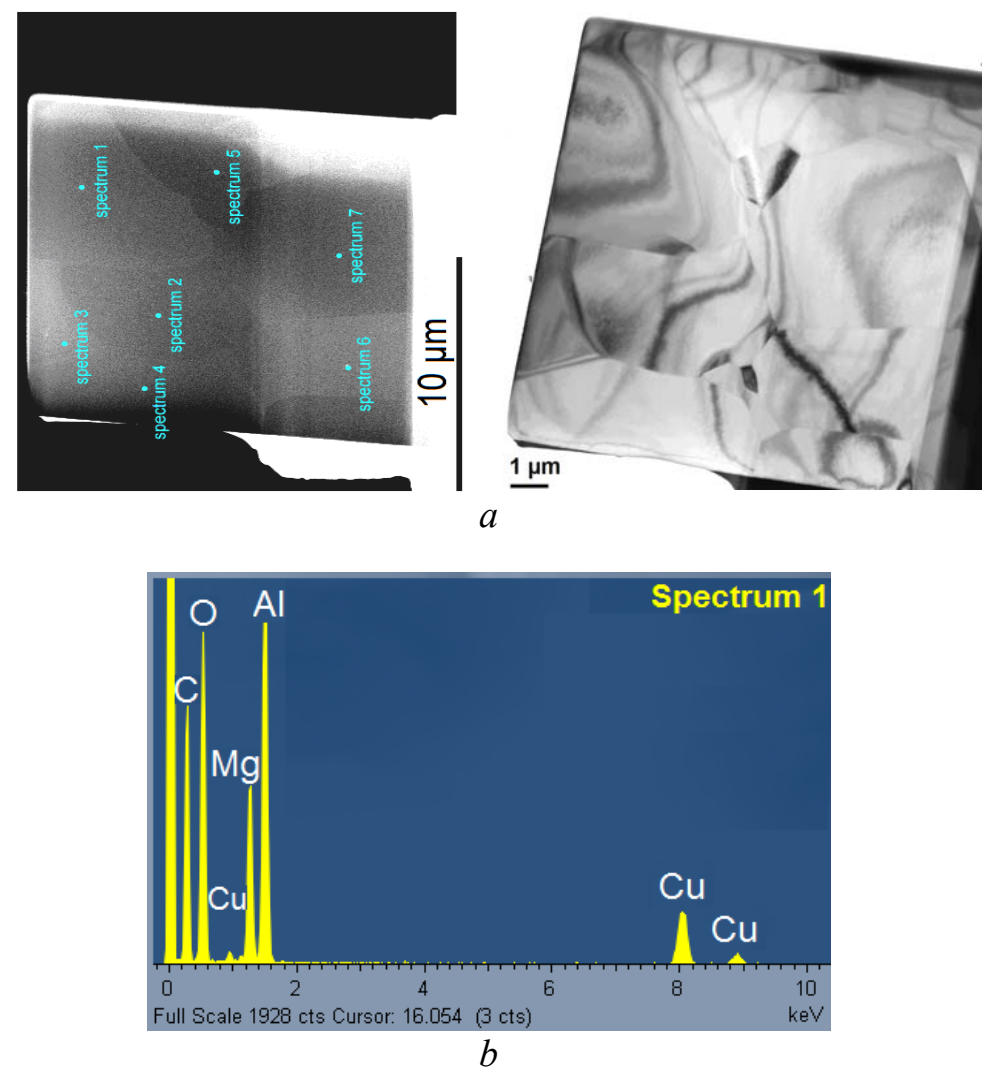

Fig. 21: Fine-grained spinel lamella investigated via (a) TEM and (b) EDX.

\subsection{X-ray analysis}

An X-ray phase analysis confirmed that there are no evident impurities in the fine-grained and coarse-grained transparent spinels, proving $f c c$ cubic spinel crystal structure (Fig. 22, Fig. 23). The obtained lattice parameter, $0.808 \mathrm{~nm}$, coincides with literature findings (see section 2.1). Therefore, XRD and EDX element analyses 
confirmed the purity of the magnesium aluminate spinel, permitting the comparison of the mechanical data to the literature values of this material.

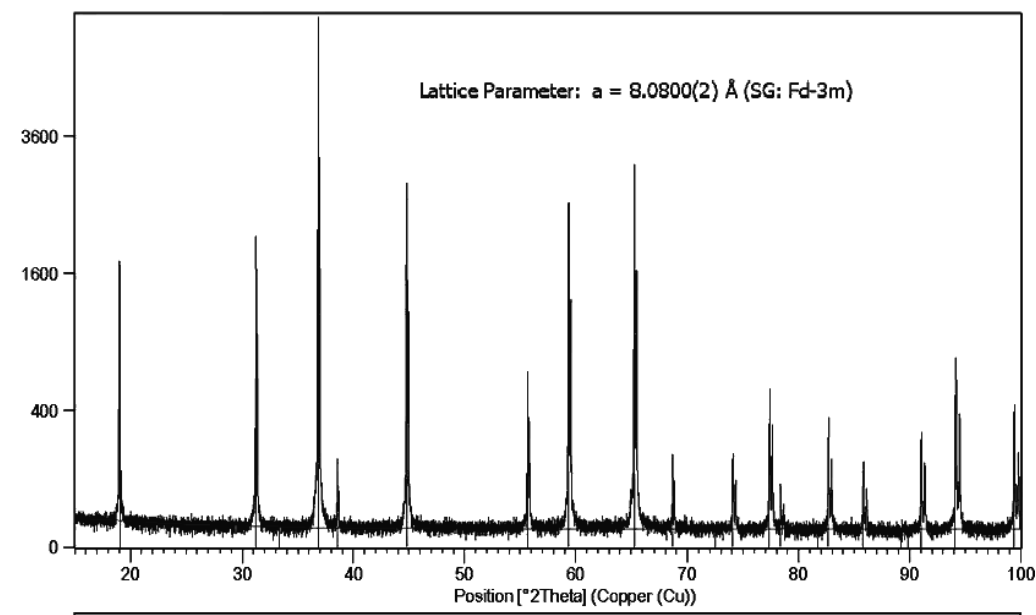

00-021-1152; Mg Al2 O4; Spinel, syn; Cubic

Fig. 22: XRD diagram of the fine-grained transparent magnesium aluminate spinel

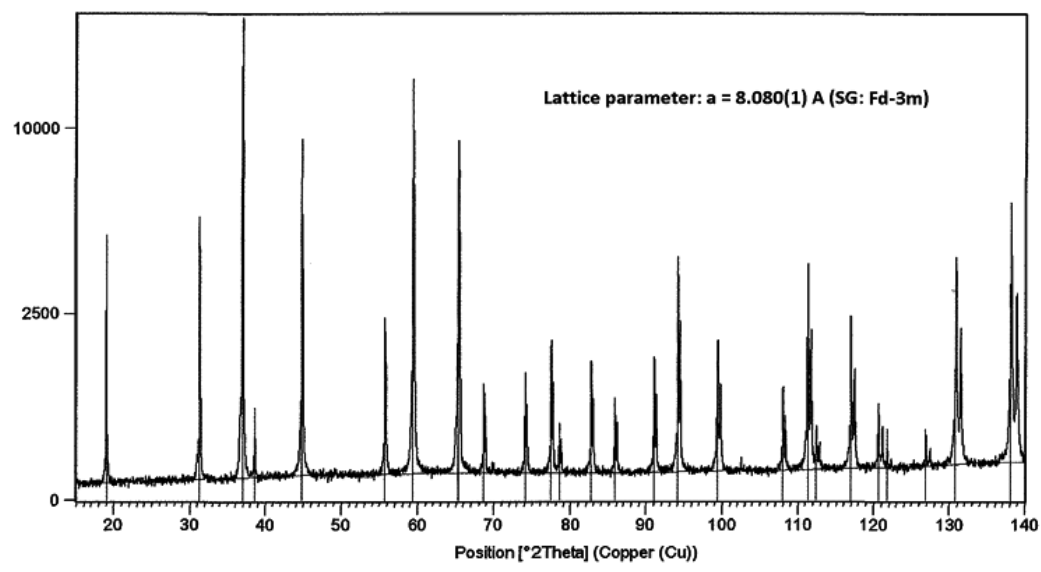

00-p21-1152; Mg Al2 194; Spinel, syn; Cupic;|Fd-3m

Fig. 23: XRD diagram of the coarse-grained transparent magnesium aluminate spinel 


\subsection{Young's modulus}

Young's modulus was determined using bending, impulse excitation and indentation testing (see sections 2.6.1.1, 2.6.1.2, 2.6.1.3). The value for fine-grained spinel derived from the ring-on-ring bending tests without compliance correction decreases significantly, with increasing specimen thickness from $270 \mathrm{GPa}$ down to $\sim 160$ GPa ( 45\%) (Fig. 24).

The circle-shaped data points in Fig. 25 represent Young's Moduli from ring-onring bending tests after compliance correction, as outlined in section 3.3.2. The deformation of the experimental setup used for compliance calibration (see section 3.3.2) was $\sim 3.5 \mu \mathrm{m}$ in the load range $550-650 \mathrm{~N}$, whereas for fine-grained spinel the deflection of the specimens was $\sim 20 \mu \mathrm{m}$ at the same load range. Assuming an uncertainty in the compliance calibration of $1 \mu \mathrm{m}$ leads to an uncertainty in the experimentally determined modulus of $\sim 7 \%$ for fine-grained spinel. The value measured for the thinnest specimens is $\sim 270 \mathrm{GPa}$, whereas for larger thicknesses the modulus decreases by $\sim 10 \%$ (Fig. 25). Therefore, this effect is close to the limits of uncertainty.

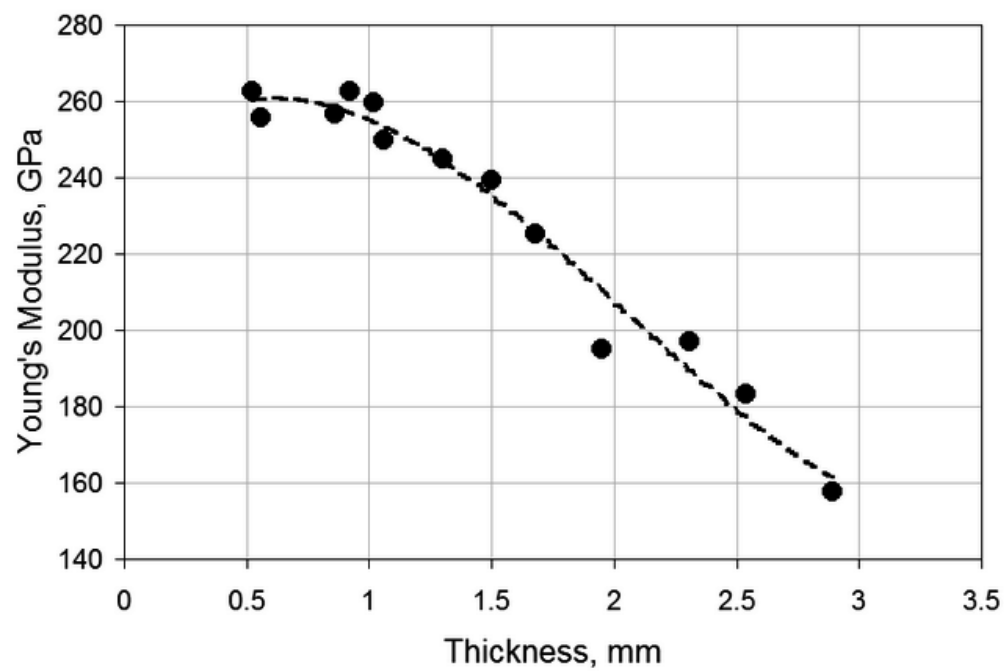

Fig. 24: Apparent Young's modulus (not corrected for compliance) of fine-grained spinel as a function of the specimen thickness. 


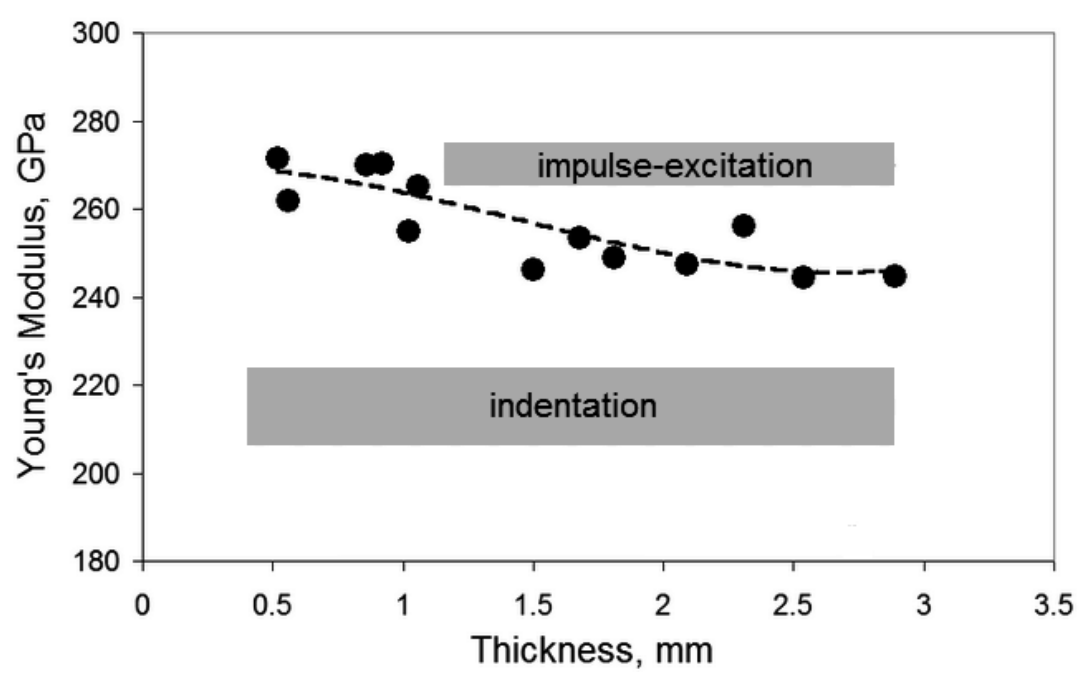

Fig. 25: Apparent Young's modulus as a function of specimen thickness. Results are derived from compliance-corrected load-displacement curves obtained in ring-on-ring bending tests for fine-grained spinel specimens.

The value of $\sim 270 \mathrm{GPa}$ determined for thin specimens $(\sim 1 \mathrm{~mm})$ coincides with the average modulus determined using the impulse excitation technique $(\sim 270 \pm 5 \mathrm{GPa})$, whereas the depth-sensitive indentation technique yielded a 20\% lower value $(\sim 210 \pm 10$ GPa, for loads from 0.5 to $1 \mathrm{~N}$ ) (Fig. 25). The low Young's Modulus obtained by indentation can be explained by surface effects $\left[{ }^{141}\right]$.

The same bending test procedure was also used for the coarse-grained spinel. However, specimens were only available with a thickness of around $2 \mathrm{~mm}$. After compliance correction, the ring-on-ring bending tests yielded $E_{R O R}$ values of $242 \pm 13$ $\mathrm{GPa}$, whereas impulse excitation and indentation tests resulted in Young's moduli of $\sim 270 \pm 5$ and $\sim 225 \pm 10 \mathrm{GPa}$, respectively.

Overall, the data for fine- and coarse-grained material coincide only for impulse excitation. The bending tests yield lower values, which might be biased by morphological effects, e.g., the grain size and local defects (Fig. 20, Fig. 54). Indentation tests reveal $\sim 5 \%$ higher values for the coarse-grained spinel, compared to the fine-grained material. This difference might be related to the number and amount of the coarse-grained areas with higher local Young's modulus in the fine-grained material (see section 4.4). The 
nearly identical value of $\sim 270 \mathrm{GPa}$ determined by impulse excitation technique for both spinel variants reflects the low sensitivity of this technique to local structural inhomogeneities. The result obtained using this method represents the integral property of the entire specimen volume.

The local indentations into grains (see section 4.4) were analyzed in more detail to obtain insight into the origins of the differences between indentation moduli and the global values obtained from bending and impulse excitation tests. The microindentation into the thermally-etched grain structure (see section 3.1.3) verified that (for fine-grained spinel in particular), the modulus is also affected by the local structure of the material. For instance, fine-structured spinel areas (grain size $0.5-5 \mu \mathrm{m}$ ) lead to a large scatter from 140 to $240 \mathrm{GPa}$, whereas coarse-structured spinel areas in the fine-grained material (grain size $20-60 \mu \mathrm{m}$ ) revealed data with less deviation (from $190-230 \mathrm{GPa}$ ). Although thermal etching appeared to increase the average Young's modulus by $\sim 10 \%$ ( $\sim 5 \%$ for the hardness), it can be concluded that the average of the local properties is not equal to the global properties determined by bending and impulse excitation, due to the different integral effect of grain boundaries and defects. A similar behavior could not be confirmed for the coarse-grained spinel (see section 4.4). Consequently, these data revealed less scatter in comparison with fine-grained spinel, due to different morphology of the material (big single grains and grain boundaries of relatively fine grains between them yield ranges of $170-190 \mathrm{GPa}$ and $210-230 \mathrm{GPa}$, respectively).

In addition, the temperature dependency of the Young's modulus (up to $1000{ }^{\circ} \mathrm{C}$ ) was determined for the fine- and coarse-grained spinels using bar-shaped specimens by impulse-excitation testing in air. Plates could not be tested at high temperature using the available experimental setup. The temperature dependency corresponds with the decrease of $1 \%$ per $100 \mathrm{~K}$ quoted in literature for ceramic materials $\left[{ }^{106}\right]$ (Fig. 26). Since the temperature dependence of the Young's modulus is an intrinsic materials behavior, it might considered to be representative also for the coarse-grained batch. Indeed, for both spinels Young's modulus linearly decreases with temperature increasing. Only one measurement was carried out for each of both spinels and the respective Young's modulus shows a difference of $\sim 5 \%$ over the entire temperature interval. However, 
Young's modulus of the coarse-grained spinel decreases at a slightly stronger rate with increasing temperature.

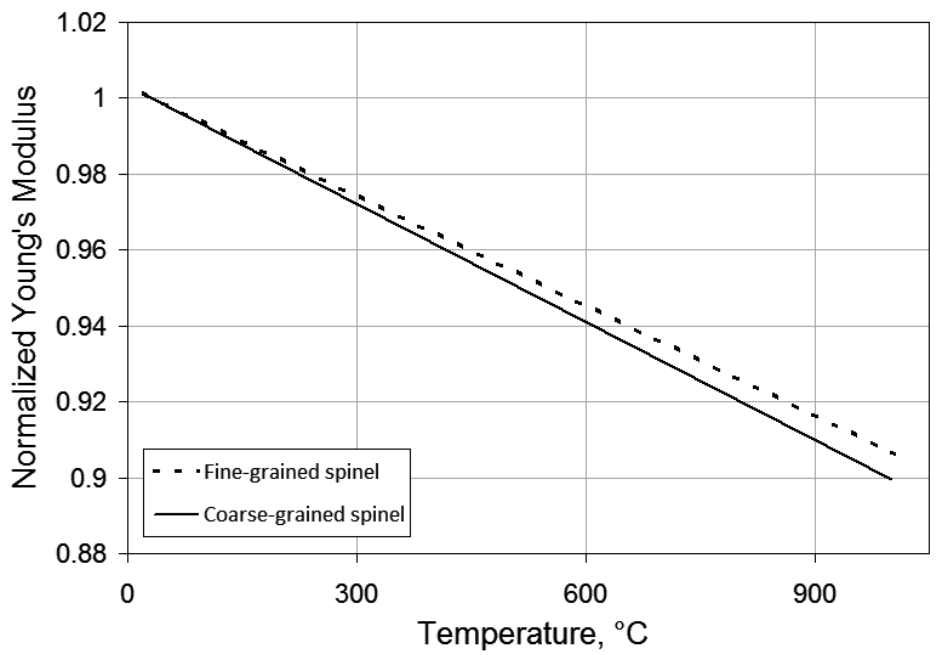

Fig. 26: Normalized Young's Modulus of the fine-and coarse-grained spinels as a function of temperature determined by impulse excitation $\left(E_{I E}\right)$.

\subsection{Hardness}

Impression tests were carried out for a load range from 1 to $98 \mathrm{~N}$ in the specimen surface using micro- and macro-indentation (see sections 3.4.1, 3.4.2). Three impressions were applied at loads of 1, 3, 9.8, 49 and $98 \mathrm{~N}$ each. Fig. 27 illustrates the loaddependency of hardness, which is less pronounced for the fine-grained spinel. The hardness becomes almost load-independent above $1 \mathrm{~N}$ for the fine-grained spinel, whereas for the coarse-grained spinel the hardness is still load-dependent even at $96 \mathrm{~N}$. 


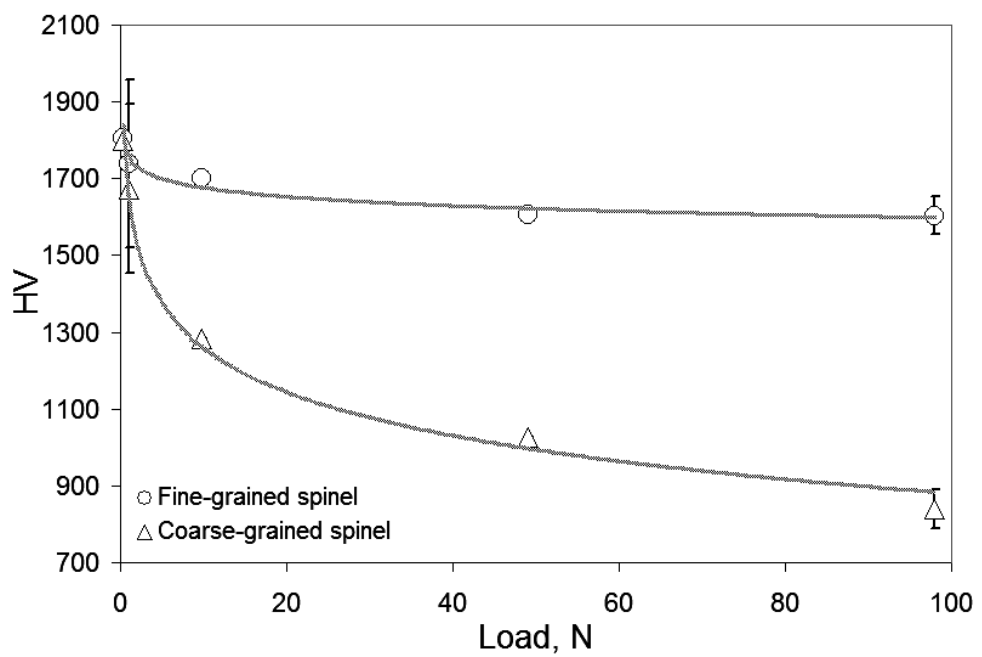

Fig. 27: Vickers hardness - indentation load dependency of the fine-grained and coarsegrained spinel (surface).

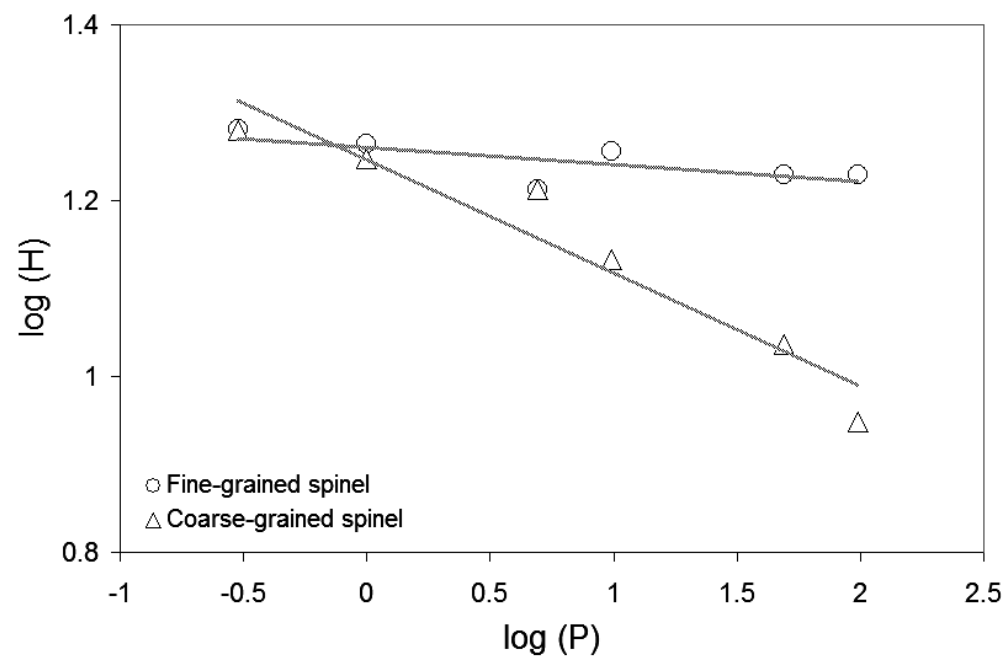

Fig. 28: Indentation size effect for fine-grained and coarse-grained spinel materials.

Such load dependencies of indentation hardness were often reported for ceramics [e.g. ${ }^{142}$ ] and are usually referred to as indentation size effects. A clearer representation of 
the effect can be obtained from a log-log plot of the data (Fig. 28), yielding rather linear dependencies. A larger slope is obtained for the coarse-grained material. Literature has suggested that a larger slope indicates that the material that is less prone to impact damage $\left[{ }^{143},{ }^{144}\right]$.

Note that a load of $1 \mathrm{~N}$ yielded an average indentation hardness of $16 \pm 2 \mathrm{GPa}$ for both materials for impressions carried out in surface and cross-section.
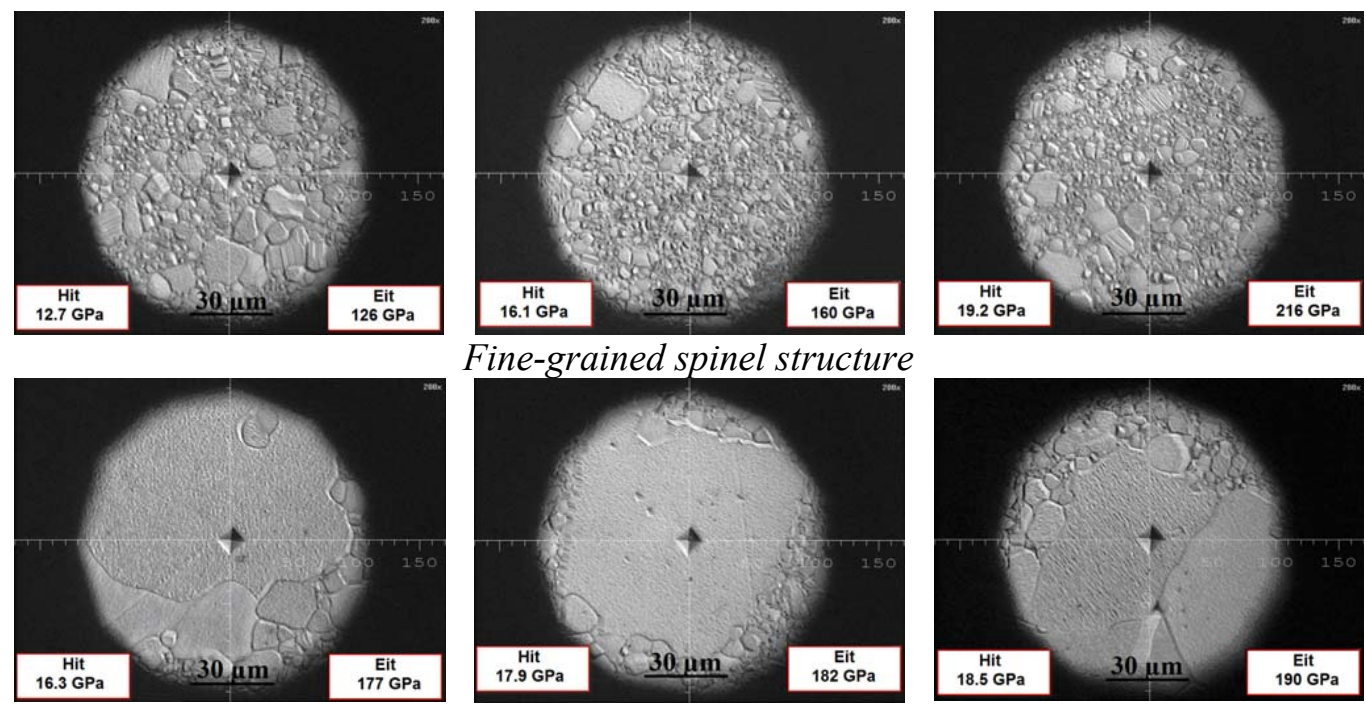

Fine-grained spinel structure
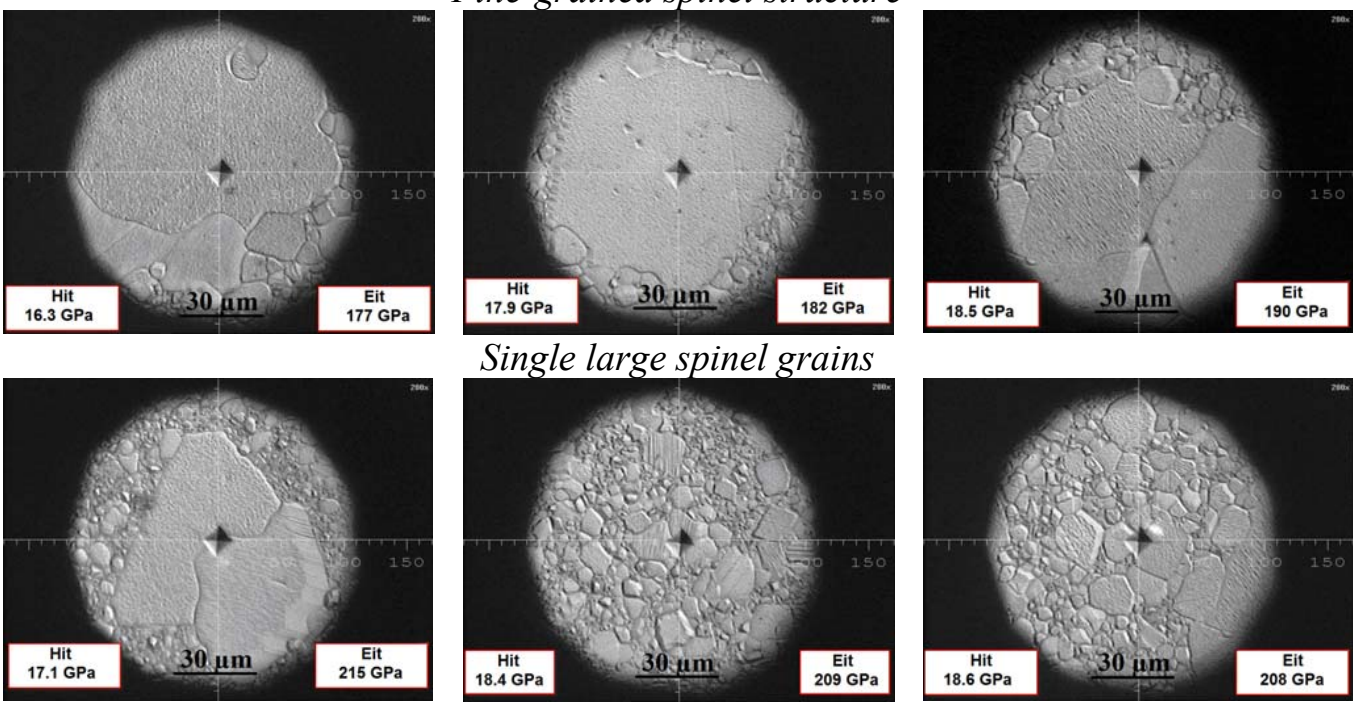

Grain boundary influence

Fig. 29: Typical hardness impressions in the fine grained spinel surface $(P=1 \mathrm{~N})$

Additional indentation tests were carried out to determine if a correlation of microstructure and local hardness exists. Before indentation, the fine-grained and coarsegrained specimens were thermally etched as described in the experimental section. The 
negligible increase of the average hardness of 5\% after etching verifies that the etched specimens are comparable to the initial condition.

As indicated in Fig. 29, impressions in the larger grains $(20-60 \mu \mathrm{m})$ yield hardness values of $16-18 \mathrm{GPa}(P=1 \mathrm{~N})$. The impressions into nano/micro-grained spinel areas lead to larger hardness variations, with values in the range of 13 to $19 \mathrm{GPa}$ that might be attributed to the effect of structural inhomogeneities, such as grain boundaries, twin boundaries, inclusions or precipitates.
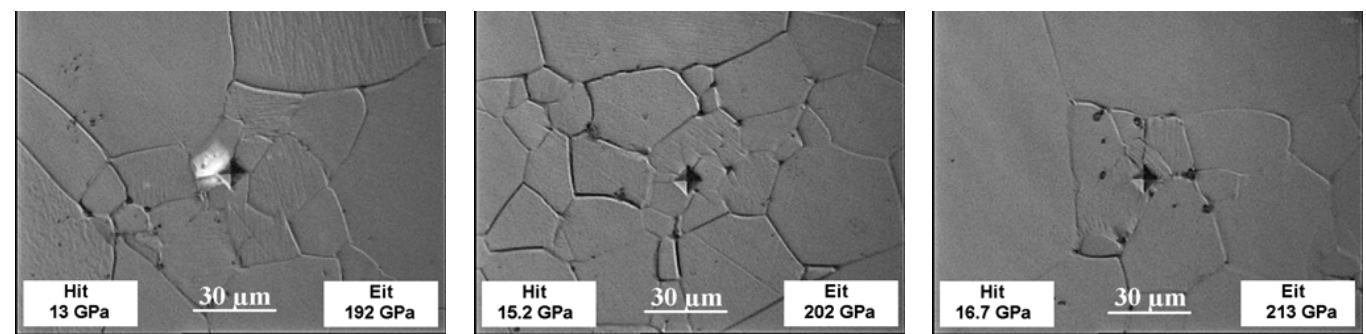

\section{Relative fine-grained spinel structure}
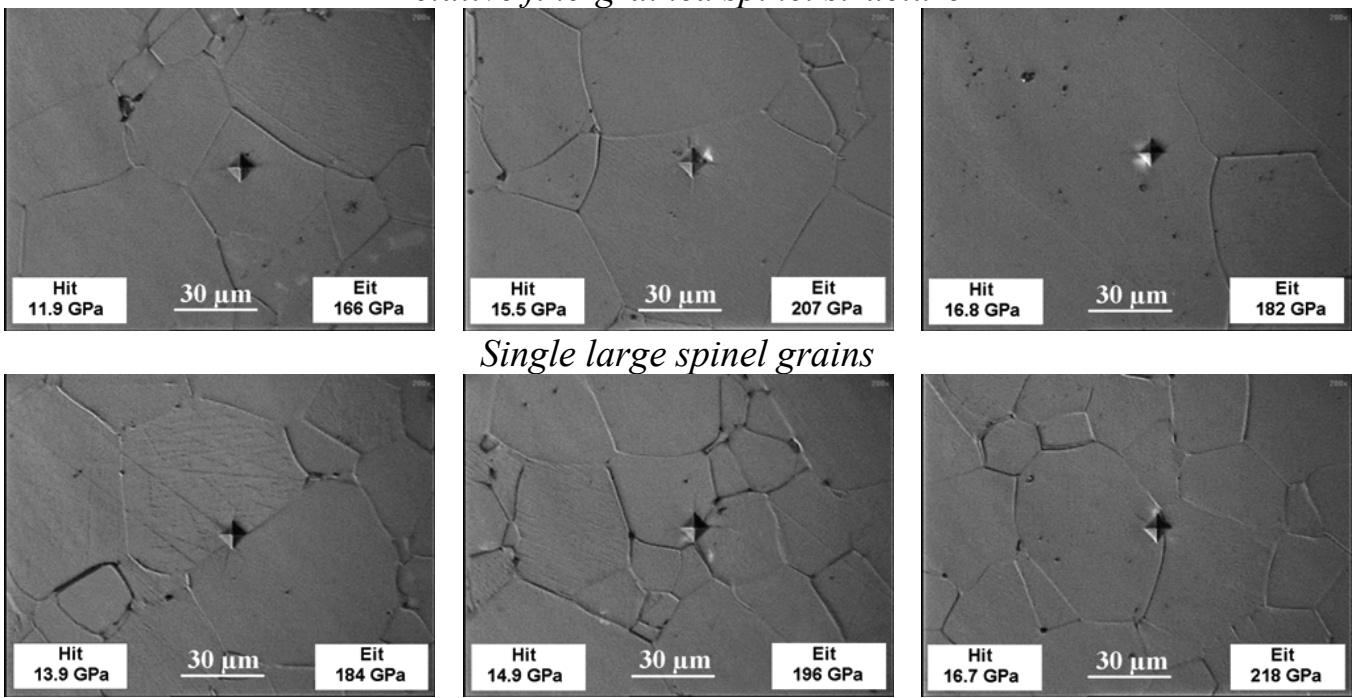

Grain boundary influence

Fig. 30: Typical hardness impressions in the coarse-grained spinel surface $(P=1 \mathrm{~N})$ 
For the coarse-grained material, a hardness range from $\sim 12$ to $17 \mathrm{GPa}$ was obtained for all local grain sizes (Fig. 30). Overall, the data do not lead to conclusions regarding grain size effect.

\subsection{Fracture toughness}

\subsubsection{Indentation}

The calculation of indentation fracture toughness requires first a determination of the crack shape. An accurate way to determine the indentation crack shape is to break up a specimen after applying a line of indents (here load $49 \mathrm{~N}$, distance between indents $\sim 500 \mu \mathrm{m})$. After manual breakage, it could be confirmed that the cracks have a halfpenny shape for both spinels (Fig. 31), an important prerequisite for choosing the relevant geometric factor in the fracture toughness relationship (see section 2.6.3.4), which was here $(Y / Z) \sim 1.27$.

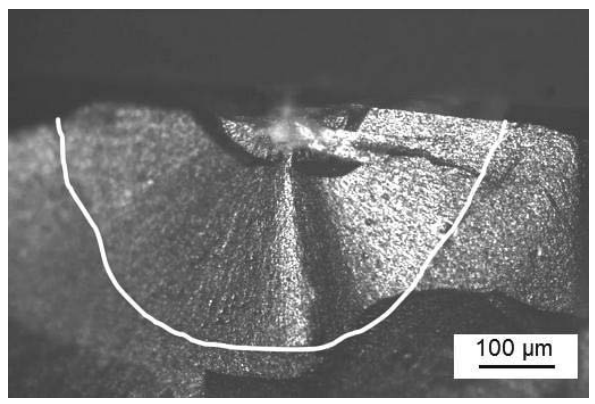

$a$

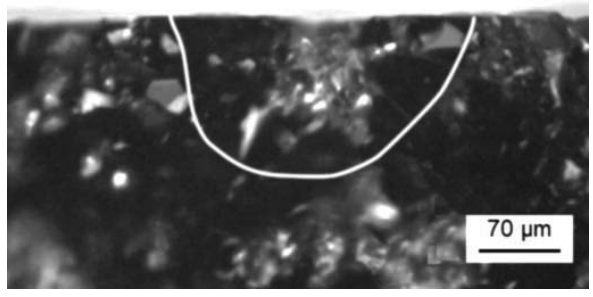

$b$

Fig. 31: Half-penny shaped crack starting at a Vickers indent $(P=49 N)$ : a) finegrained and b) coarse-grained spinel.

However, crack growth appears also to be influenced by the local stress field. In indentation testing, the radial cracks in fine-grained spinel are formed in a mixed transand inter-granular fracture mode (Fig. 32a), whereas the central region beneath the Vickers impression (which is under compressive stress), reveals an intergranular fracture (crushing) (Fig. 32b). Since for coarse-grained spinel the use of higher loads lead to 
chipping of the indented areas, whereas no radial cracks could be obtained at low loads, the fracture mode could not be characterized for this material. But it does not appear farfetched to assume that the transgranular fracture prevails during the indentation for both regions of the impression.

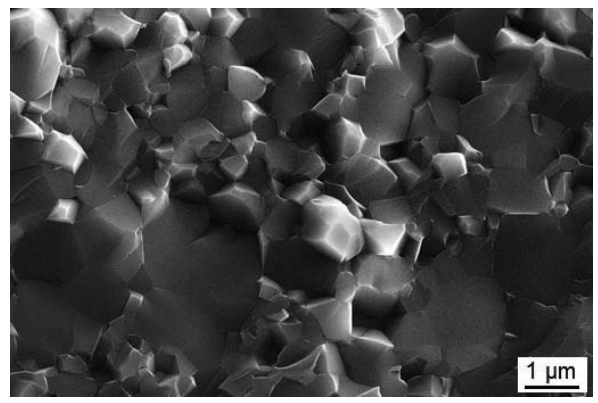

$a$

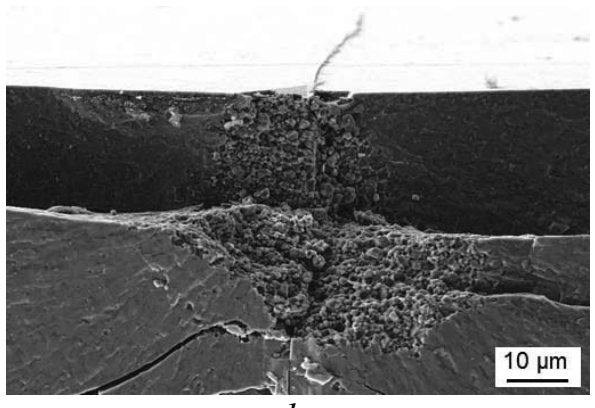

$b$

Fig. 32: Fracture path in the fine-grained material a) after bending test $(\sigma=135 \mathrm{MPa})$ and b) central region under the indentation $(P=49 \mathrm{~N})$.

The device, developed in-house and built to observe hardness impression tests insitu (see section 3.6), allowed further analysis of indentation crack formation in transparent ceramics. The fine-grained spinels revealed radial crack formation (Fig. 33a) during loading, whereas a test carried out for comparative purposes at silica glass showed cone crack formation (Fig. 33b).

Despite the clear images obtained using the optical microscope, the very narrow crack tips are not clearly visible in reflecting light images (Fig. 34a). In Fig. 34b, the same impression depicted via transmitted light microscope shows a sharper contour and the length of the lateral, as well as of the radial cracks, which can be measured more accurately. The difference between the results obtained using reflected and transmitted light is $\sim 10 \%$. Hence, the use of transmitted light is recommended. 

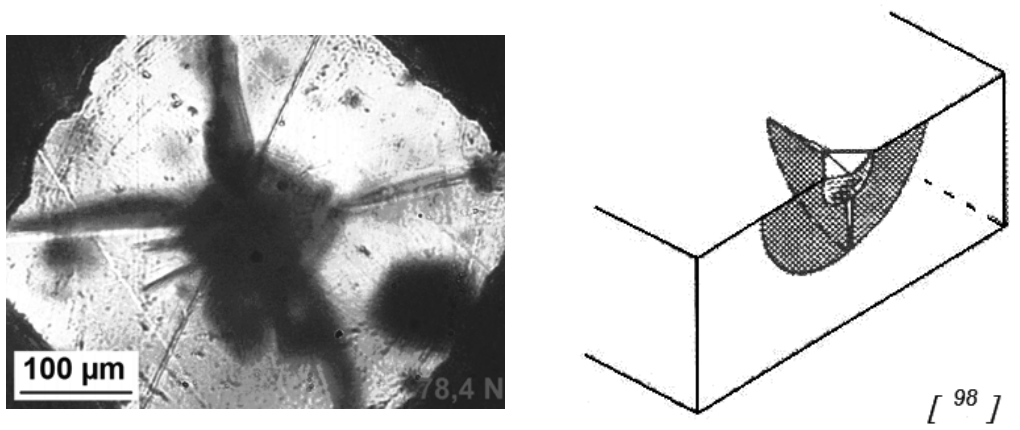

$a$
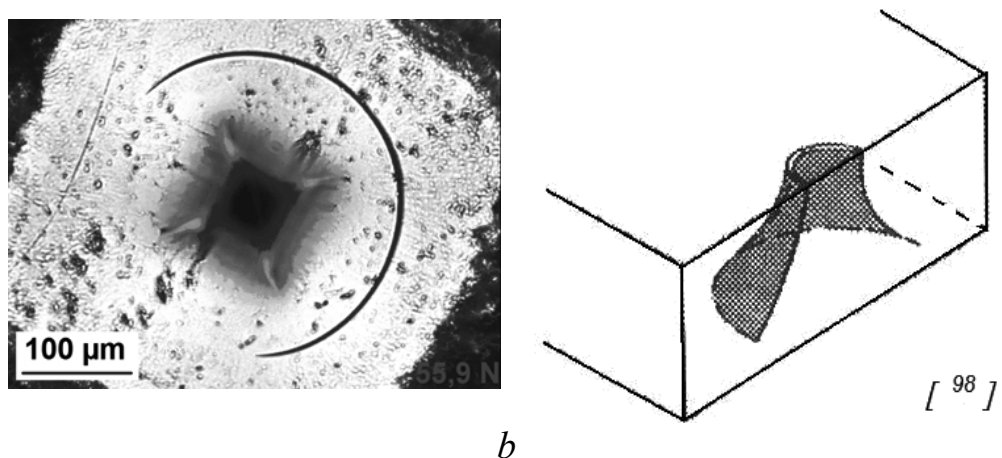

Fig. 33: In-situ fracture observation and schematic crack morphology at indentations in a) fine-grained spinel and b) silica glass.

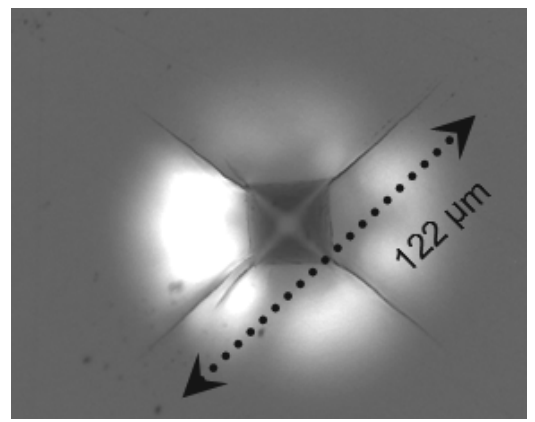

$a$

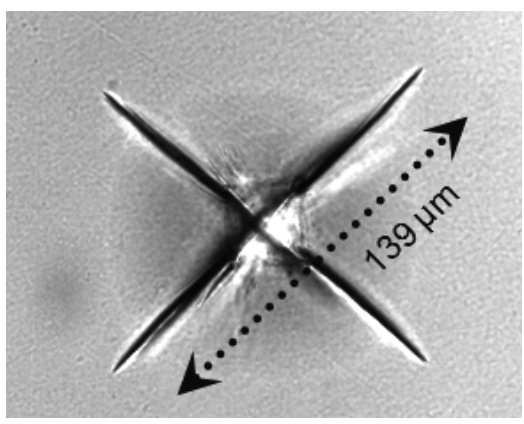

$b$

Fig. 34: Vickers impression in fine-grained spinel $(P=9.8 \mathrm{~N})$, analyzed using a) reflected and b) transmitted light microscopy. 
To determine the indentation fracture toughness, the relationships by Lankford et al. $\left[{ }^{99}\right]$, Niihara et al. $\left[{ }^{93}\right]$ and Anstis et al. $\left[{ }^{94}\right]$ were selected in accordance with the observed crack shape (see section 2.6.3.1). The obtained fracture toughness values remained unchained, independent of the applied loads in the load range from 3 to $98 \mathrm{~N}$ for the fine-grained spinel (Fig. 35 and Table 7). However, high loads lead to large delamination and spallation for coarse-grained spinel (Fig. 38b). Therefore, all further investigations were performed with a load of $3 \mathrm{~N}$ (Fig. 36), which resulted in welldefined radial cracks (Table 7).

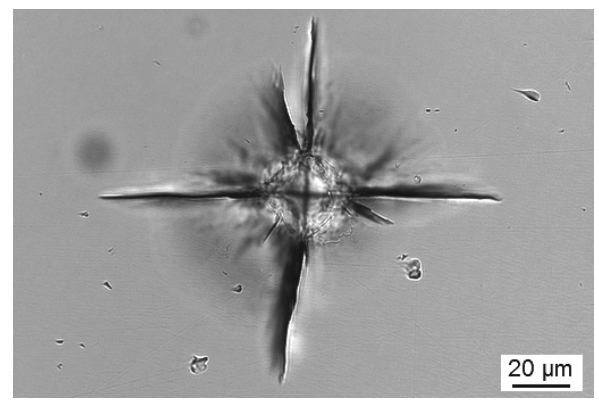

$a$

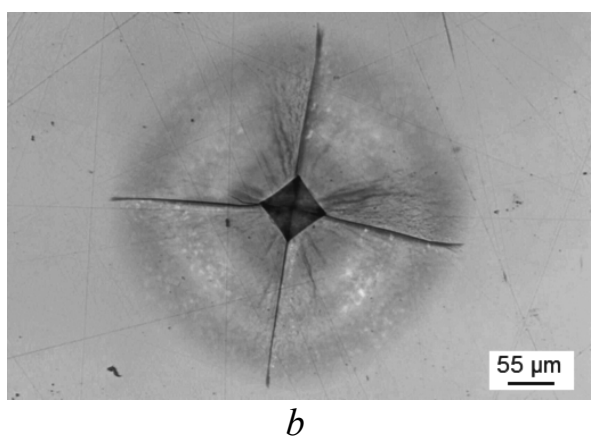

$b$

Fig. 35: Vickers impressions in fine-grained spinel for loads of a) $9.8 \mathrm{~N}$ and b) $49 \mathrm{~N}$.

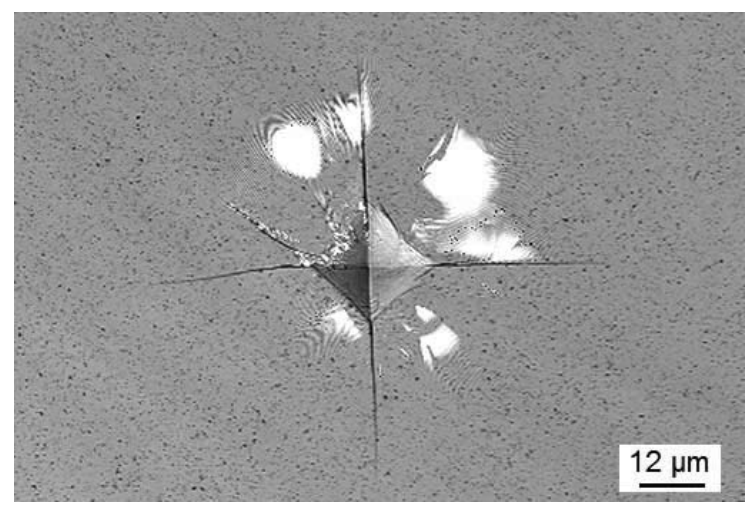

Fig. 36: Vickers impression in etched coarse-grained spinel for a load of $3 \mathrm{~N}$. 
Table 7. Indentation fracture toughness $\left(K_{I N D}\right)$ as a function of load

\begin{tabular}{|c|c|c|}
\hline & $\begin{array}{l}K_{I N D},\left(\mathrm{MPa} \cdot \mathrm{m}^{0.5}\right) \text { for } \\
\text { fine-grained spinel }\end{array}$ & $\begin{array}{c}K_{I N D},\left(\mathrm{MPa} \cdot \mathrm{m}^{0.5}\right) \text { for } \\
\text { coarse-grained spinel }\end{array}$ \\
\hline \multicolumn{3}{|l|}{$\begin{array}{l}K_{I N D} \quad(\text { Lankford et al. } \\
\left.\left.l^{99}\right], c / a>2\right)\end{array}$} \\
\hline loads $3 \mathrm{~N}$ & & 2.2 \\
\hline $5 \mathrm{~N}$ & 2 & \\
\hline $9.8 \mathrm{~N}$ & 2.1 & \\
\hline $49 \mathrm{~N}$ & 1.9 & \\
\hline $98 \mathrm{~N}$ & 2.1 & \\
\hline \multicolumn{3}{|l|}{$\begin{array}{l}\left.K_{I N D} \text { (Niihara et al. } I^{93}\right] \text {, } \\
c / a>2.5)\end{array}$} \\
\hline loads $3 \mathrm{~N}$ & & 1.2 \\
\hline $5 \mathrm{~N}$ & 2 & \\
\hline $9.8 \mathrm{~N}$ & 1.9 & \\
\hline $49 \mathrm{~N}$ & 1.8 & \\
\hline $98 \mathrm{~N}$ & 2 & \\
\hline \multicolumn{3}{|l|}{$\begin{array}{l}\left.K_{I N D} \text { (Anstis et al. } I^{94}\right], \\
c \geq 2 a)\end{array}$} \\
\hline loads $3 \mathrm{~N}$ & & 0.8 \\
\hline $5 \mathrm{~N}$ & 1.2 & \\
\hline $9.8 \mathrm{~N}$ & 1.3 & \\
\hline $49 \mathrm{~N}$ & 1.2 & \\
\hline $98 \mathrm{~N}$ & 1.3 & \\
\hline
\end{tabular}

* for all obtained values the uncertainty is $\sim 0.05$

The $K_{I N D}$ values for fine-grained spinel reveal a slight difference of $\sim 5 \%$ between the results obtained using the equation by Lankford et al. $\left[{ }^{99}\right]$ and Niihara et al. $\left[{ }^{93}\right]$, whereas in case of the coarse-grained spinel the difference is $\sim 45 \%$. The calculated $K_{I N D}$ value based on the equation by Anstis et al. $\left[{ }^{94}\right]$ results in the lowest fracture toughness value of $\sim 1.3 \mathrm{MPa} \cdot \mathrm{m}^{0.5}$ for the fine- and $\sim 0.8 \mathrm{MPa} \cdot \mathrm{m}^{0.5}$ for the coarse-grained spinel. Note that all equations consider a half-penny shaped crack. The difference between these equations is the adjustment of a calibrated geometrical factor based on industrial ceramics experiments (see section 2.6.3.1) $\left[{ }^{94},{ }^{145}\right]$. Based on the results obtained in the current study using ISM and SENB methods, as well as the Griffith criterion (see sections 2.6.3.2, 2.6.3.3, 2.6.3.4), it is suggested that the relationships suggested by Lankford et al. 
$\left[{ }^{99}\right]$ and Niihara et al. $\left[{ }^{93}\right]$ are most appropriate for evaluating the fracture toughness of the fine-grained spinel material currently studied.

\subsubsection{Indentation-Strength-Method}

Fracture loads obtained in ring-on-ring bending tests for pre-indented specimens (ISM, see sections $\left.2.6 .3 .2,3.5 .2){ }^{40}\right]$ were also used to determine the fracture toughness $\left(K_{I S M}\right)$ of coarse- and fine-grained spinels. Before the ISM test, typically up to four impressions are placed at the tensile loaded ring-on-ring bending specimen surface. It was verified fractographically for every tested specimen that failure occurred from only one of the impression cracks. The reduction of average fracture stress due to the preindentation cracks of $c_{0}=67 \mu \mathrm{m}$ was $\sim 35 \%$ compared to material without indentation cracks, verifying again that indentation cracks were the failure origins in these bending tests. The indentation cracks grow subcritically during the bending test, until one of them results in fracture (Fig. 37). The validity of the ISM also depends on the subcritical crack extension before failure, since this parameter enters the calculation via the calibration factor $A$ (Eq. 9).

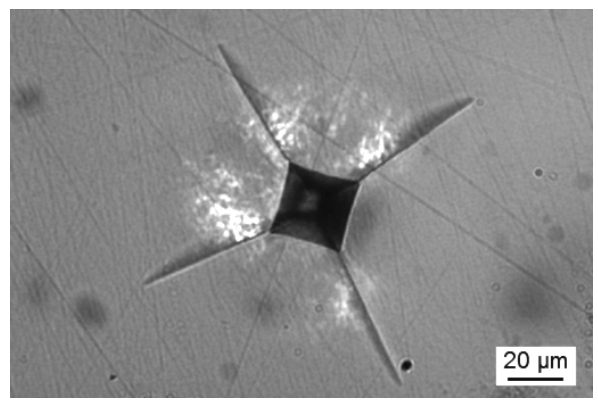

$a$

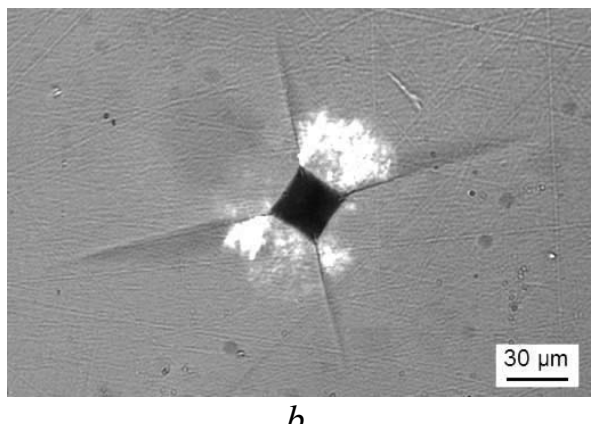

$b$

Fig. 37: Indentation cracks in fine-grained spinel after indentation loading 9.8 N. a) before and b) after bending test

Therefore, the indentation crack size was measured before and after the test, and the crack length after stable crack growth $c_{m}$ was estimated from the three impressions that did not lead to failure. This yielded a value of $130 \pm 10 \mu \mathrm{m}$, which was twice the 
initial crack length. Since the calibration factor is proportional to the ratio of the crack length to the power of (3/8), a $16 \%$ larger $A$ factor had to be used in Eq. 9. Finally, a value of $K_{I S M} \sim 1.9 \mathrm{MPa} \cdot \mathrm{m}^{0.5}$ was obtained, which is similar to the $K_{I N D}$ results, further verifying the methodology used. However, the use of the ISM test for coarse-grained spinel was not possible, since starting from $5 \mathrm{~N}$ the radial cracks and the associated intergranular fracture lead to delamination of grains (Fig. 38). Note that defined crack extension during bending is one of the main conditions, which must be satisfied for the ISM.

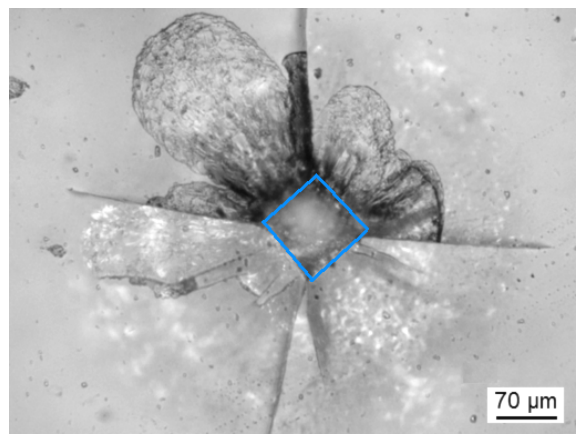

$a$

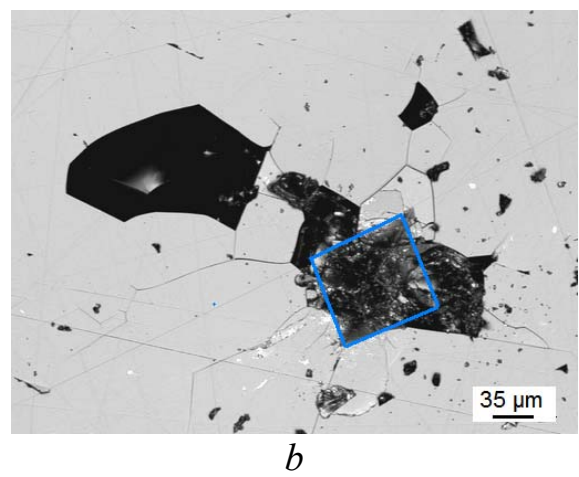

Fig. 38: Vickers impressions $(P=49 N)$ into a) fine-grained spinel and b) coarsegrained spinel $(P=49 N)$.

\subsubsection{Single edge notch bending}

The $K_{\text {SENB }}$ was determined for fine- and coarse-grained spinels from four-point bending tests (see section 2.6.3.3) following ASTM C 1421. The fine-grained spinel shows higher single edge notch bending toughness $1.8 \pm 0.2 \mathrm{MPa} \cdot \sqrt{\mathrm{m}}$ compared with coarse-grained spinel $1 \pm 0.4 \mathrm{MPa} \cdot \sqrt{\mathrm{m}}$. The lower $K_{S E N B}$ of coarse-grained spinel and its higher scatter might be partially attributed to the existence of weak grain boundaries (inherent defects), (see section 4.8), but also the limited number of available specimens (see section 3.1.2). 


\subsubsection{Griffith criterion}

This method requires fractographic analysis of the broken specimens and localization of the fracture origin. The size of the defect originating the crack and the fracture stress determined in the ring-on-ring bending test can then be used to calculate fracture toughness using Eq. 12. Fractography yielded defect sizes from $200 \mu \mathrm{m}$ to almost $1 \mathrm{~mm}$ (Fig. 51, Fig. 53), yielding fracture toughness values of $\sim 1.6 \pm 0.2$ $\mathrm{MPa} \cdot \sqrt{\mathrm{m}}$, coinciding with the data obtained by the other two methods (see Table 8 ).

Table 8. Fracture toughness obtained by different methods

\begin{tabular}{|l|c|c|}
\hline \multicolumn{1}{|c|}{ Method } & Fine-grained spinel & Coarse-grained spinel \\
\hline \multirow{4}{*}{$K_{I N D}, \mathrm{MPa} \cdot \sqrt{\mathrm{m}}$} & $2 \pm 0.1$ & \multicolumn{2}{|c|}{ Lankford } \\
\cline { 2 - 3 } & \multicolumn{2}{|c|}{ Niihara } \\
\cline { 2 - 3 } & $1.9 \pm 0.1$ & $1.2 \pm 0.05$ \\
\cline { 2 - 3 } & $1.3 \pm 0.05$ & $0.8 \pm 0.05$ \\
\cline { 2 - 3 } & $1.9 \pm 0.2$ & $1 \pm 0.4$ \\
\hline$K_{I S M}, \mathrm{MPa} \cdot \sqrt{\mathrm{m}}$ & $1.8 \pm 0.2$ & -- \\
\hline$K_{S E N B}, \mathrm{MPa} \cdot \sqrt{\mathrm{m}}$ & $1.6 \pm 0.2$ & \\
\hline$K_{I C}(\mathrm{Griffith})$, & Anstis \\
$\mathrm{MPa} \cdot \sqrt{\mathrm{m}}$ & & \\
\hline
\end{tabular}

The SENB test suggests that in the case of indentation, the Niihara equation $\left[{ }^{93}\right]$ is the most appropriate for estimating the fracture toughness of both spinels.

\subsection{Photoelasticity}

The photoelastic effect (see section 2.6.6) can be used for a qualitative analysis of local strains that might be associated with structural inhomogeneities and defects $\left[{ }^{130},{ }^{131}\right]$. The strain field induced by Vickers indentations and secondary cracks in a spinel fragment after bending was studied. Observation via a polarization microscope revealed 
two main areas of higher light intensities, one close to the center of the impression and at the end of a radial crack tip, and the other at the end of a secondary crack tip that remained after bending tests (Fig. 39a, b), respectively. The light intensity close to the center of the impression could be related to lateral cracking and associated interference effects, and therefore was an artifact unrelated to residual strains. However, closer observation also revealed higher intensities near the radial crack tips, induced by indentation, which coincided with observations made at secondary crack tips in the fractured bending specimens.

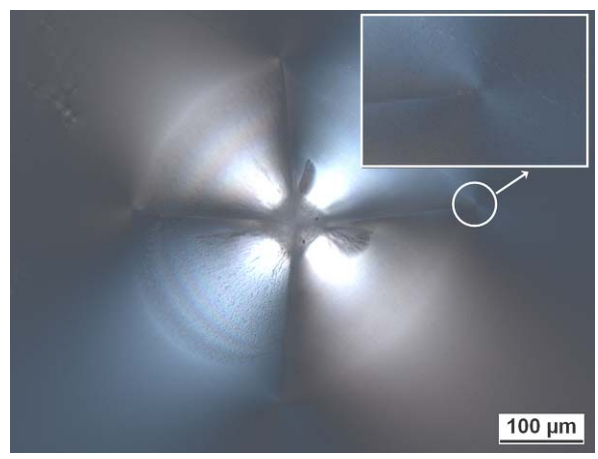

$a$

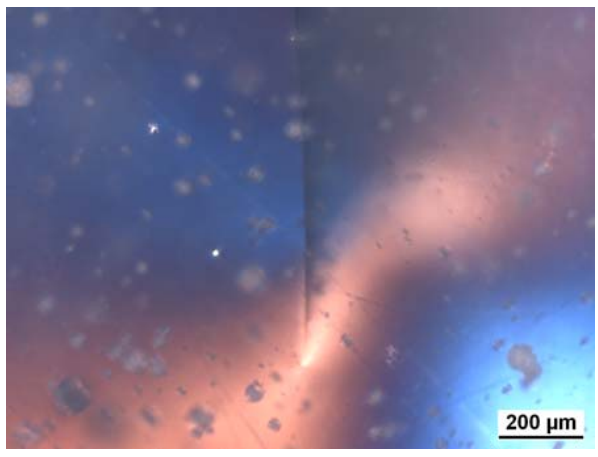

$b$

Fig. 39: Light intensities of strained zones: a) at crack tips (marked white) initiated by indentation $(P=49 \mathrm{~N}) ; b)$ at a crack in a spinel fragment after bending $(\sigma=147 \mathrm{MPa})$.

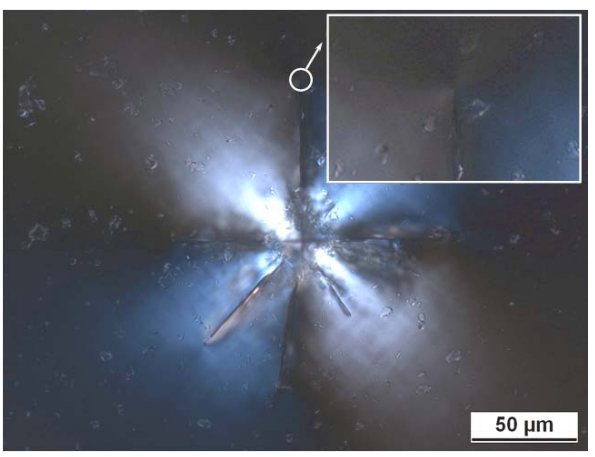

$a$

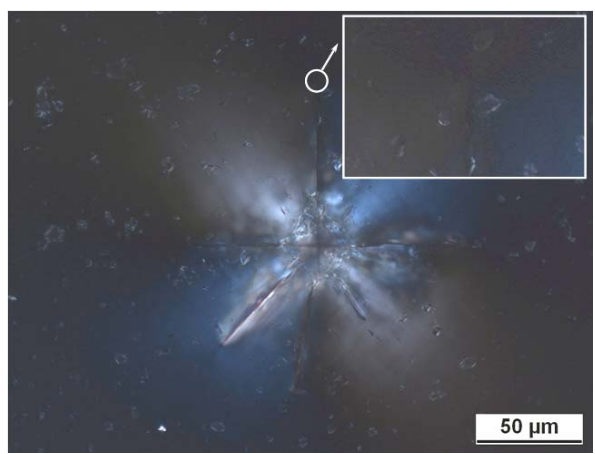

$b$

Fig. 40: Strained zones at one impression $(P=9.8 N)$ a) before and b) after heat treatment. 
Subsequent annealing at $\left(1000{ }^{\circ} \mathrm{C}, 1 \mathrm{~h}\right)$ in air appeared to relax deformations and strains, particularly the size of the local strain field surrounding the crack tip (Fig. 40).

\subsection{Fracture strength}

In initial experiments, the effect of polishing conditions on fracture strength of fine-grained spinel was tested for three different surface states (see section 3.1.2) in order to optimize the preparation process. The Young's Modulus was, as expected, independent of the polishing procedure, whereas the strength increased (from $\sim 130 \mathrm{MPa}$ up to $\sim 160 \mathrm{MPa}$ ) when the roughness was decreased from low to medium quality, and remained constant at high-quality polishing. The lower Weibull modulus of the high quality polished batch can be explained by remaining local scratches after machining. As expected, the surface condition has an influence on the fracture strength for large roughness values (Table 9), and therefore the average polishing procedure was used for further experimental work (see section 3.1.2).

Table 9. Effect of three different polishing qualities on the mechanical properties of finegrained spinel

\begin{tabular}{|c|c|c|c|}
\hline Roughness, $\boldsymbol{R}_{\boldsymbol{a}}$ & $\begin{array}{c}\boldsymbol{\sigma}_{\boldsymbol{f}}, \\
\text { MPa }\end{array}$ & $\begin{array}{c}\boldsymbol{E}_{\boldsymbol{R} O \boldsymbol{R}}, \\
\mathbf{G P a}\end{array}$ & $\boldsymbol{m}$ \\
\hline 2.34 & $132 \pm 21$ & $233 \pm 6$ & $8 \pm 2$ \\
\hline 1.3 & $165 \pm 32$ & $240 \pm 8$ & $6 \pm 2$ \\
\hline $0.83-1.26$ & $162 \pm 46$ & $234 \pm 6$ & $4 \pm 1$ \\
\hline
\end{tabular}

The fracture stress measurements yielded a fracture strength of $\sigma_{f}=155 \pm 38 \mathrm{MPa}$ for all fine-grained spinel batches of average and high quality polishing $(\sim 150$ specimens), which is slightly lower than the values determined for individual batches of 30 specimens (see Table 9). Contrary to the Young's modulus (see section 4.3), the fracture stresses did not show a dependency on specimen thickness $(1.3-2.8 \mathrm{~mm})$ within the limits of experimental uncertainty. Hence, in agreement with ASTM C1499, the fracture stress and therefore strength, is less sensitive to thickness variations. From the Weibull representation of the results (Fig. 41), a characteristic strength of $\sigma_{0}=169 \pm 3 \mathrm{MPa}$ 
was derived for fine-grained spinel. The Weibull modulus reflecting the scatter of the results is rather low with $m \sim 5 \pm 2$. The confidence interval is $4.4<5<5.5$ (see section 2.6.4).

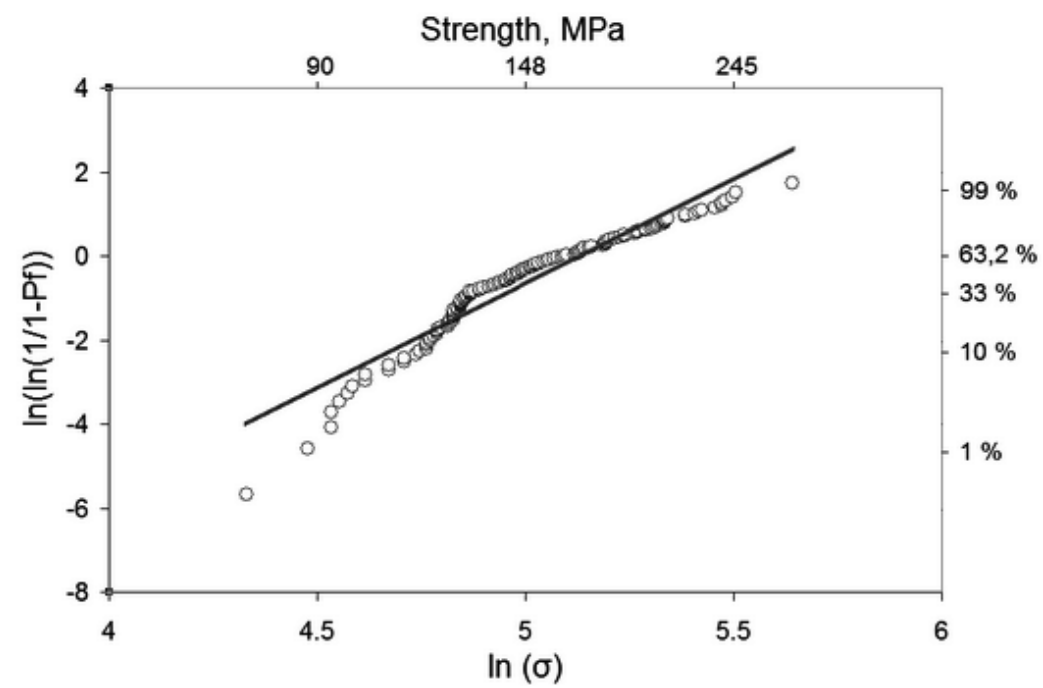

Fig. 41: Two-parameter Weibull plot of the fracture stress data of fine-grained spinel.

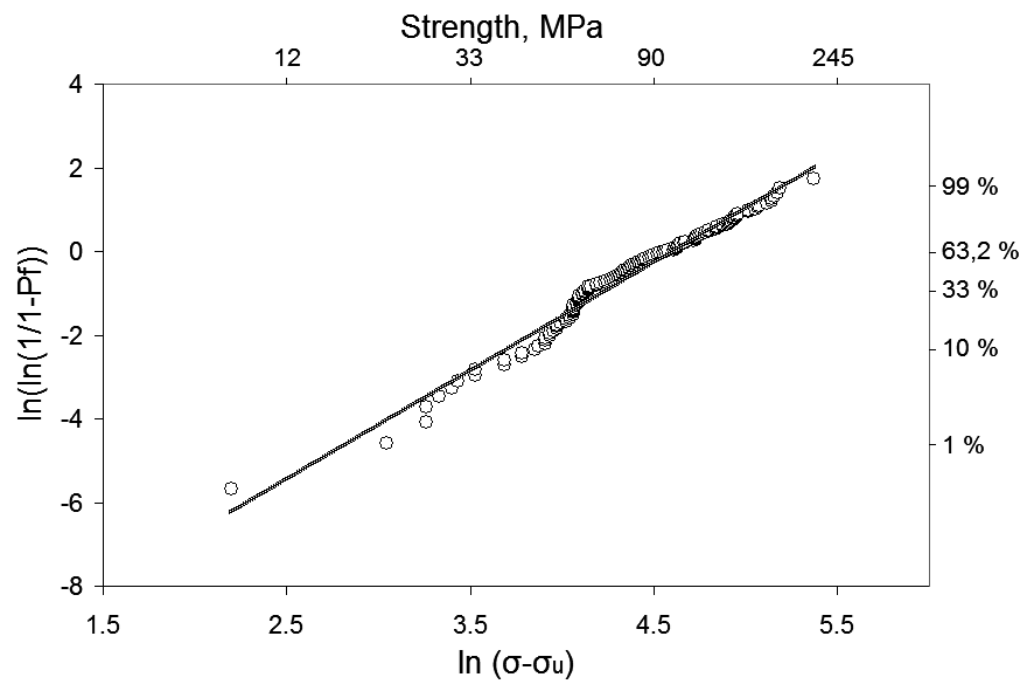

Fig. 42: Three-parameter Weibull plot of the fracture stress data for the fine-grained spinel. 
Utilizing a three-parameter Weibull distribution leads to a better description of the data and therefore to a higher correlation coefficient $R^{2}(\sim 0.92$ for the two- and $\sim 0.98$ for the three-parameter Weibull distribution). The threshold stress $\sigma_{u}$ was obtained by optimization of $R^{2}$ to $\sigma_{u}=67 \mathrm{MPa}$. The three-parameter Weibull distribution yields a characteristic strength $\sigma_{0}=166 \pm 3 \mathrm{MPa}$ for fine-grained spinel. The lower Weibull modulus of $m=2.6 \pm 0.3$ (Fig. 42) is typical for the description of data with a threeparameter distribution $\left[{ }^{146}\right]$.

Due to the limited number of $\sim 30$ specimens the data obtained for the coarsegrained materials were only described by a two-parameter distribution since an amount of $\sim 100$ specimens is required for three-parameter Weibull distribution $\left[{ }^{147},{ }^{148}\right]$. The average fracture stress is $\sigma_{f}=73 \pm 9 \mathrm{MPa}$, the characteristic strength $\sigma_{0}=77 \pm 1 \mathrm{MPa}$ and the Weibull modulus $m=10 \pm 2$ (Fig. 43). Therefore, the coarse-grained spinel has a lower strength, but a higher Weibull modulus than the fine-grained material. From this, it can be concluded that defects in the coarse-grained spinel are larger but distributed more uniformly. For coarse-grained spinel, the confidence interval is $7.7<10.2<12.4$.

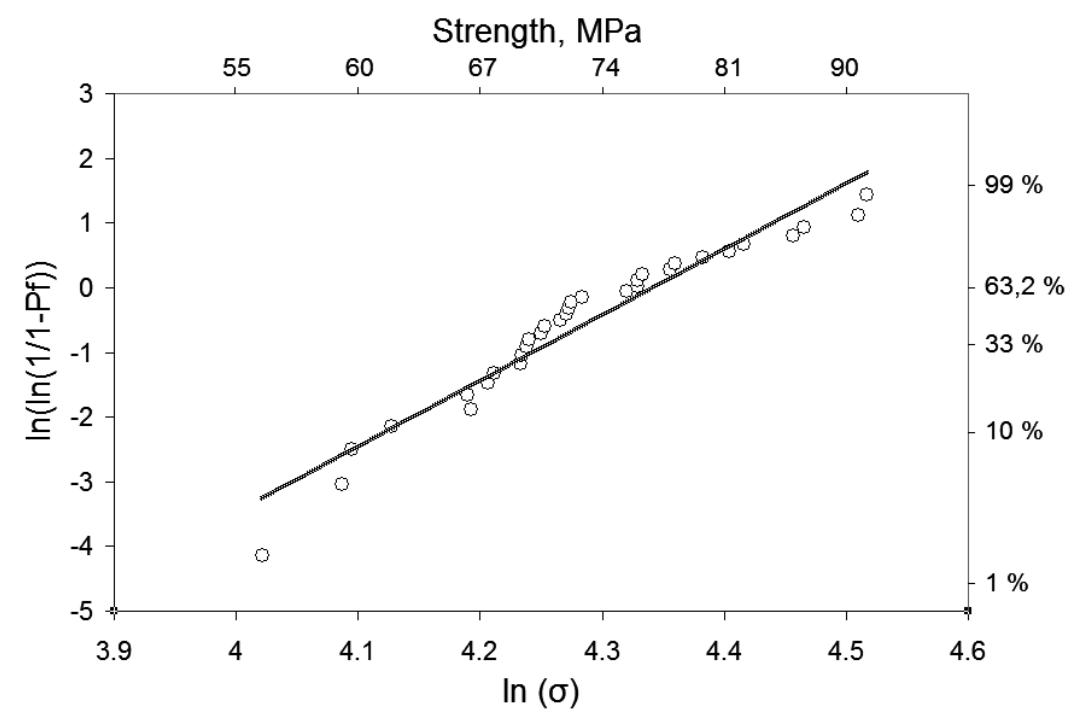

Fig. 43: Two-parameter Weibull plot of the fracture stress data of the coarse-grained spinel 


\subsubsection{Weibull modulus uncertainties}

The accuracy of statistical evaluation mostly depends on the number of available specimens $N$ and the Weibull modulus $m$. In addition, a program compilation via JavaScript software permitted to partially evaluate the available data sets.

A procedure assesses the effect of dataset selection on the uncertainty of statistical strength evaluation of the fine-grained spinel. From the entire set, 30 fracture stress values were selected 10 times randomly, and the maximum and minimum Weibull modulus was calculated. The number of selections of the 30 data values was increased in subsequent calculations to 30,60 and 90 , in order to determine whether there is any effect on the resulting maximum and minimum values. The range of uncertainty of the Weibull modulus increases from $4.2<m<6.3$ for 10 loops to $4<m<6.7$ for 90 loops (Fig. 44). This compares quite well to the standard deviation of $s(m=5)=1$ and confidence interval of $4.4<5<5.5$ (see section 2.6.4). The influence of the number of cycles on the Weibull modulus seems to be negligible, since the Weibull modulus only was changed by $\sim 5 \%$.

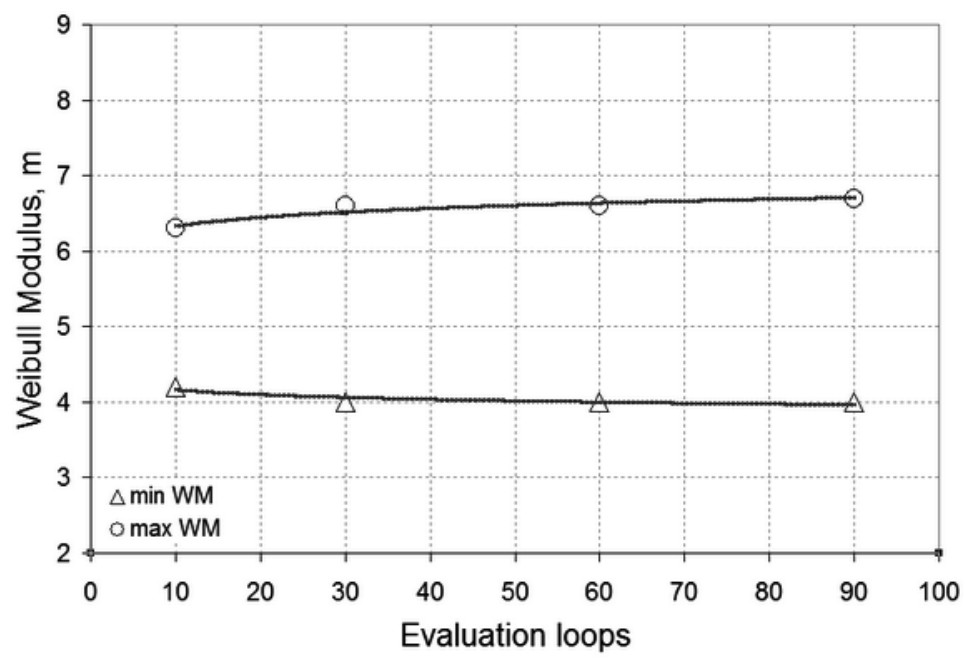

Fig. 44: Relation between number of calculation cycles and obtained Weibull moduli 


\subsubsection{Particle-size distribution}

Fine-grained spinel contained relatively large agglomerates that affected the transparency. As a result, one question to be answered concerned whether these agglomerates also affect the strength (Fig. 45, Fig. 46).

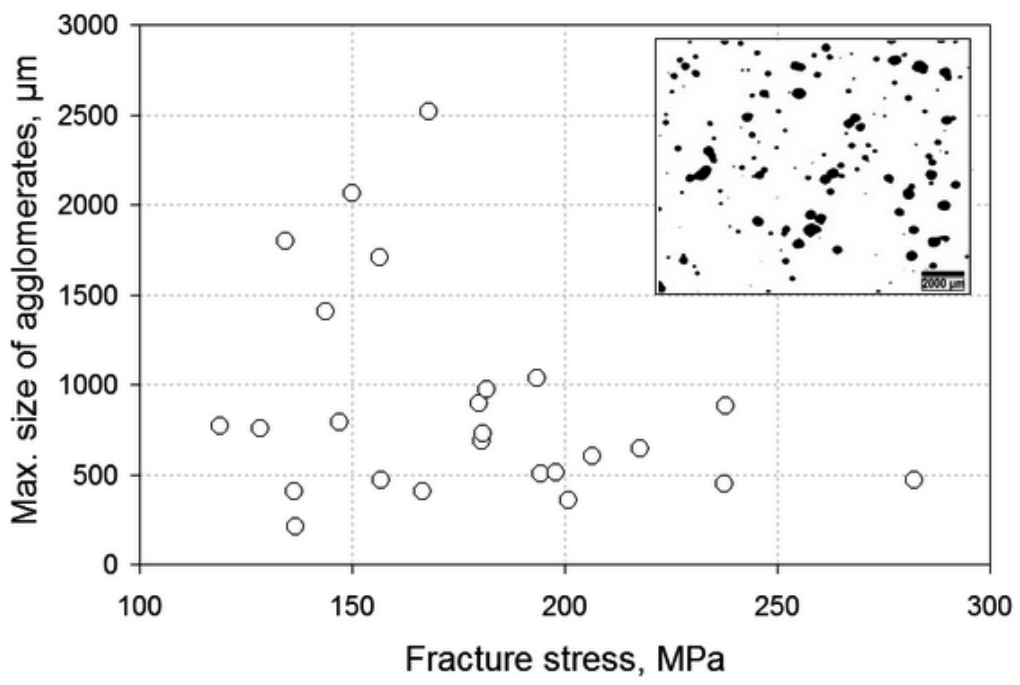

Fig. 45: Fracture stress as a function of the maximum size of agglomerates.

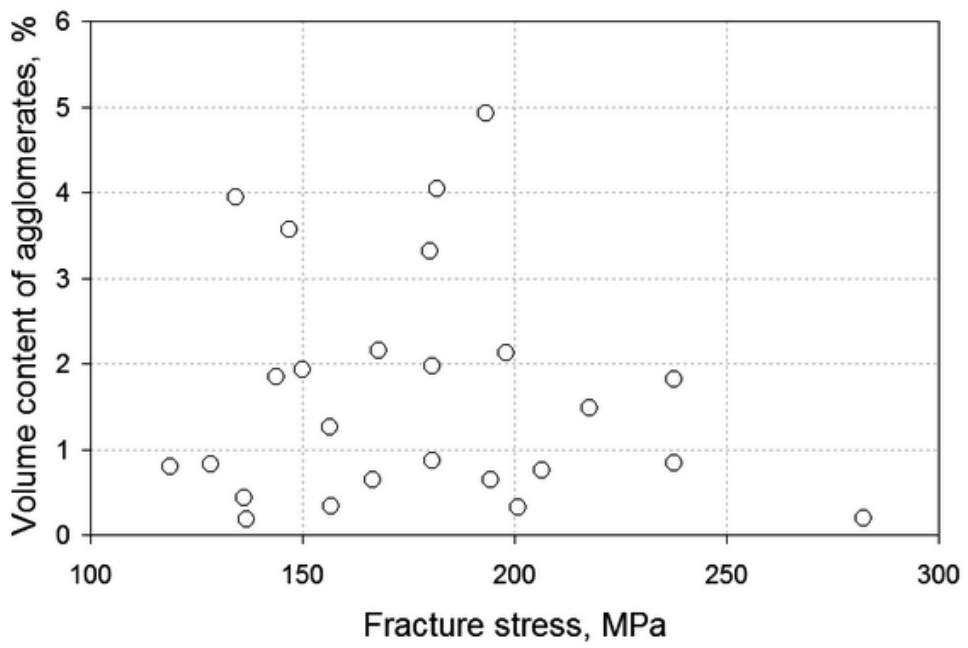

Fig. 46: Fracture stress as a function of the specific volume of agglomerates. 
Maximum size and volume of agglomerates were provided for selected finegrained specimens by the project partner CeramTec-ETEC, as obtained by light microscopy and subsequent quantitative image analysis (see section 3.2.2). Maximum size and volume of agglomerates for the characterized 25 fine-grained spinel specimens were within the interval $210-2530 \mu \mathrm{m}$ and $0.17-4.9 \%$, respectively. The specimens were fractured in ring-on-ring bending tests. Fig. 45 and Fig. 46, which display the fracture stress values versus maximum defect size and volume, respectively, illustrate that there is no correlation of fracture stress with either of these parameters. As a result, such visible defects are not failure-relevant for this material.

\subsubsection{Local strain field}

Although a macromechanical effect of optically visible agglomerates can be ruled out, the micromechanical effect still requires assessment. Therefore, in an extension of the photoelastic analysis of the strain at hardness impressions (see section 4.6), the photoelastic method was also used to qualitatively determine the local strain field at optically visible agglomerates. Fig. 47 clearly verifies the existence of a residual strain field around these agglomerates. After an additional heat treatment $T=1000{ }^{\circ} \mathrm{C}$ for $1 \mathrm{~h}$ (Fig. 47b) (see section 3.1.3), the local strains appear to be slightly lower due to relaxation. In an attempt to assess whether heat treatment affects fracture stress, three specimens were subsequently fractured in ring-on-ring bending tests. The average fracture stress $137 \pm 9 \mathrm{MPa}$ and Young's modulus of $235 \pm 5 \mathrm{GPa}$ were obtained for heat treated fine-grained specimens, which corresponds with the as-received state. However, the Young's modulus determined using indentation (24 indents in the surface) increased from $205 \pm 12$ to $232 \pm 9 \mathrm{GPa}$, and hardness from $17.2 \pm 1$ to $17.7 \pm 1 \mathrm{GPa}$ compared to the same specimen in the as-received state. This slight effect, especially on the Young's modulus, might be related to oxygen diffusion or reactions in the surface areas that do not affect the global properties obtained in a bending test $\left[{ }^{149},{ }^{150}\right]$. 


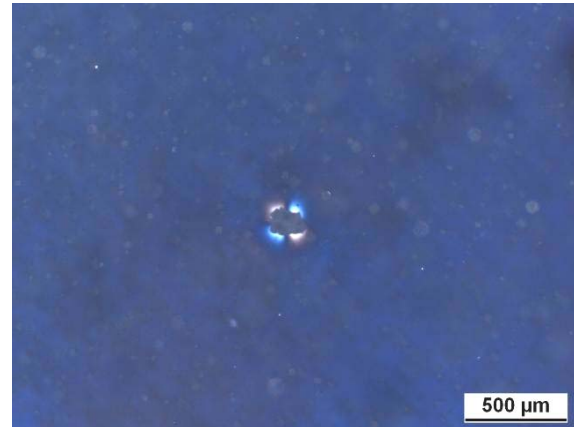

$a$

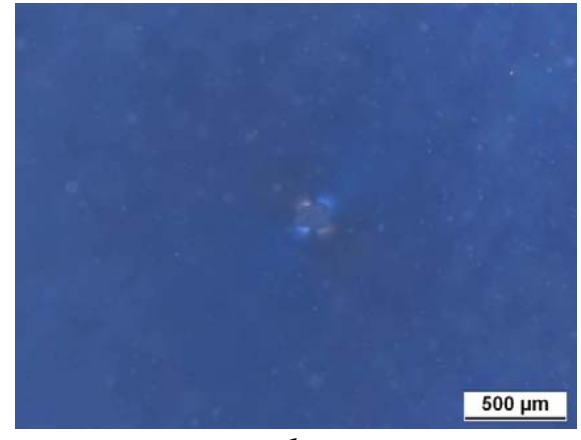

$b$

Fig. 47: Photoelastically determined residual stress field around agglomerates a) before and b) after heat-treatment.

Also tested was whether the local agglomerates influence crack growth. A crosssection through a coarse-grained spinel agglomeration was loaded by a wedge after an additional notch had been introduced. Polarization microscopy revealed that the agglomerate was surrounded by a local residual strain field (Fig. 48a). In the subsequent wedge test, the crack bypassed the agglomerate shown in the SEM image in Fig. 48b. Even subsequently introduced indentations did not lead to a fracture path through the particle, suggesting the existence of a local compressive strain field surrounding the particle. Therefore, even though a direct correlation of the macromechanical properties with the agglomerates was not possible, the micromechanical tests revealed that crack growth is affected by these inhomogeneities of microstructure and in fact, suggests that the optically visible agglomerates enhance the micromechanical properties. The absence of any effect in the macromechanical test might be related to the limited number of specimens, or that the majority of the optically visible agglomerates are not related to local strain fields. 


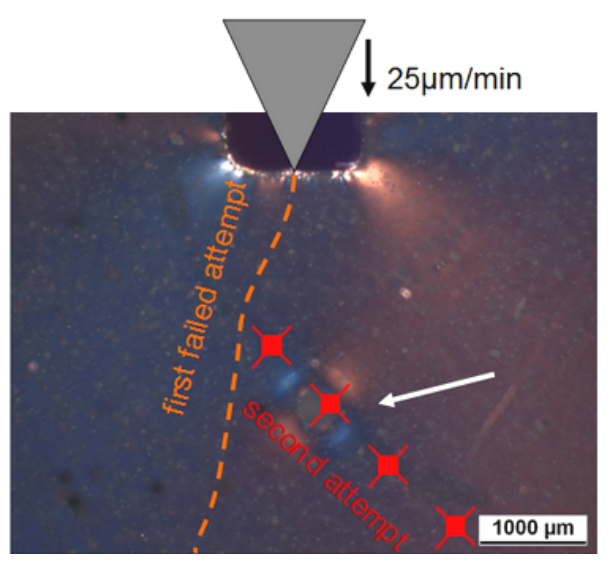

$a$

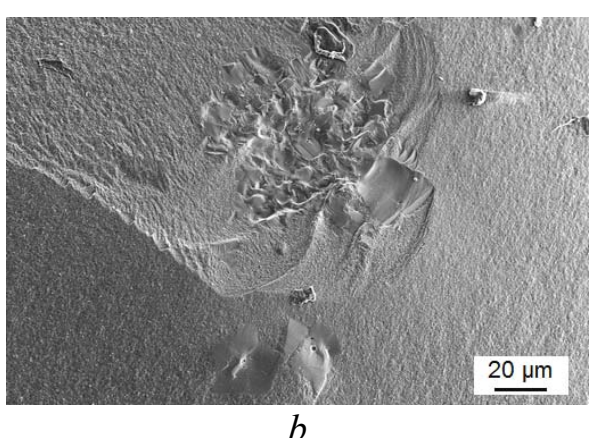

$b$

Fig. 48: Influence of a coarse-grained agglomerate on fracture path. a) Sketch of the implemented measurements (the agglomerate is indicated by an arrow); b) SEM image of the agglomerate after indentation.

\subsection{Fractography}

After ring-on-ring bending testing, specimens were investigated with respect to their fracture modes. As shown in Fig. 49a, a mixture of inter- and transgranular fracture paths is typical for fine-grained spinels. A transgranular fracture path is visible in local structures with grain sizes larger than $1 \mu \mathrm{m}$, whereas intergranular fracture was observed in the nano-grained regions $(0.2-1 \mu \mathrm{m})$. The coarse-grained spinel failed only in an intergranular fracture mode (Fig. 49b).

However, the stresses field at large-grained agglomerates in fine-grained spinel also appears to influence the fracture mode. Indentation testing leads to radial cracks in a mixed mode, whereas the central region beneath a Vickers impression (which mainly undergoes compressive stresses) reveals intergranular fracture (crushing) (Fig. 32b).

In general, the number of fractured pieces in the biaxial ring-on-ring tests appeared to scale with the fracture stress (Fig. 50); i.e., more pieces were obtained for a specimen that fractured at high stress. This study observed similar fracture patterns to ones reported by Quinn $\left[{ }^{151}\right]$. Characteristic positions (kinks and crack undulations) in 
selected specimens that failed at low fracture stresses (corresponding to the largest defects) were chosen for subsequent fractographic analysis.

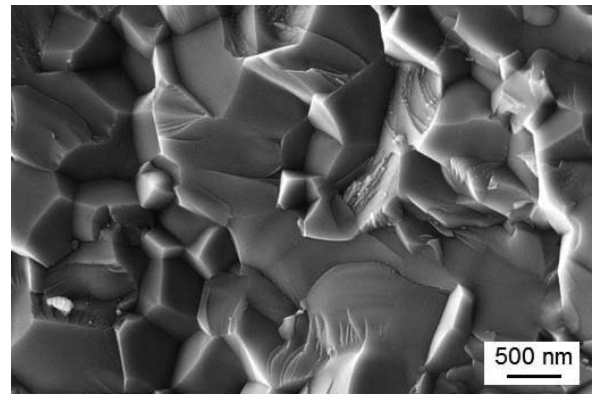

$a$

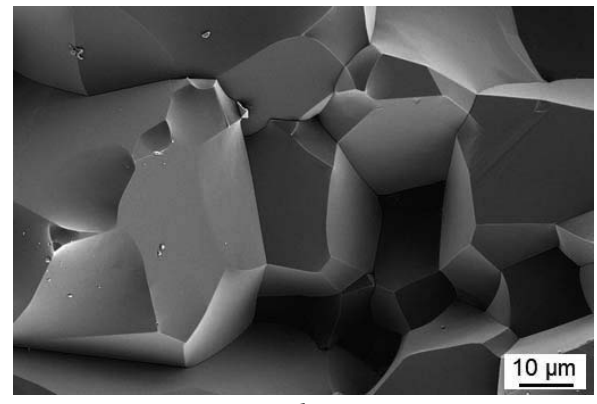

$b$

Fig. 49: a) Mixed trans- and inter-granular fracture in fine-grained spinel and b) intergranular fracture in coarse-grained spinel.

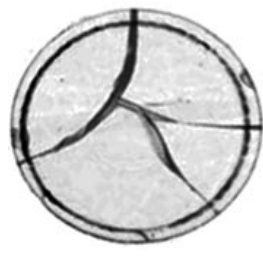

$119 \mathrm{MPa}$

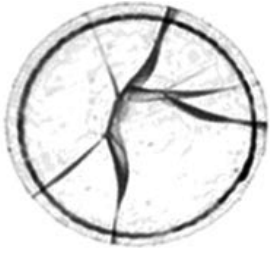

$168 \mathrm{MPa}$

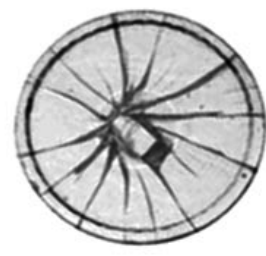

$282 \mathrm{MPa}$

Fig. 50: Specimens after fracture tests illustrating the correlation of fracture stress and number of fractured pieces. The measured fracture stress values are indicated.

Optical micrographs and SEM images suggest that coarse-grained agglomerates and associated local microcracks are the failure origin for the fine-grained material (Fig. 53). In fact, these results confirm a strong influence of surface preparation and surface condition (see sections 3.1.2 and 4.7) on strength, since crack-like features surrounding the large grains are not observed in fracture surfaces. Hence, the inherent local microcracks in the vicinity of coarse-grained agglomerates might have already existed in the raw material and then extended during the grinding and polishing. The correlation of 
individual fracture stresses with defect sizes was also used to estimate fracture toughness (see section 4.5.4). Initial defect sizes measured at fracture surfaces ranged from $150 \mu \mathrm{m}$ up to $\sim 1 \mathrm{~mm}$ (Fig. 51, Fig. 52, Fig. 53). This correlation is illustrated in Fig. 51, which shows an agglomerate of large grains (size $\sim 1 \mathrm{~mm}$ ) and associated microcracks before and after a bending test, and clearly identifies this agglomerate as failure origin.
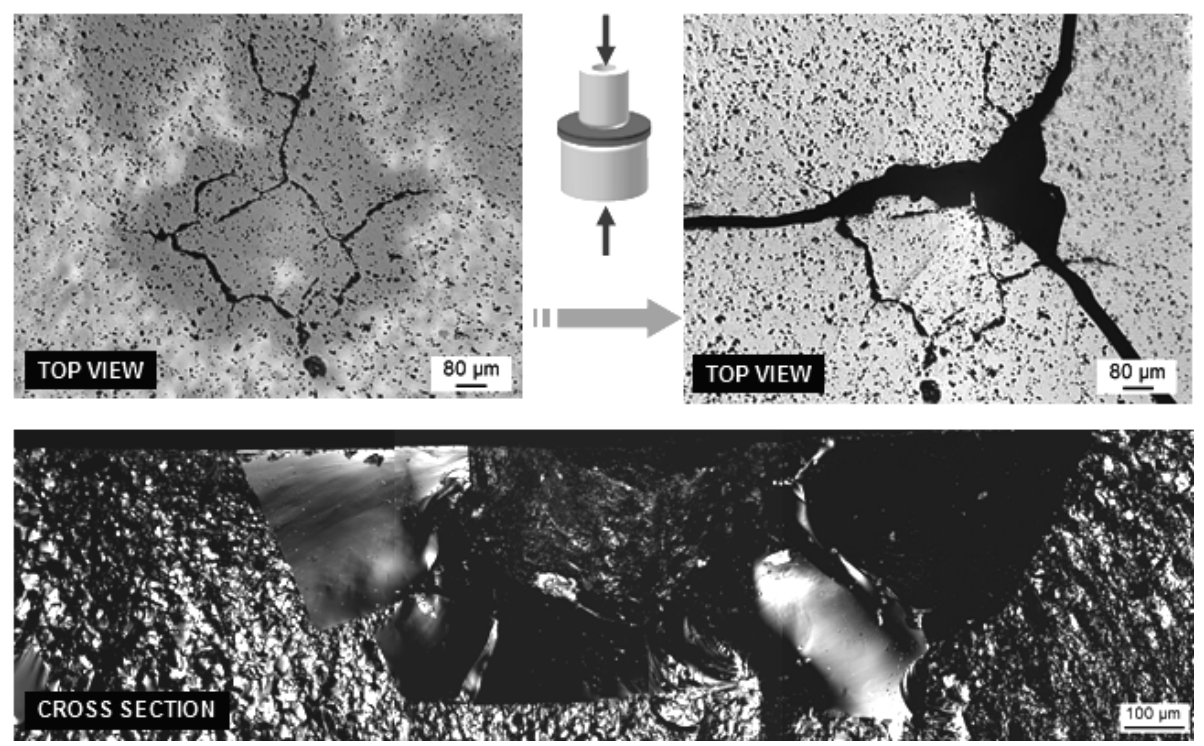

Fig. 51: A typical surface defect as fracture origin in a fine-grained spinel specimen. a) agglomerate and associated microcrack before the test, b) reassembled specimen after the test, confirming the failure origin and c) fracture surface confirming the extent of the coarse-grained zone.

SEM/EDX analysis of a similar coarse-grained area verified that the chemical composition of fine-grained structures and coarse-grained agglomerates are identical (Fig. 52b). 

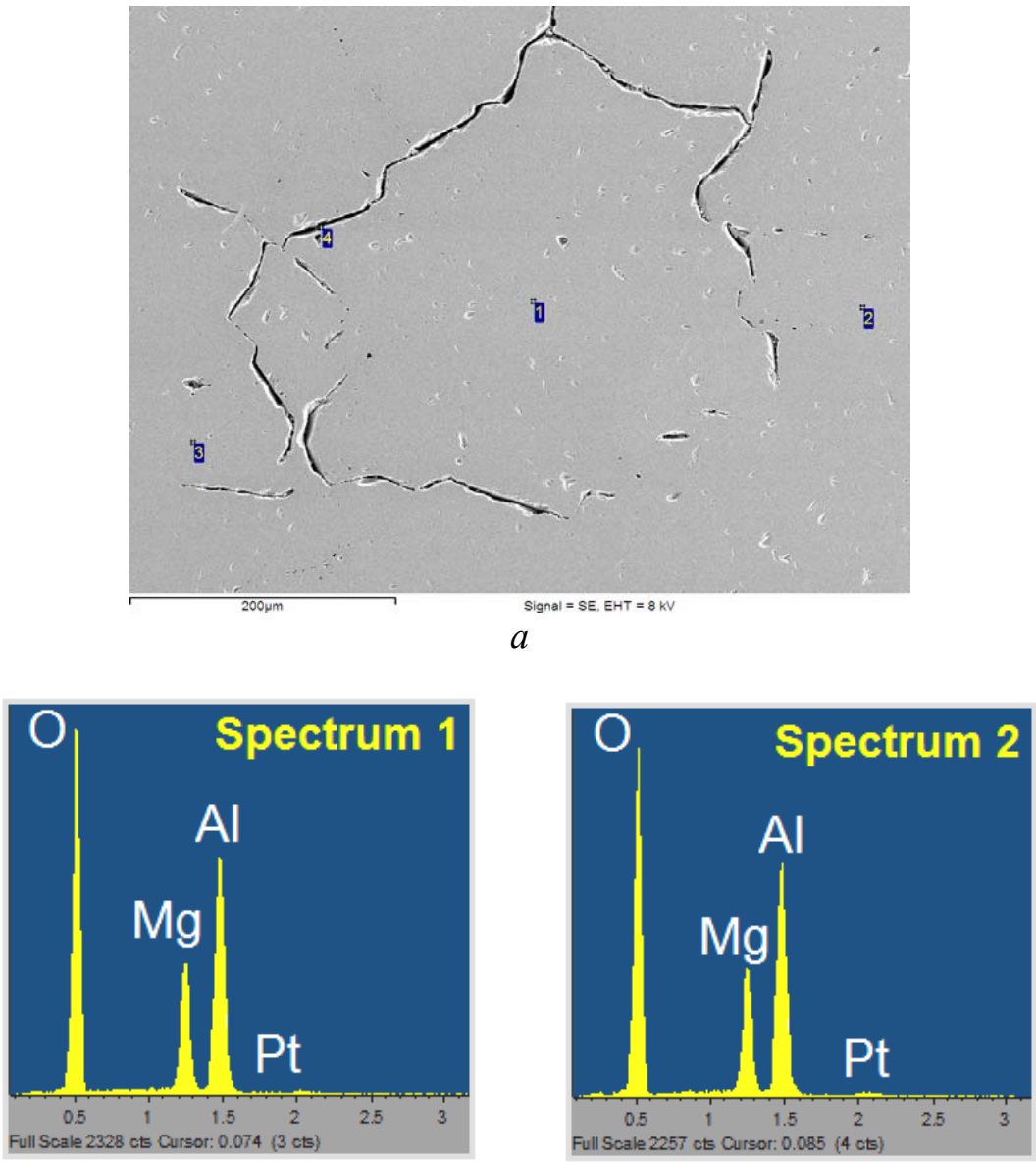

$b$

Fig. 52: SEM/EDX analysis of fine-grained structures and coarse-grained agglomerates.

Other typical failure origins in fine-grained spinel specimens, shown in Fig. 53, confirm the correlation of crack origin and coarse-grained agglomerates. Typical fracture originating agglomerates with sizes from 200 to $450 \mu \mathrm{m}$ have been detected. Note that overall the agglomerates appear to be related to failure, and act as failure origin. Optically visible agglomerates do not appear to be responsible for failure, suggesting that different kinds of agglomerates exist in the material. Furthermore, micromechanical tests suggest a compressive stress field around the agglomerates, which should be balanced by tensile 
stresses in the agglomerates - another possible reason for microcracks, which could be initiated and enhanced by polishing.
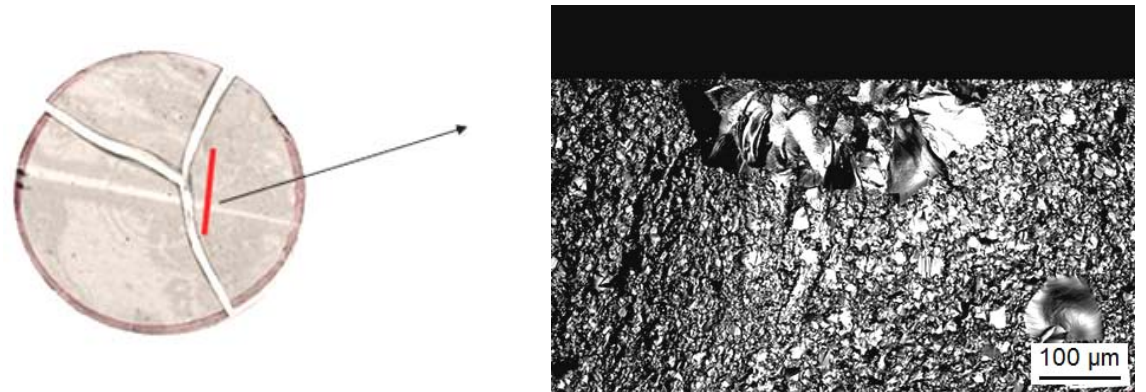

$a(\sigma=83 \mathrm{MPa})$
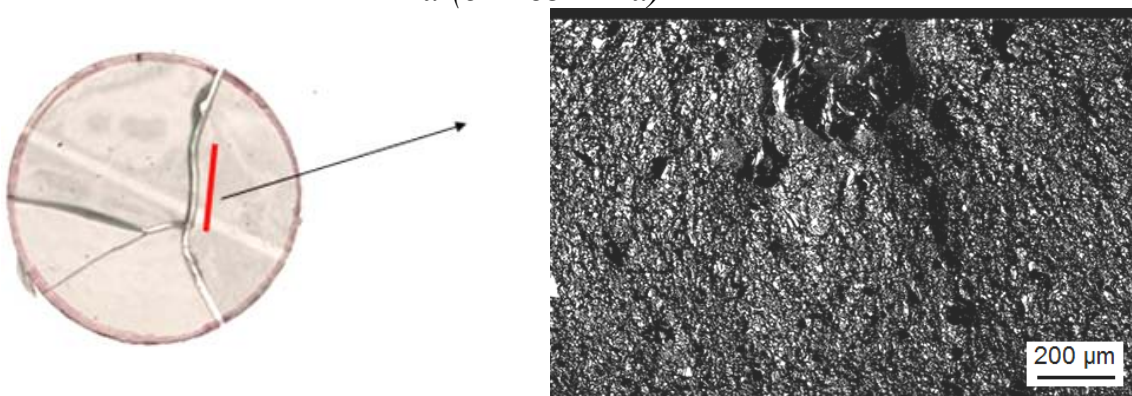

$$
b(\sigma=89 \mathrm{MPa})
$$
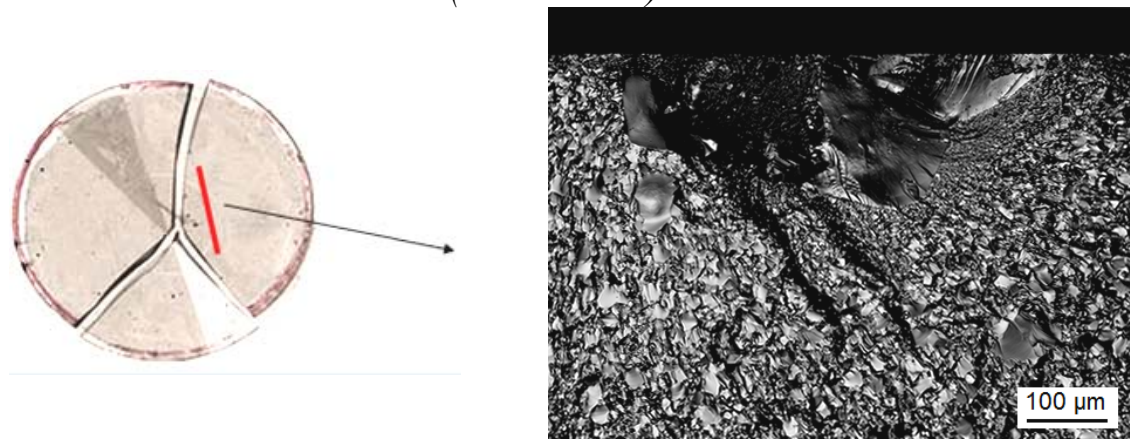

$c(\sigma=67 \mathrm{MPa})$

Fig. 53: Fracture origin determination after ring-on-ring bending tests.

Weak grain boundaries and pores appear to be more pronounced for coarsegrained spinel, and seem to be characteristic crack initiating defects (Fig. 54). The length 
of weak boundaries can reach $200 \mu \mathrm{m}$ and therefore might be considered as fracture origins.

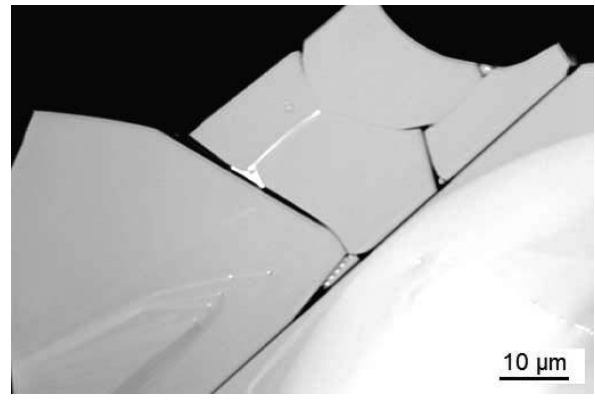

$a$

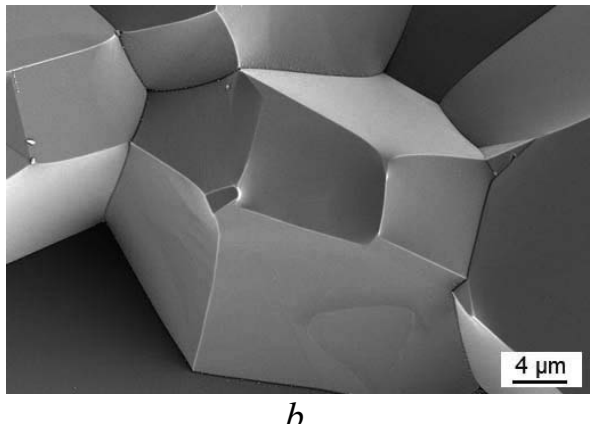

$b$

Fig. 54: Inherent porosity (a) and weak grain boundaries (b) as possible fracture origins for the coarse-grained spinel.

\subsection{Statistical analysis}

\subsubsection{Area effect on fracture strength}

The area effect on fracture strength was calculated (Fig. 55) using statistical analysis (see section 2.6.5) in order to estimate the properties of life-size components. The representations are based on data from ring-on-ring bending (characteristic strength $\sigma_{0}=169$ and $77 \mathrm{MPa}$ for fine-grained and coarse-grained spinel, respectively). The figure illustrates how strength decreases with increasing area at a given thickness of $\sim 2 \mathrm{~mm}$. Note that the coarse-grained spinel is less sensitive to the area effect due to its higher Weibull modulus (see section 4.7), but generally yields a lower strength.

Based on the Hertzian theory (see section 2.6.4.1), the local strength was estimated for the fine-grained material using two spherical indenters of different radii ( 0.5 and $2.5 \mathrm{~mm}$, respectively). Impressions were made in the load range from 30 to 245 $\mathrm{N}$, with load steps of $49 \mathrm{~N}$. The critical load for the formation of cone cracks was estimated visually after the impression, using an optical microscope. The estimated critical load $P_{c}$ was used to calculate contact areas by Eq. 24 and local strengths by Eq. 23. The results for the fine-grained spinel are given in Table 10 and depicted in Fig. 56. 
Although the estimate of critical load includes a rather large uncertainty of $\sim 40 \%$ due to the discrete loading steps $49 \mathrm{~N}$ of the used machine, it can be seen that the data agree with an extrapolation of the results from ring-on-ring bending tests to lower deformed areas (see Fig. 56).

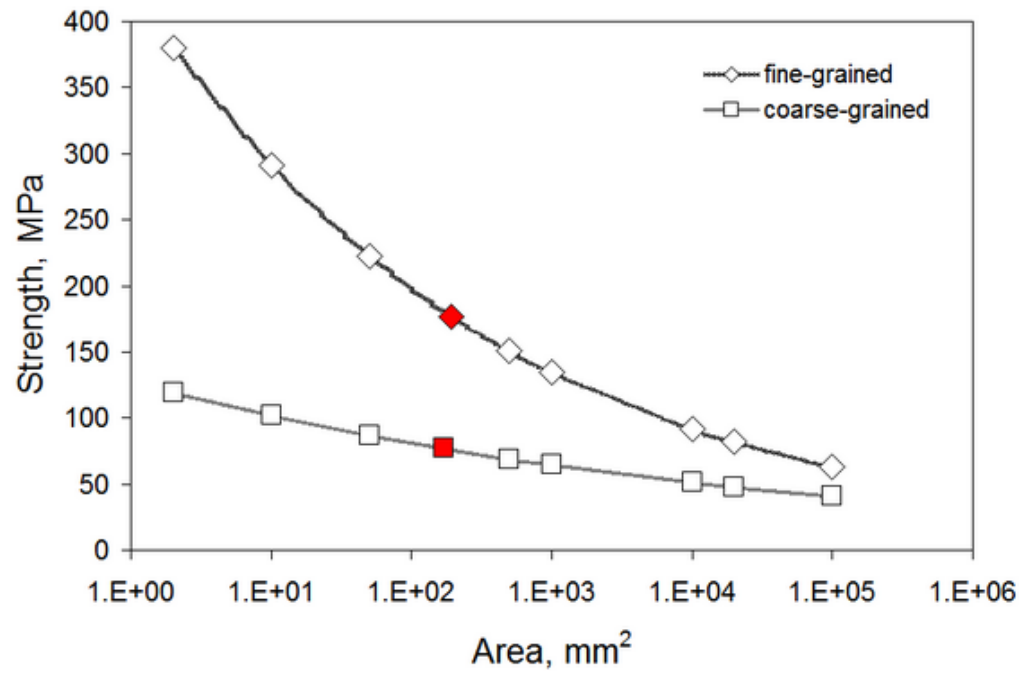

Fig. 55: Area effect on fracture strength for fine- and coarse-grained spinels. The experimental strength value is marked by red color.

Table 10. Obtained results for fine-grained spinel after Brinell indentation.

\begin{tabular}{|c|c|c|c|}
\hline $\boldsymbol{R}, \mathbf{m m}$ & $\boldsymbol{P}_{\boldsymbol{c}}, \mathbf{N}$ & $\boldsymbol{A}_{\text {eff.Hertzian }}, \mathbf{m m}^{\mathbf{2}}$ & $\boldsymbol{\sigma}_{\text {Hertzian }}, \mathbf{M P a}$ \\
\hline 0.5 & 98 & 1.4 & 470 \\
\hline 2.5 & 196 & 6.6 & 287 \\
\hline
\end{tabular}

The effective area deformed under tensile stress in bending was calculated according to Eq. 19 and according to Eq. 24 for spherical indentation. The stress gradient in the surface has been considered in these equations. 


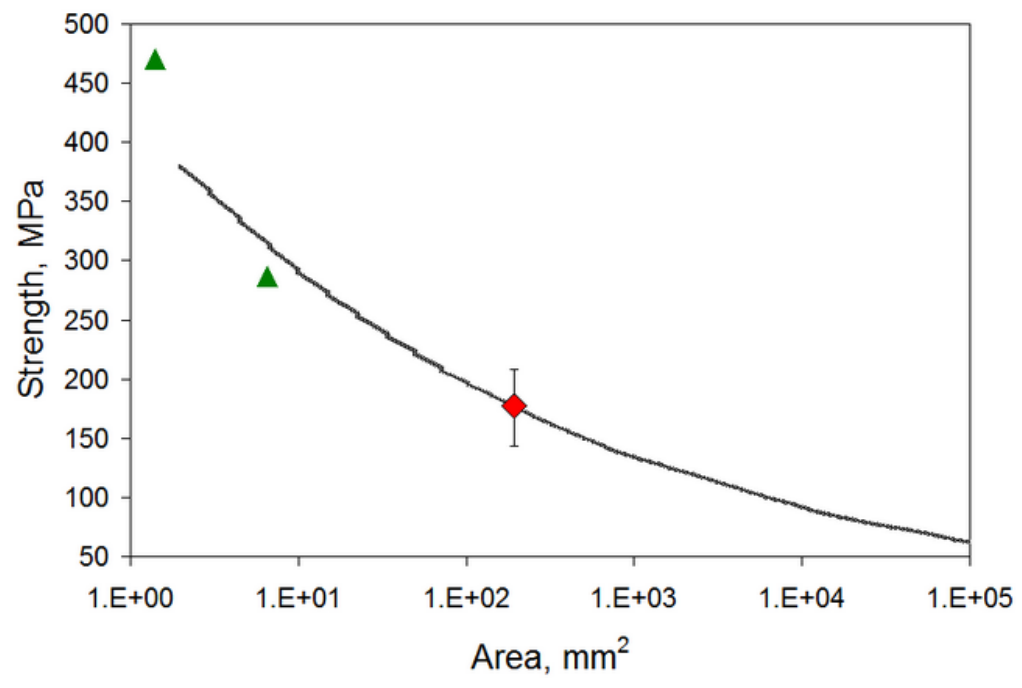

Fig. 56: Area effect on fracture strength in bending (black trend calculated from the experimental value (red) and Eq. 20) and from Brinell indentation (green triangles) for fine-grained spinel.

\subsubsection{Slow crack growth behavior}

An assessment of the effect of slow crack growth sensitivity of $\mathrm{MgAl}_{2} \mathrm{O}_{4}$ can be carried out using the strength values measured as a function of the loading rate (see also section 2.6.5). Graphical representations of data for the fine- and coarse-grained material are given in Fig. 57 and Fig. 58, respectively. The data were mathematically described using Eq. 25.

The derived SCG parameters for the fine-grained transparent $\mathrm{MgAl}_{2} \mathrm{O}_{4}$ are $n \sim 50$ and $D \sim 140 \mathrm{MPa}$. For the coarse-grained spinel $n \sim 23$ and $D \sim 71 \mathrm{MPa}$ (Fig. 58) are obtained.

RT values of $n \sim 8$ to 22 have been reported for soda lime glass and $n \sim 37-50$ for $\mathrm{Al}_{2} \mathrm{O}_{3}\left[{ }^{152}\right]$. Contrary to the SCG-sensitive soda lime glass, the high $n$ value of especially the fine-grained $\mathrm{MgAl}_{2} \mathrm{O}_{4}$ spinel, which is similar to that of $\mathrm{Al}_{2} \mathrm{O}_{3}$, indicates little influence of SCG at room temperature on the crack growth under standard environmental laboratory conditions. 


\section{Loading rate, $\mathrm{MPa} / \mathrm{s}$}

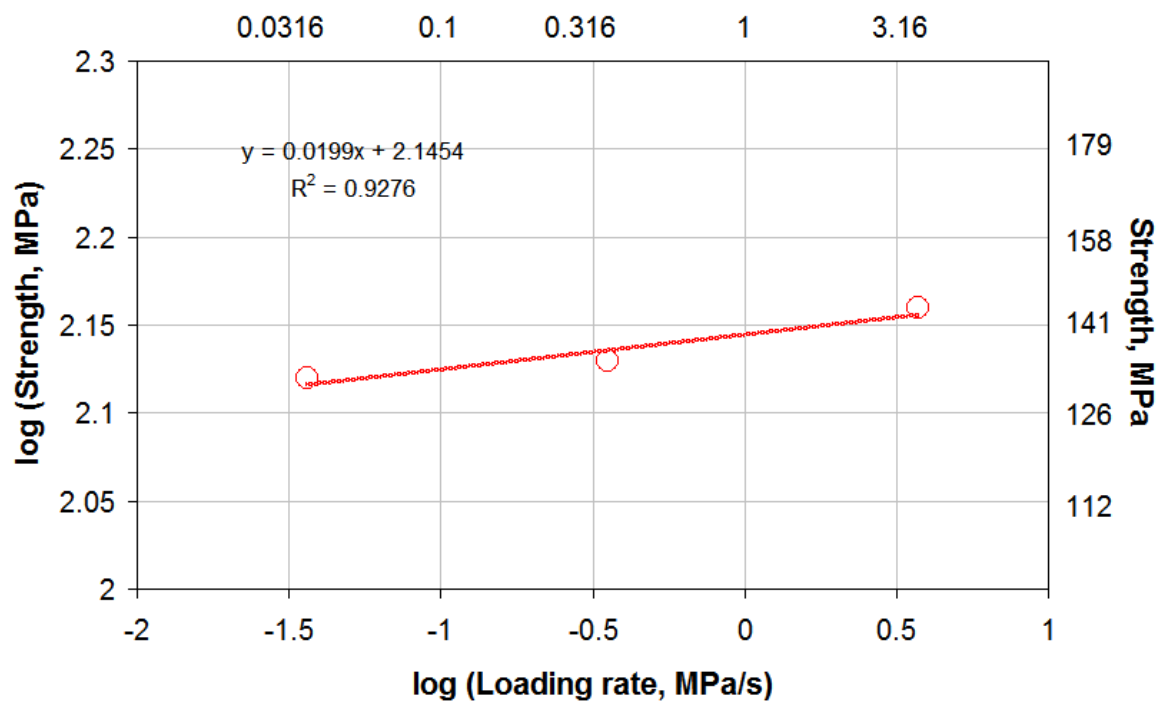

Fig. 57: Fracture strength as a function of the loading rate for the fine-grained spinel (the standard deviation for all data points is 4\%)

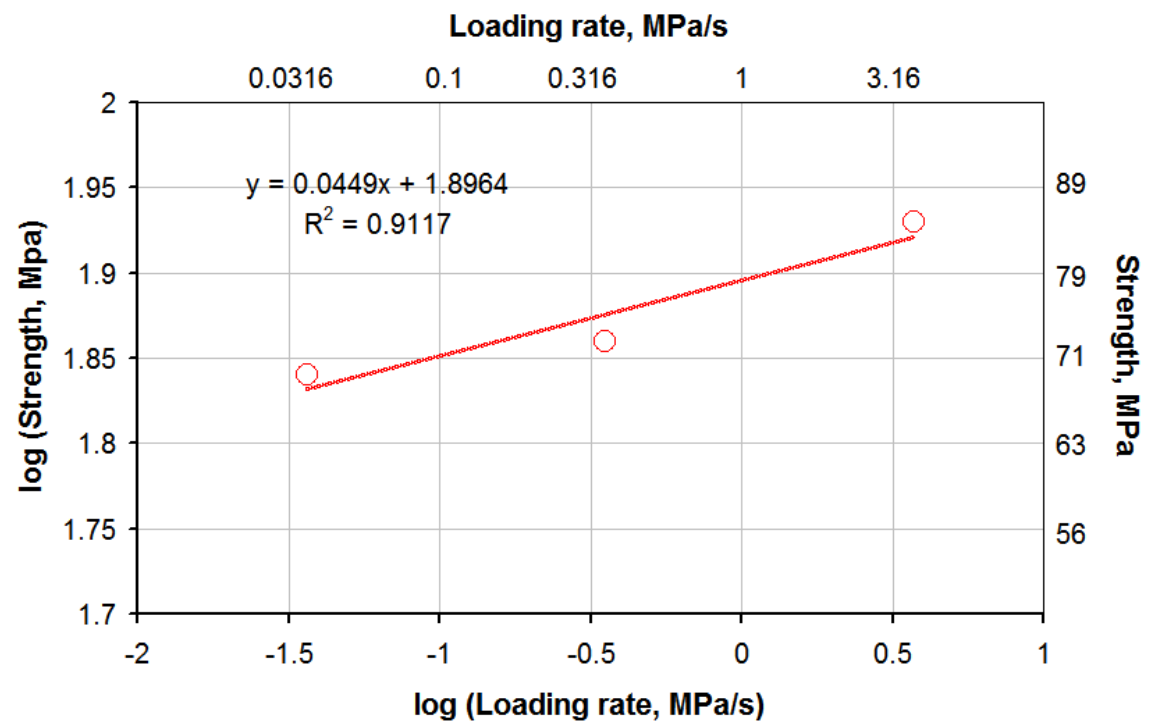

Fig. 58: Fracture strength as a function of the loading rate for the coarse-grained spinel (the standard deviations for all data points is 3\%) 


\subsubsection{Strength-probability-time behavior}

Based on the SPT diagram, the design stress for an acceptable failure probability can be estimated. The plots are constructed using strength, Weibull modulus and SCG parameters, as outlined in sections 2.6.4 and 2.6.5. As an example, Fig. 59 reveals that the maximum stress for a lifetime of 40 years should not exceed $56 \mathrm{MPa}$ in order to warrant a failure probability of $1 \%$ for the fine-grained spinel. Based on statistical evaluation of the coarse-grained spinel data, the respective SPT diagram (Fig. 60) yields a lower maximum stress of $25 \mathrm{MPa}$ for a lifetime of 40 years, warranting a failure probability of $1 \%$.

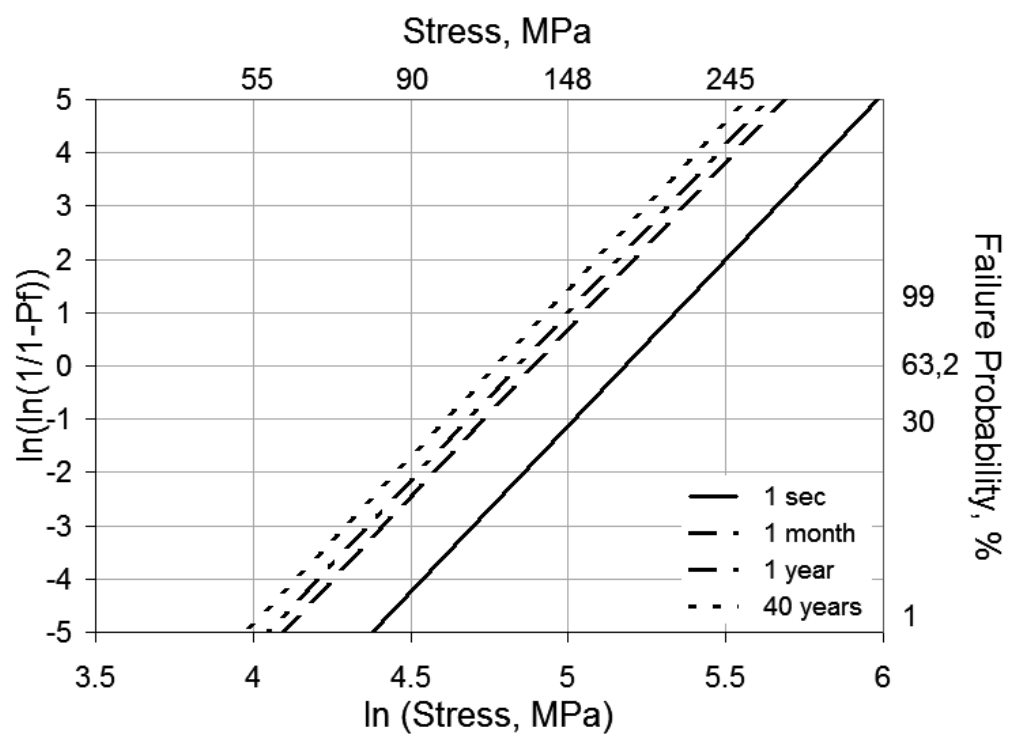

Fig. 59: Strength-probability-time plot for the fine-grained $\mathrm{MgAl}_{2} \mathrm{O}_{4}$ spinel

The SCG parameters $n$ and fracture stresses determined from the SPT plot for a lifetime of $1000 \mathrm{~h}$ are compared in Table 11 with literature data $\left[{ }^{153}\right]$ for other $\mathrm{MgAl}_{2} \mathrm{O}_{4}$ spinels.

The SPT calculations were made for the ring-on-ring specimens, according to Fig. 12. It should be noted that strength further decreases for larger component sizes, which have to be considered as outlined in section 4.9.1. 


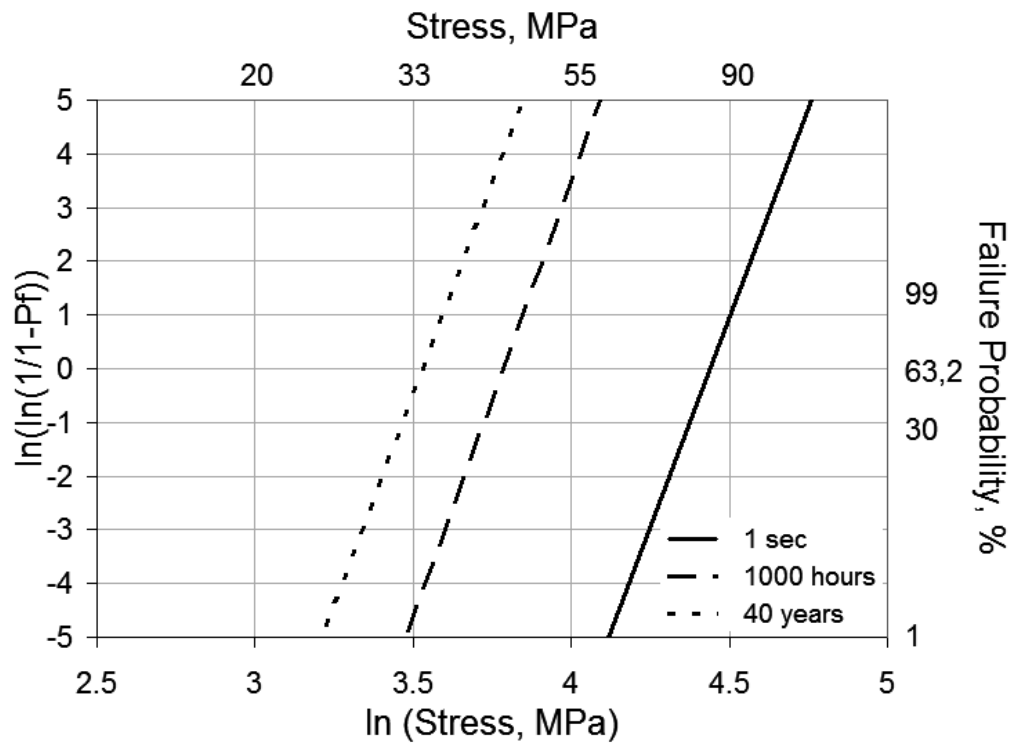

Fig. 60: Strength-probability-time plot for the coarse-grained $\mathrm{MgAl}_{2} \mathrm{O}_{4}$ spinel

Table 11. SCG parameter of spinels with different grain sizes from the present study (grey) and the literature (white) $\left.{ }^{153}\right]$.

\begin{tabular}{|l|c|c|c|c|c|}
\hline Grain size, $\boldsymbol{\mu m}$ & $\mathbf{3 0 0}$ & $\mathbf{1 1 0}$ & $\mathbf{6 0}$ & $\mathbf{2 5}$ & $\mathbf{5}$ \\
\hline SCG, $\boldsymbol{n}$ & 21 & 28 & 23 & 39 & 51 \\
\hline $\boldsymbol{\sigma}_{\boldsymbol{0}}, \mathbf{M P a}($ for $\mathbf{1 0 0 0 h ) *}$ & 31 & 35 & 44 & 52 & 106 \\
\hline
\end{tabular}

* characteristic strength $\sigma_{0}$ for $1000 \mathrm{~h}$ was calculated based on an SPT diagram.

The graphical presentation of these data in Fig. 61 clearly verifies that strength and slow crack growth parameters consistently decrease with increasing grain size. In fact, the grain size effect appears to be stronger for characteristic strength than for $n$. However, other production-related effects (different defect size distribution) might also influence the results. 


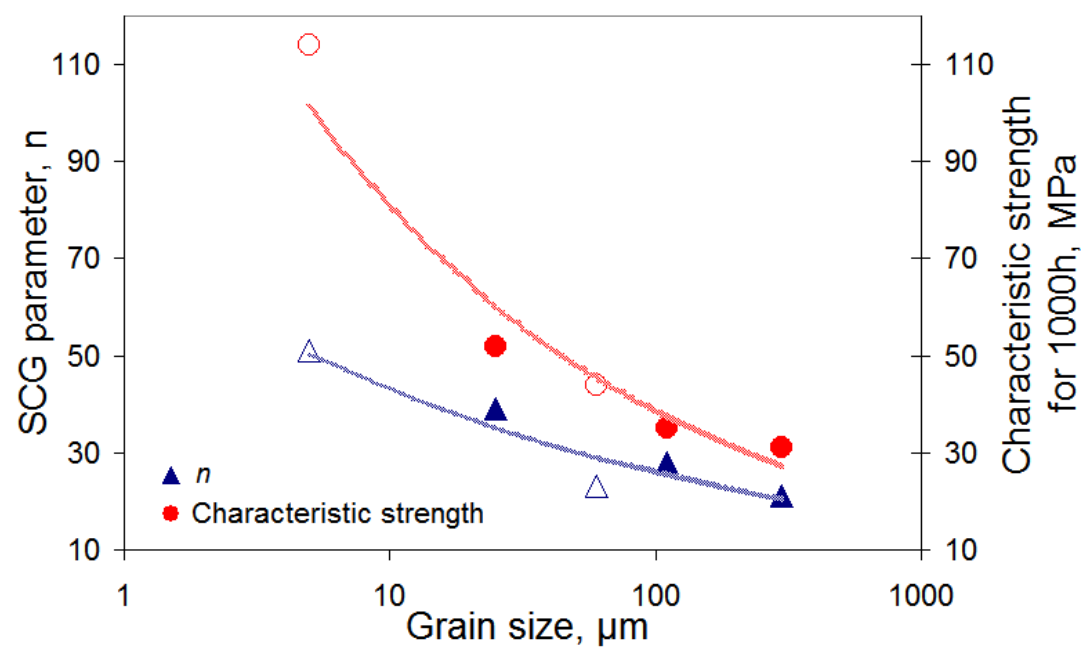

Fig. 61: Grain size dependency of SCG parameter and characteristic strength for $1000 \mathrm{~h}$ lifetime. Filled and unfilled circles are literature values and statistically calculated data from the present work, respectively. 


\section{CONCLUSION}

A combination of different mechanical testing methods has been used to characterize fine- and coarse-grained spinel materials. All obtained characteristics are summarized in Table 12.

The X-ray phase analysis revealed no differences in phase composition between both spinels, displaying face centered cubic crystalline structure with lattice parameter $a$ $=0.808 \mathrm{~nm}$. Average grain sizes of $\sim 5 \mu \mathrm{m}$ and $\sim 60 \mu \mathrm{m}$ were obtained for the fine- and coarse-grained spinel, respectively, on the basis of light and electron microscopic investigations. However, X-ray and EDX analysis confirmed that even though the grain size differs and coarse-grained agglomerates $(\sim 200-2000 \mu \mathrm{m})$ exist in the fine-grained spinel, the lattice parameter and phase composition were identical, making a direct comparison of both spinels possible.

The macro-indentation testing (which was carried out for a load range from 9.8 to $98 \mathrm{~N}$ ), revealed a hardness decrease from 17 to $13 \mathrm{GPa}$ for the fine-grained spinel, whereas hardness decreases even stronger for the coarse-grained material - from 16 to $9 \mathrm{GPa}$. However, micro-indentation yielded almost identical hardness values of $16 \pm 2 \mathrm{GPa}$ for both spinels, in a load ranging from 0.5 to $3 \mathrm{~N}$. Nevertheless, based on analysis presented in literature, it can be suggested that the coarse-grained spinel is less prone to impact damage due to the stronger indentation size effect (ISE). A detailed correlation of the measured hardness with the local microstructure of the specimens revealed that the coarse-grained material has hardness values ranging from $\sim 12$ to $17 \mathrm{GPa}$ for the entire range of existing grain sizes, a data range that seems to be more narrow than for the finegrained spinel, and, furthermore, exhibits lower average hardness values.

The fracture toughness for both spinels has been measured in a comparative approach by four different methods in order to obtain an accurate representation of the materials' behavior and to select the most appropriate and convenient method. The indentation fracture toughness $\left(K_{I N D}\right)$ appears to be less reliable than the other methods 
used, since specific materials' conditions (the minimum load necessary, strong local differences in grain structure and chipping at high loads) complicate the evaluation. Nevertheless, among the relationships used, the equations suggested by Lankford et al. and Niihara et al. appear to be the most accurate, which reveal a value of $K_{I N D}=2.0 \pm 0.1$ and $1.9 \pm 0.1 \mathrm{MPa} \cdot \mathrm{m}^{0.5}$ for the fine-grained spinel, respectively. The values obtained by the other methods $\left(K_{I S M}=1.9 \pm 0.2 \mathrm{MPa} \cdot \mathrm{m}^{0.5}, K_{S E N B}=1.8 \pm 0.2 \mathrm{MPa} \cdot \mathrm{m}^{0.5}\right.$ and $K_{I C \text { (Grifith) }}$ $=1.6 \pm 0.2 \mathrm{MPa} \cdot \mathrm{m}^{0.5}$ ) correspond well with the indentation fracture toughness and data presented in the literature. For the coarse-grained spinel, only $K_{I N D}$ and $K_{S E N B}$ values have been evaluated. In contrast to fine-grained spinel, only the indentation fracture toughness based on the Niihara equation $K_{I N D}=1.2 \pm 0.05 \mathrm{MPa} \cdot \mathrm{m}^{0.5}$ corresponds with the value obtained by the single-edge notch bending test $K_{S E N B}=1 \pm 0.4 \mathrm{MPa} \cdot \mathrm{m}^{0.5}$. In conclusion, for both spinels the indentation fracture toughness $\left(K_{I N D}\right)$ based on the Niihara equation can be applied as simplified and more rapid method for fracture toughness evaluation.

Young's modulus was also determined by several methods: indentation, bending tests and impulse-excitation (IE). Impulse-excitation tests resulted in identical values at room temperature for both materials of $E_{I E}=270 \pm 5 \mathrm{GPa}$. At elevated temperatures $\left(>1000{ }^{\circ} \mathrm{C}\right)$ the value decreases by $\sim 10 \%$. Despite careful compliance correction, the bending tests yielded $\sim 5 \%$ and $\sim 20 \%$ lower values for the fine- and coarse-grained spinel, respectively. The lowest values were obtained by indentation testing ( $25 \%$ lower). Overall, the IE and bending methods were recognized as most reliable and the data corresponded well with literature $\left[{ }^{1},{ }^{58-61}\right]$.

Surface quality, effective area, inherent defects and structure of the material strongly influence the fracture strength. In the ring-on-ring bending test, characteristic strengths of $\sigma_{0}=169 \pm 3 \mathrm{MPa}$ and $\sigma_{0}=77 \pm 1 \mathrm{MPa}$ were obtained for fine- and coarsegrained spinel, respectively. Subsequent fractographic analysis showed mixed trans- and intercrystalline fracture in fine- and pure intergranular fracture in the coarse-grained spinel. Due to the presence of coarse-grained agglomerates in the fine-grained spinel, crack growth is affected by these inhomogeneities. However, there is no correlation of fracture stress with size and volume content of the agglomerates. Furthermore, Hertzian indentation has proven to be a non-destructive characterization approach, capable of estimating the local strength. 
The experimentally obtained mechanical parameters were statistically analyzed using a Weibull distribution, a subcritical crack growth approach and strengthprobability-time prediction for long-term reliability assessment. In fact, the obtained characteristic strength $\sigma_{0}$ and slow crack growth exponent $n$ are almost a factor of 2.5 times higher for fine-grained spinel, whereas the Weibull modulus is a factor of 2 lower, compared to the coarse-grained spinel.

Overall, it can be concluded that the fine-grained spinel has a moderate strength but a lower sensitivy to slow crack growth, whereas the strength is less sensitive to the specimen size for the coarse-grained spinel, is less prone to impact damage, and has a higher Weibull modulus. 


\begin{tabular}{|c|c|c|c|c|}
\hline \multirow{3}{*}{ 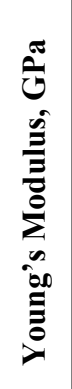 } & \multicolumn{2}{|c|}{ 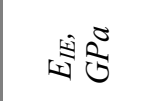 } & $\stackrel{n}{\stackrel{n}{*}}$ & 袋 \\
\hline & \multicolumn{2}{|c|}{ 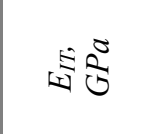 } & $\begin{array}{l}\stackrel{0}{\vec{H}} \\
\stackrel{0}{\vec{N}}\end{array}$ & 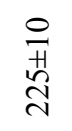 \\
\hline & \multicolumn{2}{|c|}{ 苛芯 } & $\begin{array}{l}n \\
\text { in } \\
\text { D } \\
\text { iv }\end{array}$ & $\begin{array}{l}\stackrel{n}{H} \\
\stackrel{+}{\sim}\end{array}$ \\
\hline \multirow{4}{*}{ 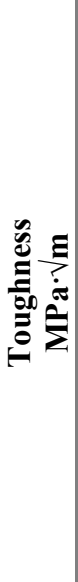 } & \multicolumn{2}{|c|}{ 氙害 } & $\begin{array}{l}\text { Nִ } \\
\text { Ḣ } \\
\stackrel{H}{0}\end{array}$ & \\
\hline & \multicolumn{2}{|c|}{ 氮 } & $\begin{array}{l}\text { Na } \\
\stackrel{+}{1} \\
\infty \\
\infty\end{array}$ & $\begin{array}{l}\stackrel{+}{0} \\
\stackrel{+}{+}\end{array}$ \\
\hline & \multicolumn{2}{|c|}{$\sqrt{2}$} & 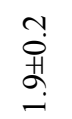 & \\
\hline & \multicolumn{2}{|c|}{ 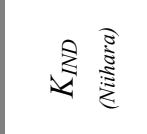 } & $\begin{array}{l}\overrightarrow{0} \\
\dot{+} \\
\text { g. }\end{array}$ & $\begin{array}{l}n \\
0 \\
0 \\
+1 \\
\end{array}$ \\
\hline \multicolumn{3}{|c|}{ 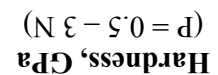 } & 븜 & 븜 \\
\hline \multirow{4}{*}{ 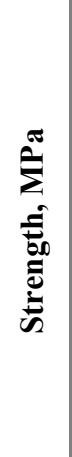 } & \multicolumn{2}{|c|}{$\underset{\omega}{0}=$} & $\bar{n}$ & 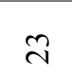 \\
\hline & \multirow{2}{*}{ 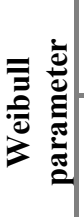 } & $\Xi$ & 苦 & $\stackrel{N}{+}$ \\
\hline & & 8 & 茾 & $\stackrel{\text { H }}{\stackrel{2}{*}}$ \\
\hline & \multicolumn{2}{|c|}{$\begin{array}{l}0 \\
\frac{8}{8} \\
\frac{0}{0} \\
\frac{8}{7}\end{array}$} & $\begin{array}{l}\infty \\
\text { In } \\
n \\
n \\
n\end{array}$ & 离 \\
\hline & & & 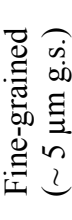 & 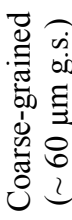 \\
\hline
\end{tabular}




\section{REFERENCES}

\footnotetext{
${ }^{1}$ A. Krell, T. Hutzler, J. Klimke, "Transmission physics and consequences for materials selection, manufacturing, and applications”, J. of the Europ. Ceram. Soc., 29 (2009), 207221.
}

2 A. Krell, T. Hutzler, J. Klimke, A. Potthoff, "Fine-Grained transparent spinel windows by the processing of different nanopowders”, J. Am. Ceram. Soc., 93 [9] (2010), 26562666.

3 S. C. Cooper, P. T. A. Hodson, "Magnesia-magnesium aluminate spinel as a refractory", Trans. J. Brit. Ceram. Soc., 81 (1982), 121-128.

4 G. Baudin, R. Martinez, P. Pena, "High-temperature mechanical behavior of stoichiometric magnesium spinel”, J. Am. Ceram. Soc., 8 [7] (1995), 1857-1862.

5 R. Dekkers C. F. Woensdregt, "Crystal structural control on surface topology and crystal morphology of normal spinel $\left(\mathrm{MgAl}_{2} \mathrm{O}_{4}\right)$ ", J. Crystal Growth 236 (2002), 441454.

${ }^{6}$ H. S. C. Oneill, A. Navrotsky, "Cation distributions and thermodynamic properties of binary spinel solid-solutions”, Am. Mineral. 69 [7-8] (1984), 733-753.

7 M. Ishimaru, et al., "Atomistic structures of metastable and amorphous phases in ionirradiated magnesium aluminate spinel”, J. Phys.-Condens. Matter, 14 [6] (2002), 12371247.

8 J. Shou-Yong et al., "Investigation on lattice constants of Mg-Al spinels", Journal of materials science letters, 19 (2000), 225-227.

9 T. R. Hinklin, R. M. Laine, "Systematic synthesis of metastable phases in the Magnesium Spinel - Alumina system”, Chem. Mater., 20 [2] (2008), 553-558.

10 M. F. Zawrah, "Investigation of lattice constant, sintering and properties of nano MgAl spinels", Mater. Sci. Eng. A., 382 (2004), 362-370.

11 A. Navrotsky, B. A. Wechsler, K. Geisinger, F. Seifert, "Thermochemistry of $\mathrm{MgAl}_{2} \mathrm{O}_{4}-\mathrm{Al}_{8 / 3} \mathrm{O}_{4}$ defects spinels”, J. Am. Ceram. Soc., 69 (1986), 418-422. 
12 A. D. Karisheff, "Refractory products and method of fabrication", France patent no. $350016,1905$.

13 Deepak Mohapatra, "Processing of $\mathrm{MgO}-\mathrm{MgAl}_{2} \mathrm{O}_{4}$ ceramics and study of its microstructure, strength and thermal shock resistance", Thesis, National Institute of Technology, Orissa, India, 2006.

14 Bray D. J., "Toxicity of chromium compounds formed in refractories", Bull. Amer. Ceram. Soc., 64 (1985), 1012-1016.

15 G. A. Gilde, P. J. Patel, M. Patterson, "Comparison of hot-pressing, rate-controlled sintering and microwave sintering of magnesium aluminate for optical applications", Proc. SPIE, 3705, Window and dome technologies and materials VI, 94 (1999).

16 D.C. Harris, "History of development of polycrystalline optical spinel in the US", Proc. SPIE, 5786 (2005), 1-22.

17 A. Gatti, Development of a process for producing transparent spinel bodies, Report, Department of the Navy, Washington D.C., 1969.

${ }^{18}$ G. I. Antonov, A. V. Kushchenko, O. M. Semenenko, G. N. Shcherbenko, "Synthesis of magnesia-alumina spinel using periclase and bauxite", Ogneupory, 10 (1991), 2-4.

19 D. W. Roy, "Hot pressed $\mathrm{MgAl}_{2} \mathrm{O}_{4}$ for UV visible and infrared optical requirements", Proc. SPIE, 297 (1981), 13-18.

20 P. Pramanik, "Chenical synthesis of nanosized oxides”, Bull. Mater. Sci., 19 (1996), 957-961.

21 Y. Ning, C. Li, "Structural inhomogeneity and crystallization behaviour of aersolreacted $\mathrm{MgAl}_{2} \mathrm{O}_{4}$ powders”, Mater. Lett., 15 [1-2], (1992), 84-88.

22 O. H. Varnier, A. Larbot, P. Bergez, L.C. Charpin, "Sol-gel synthesis of magnesium aluminum spinel from a heterometallic alkoxide", Mater. Res. Bull., 29 [5] (1994), 479488.

23 A. Krell, J. Klimke, T. Hutzler, "Advanced spinel and sub- $\mu \mathrm{m} \mathrm{Al}_{2} \mathrm{O}_{3}$ for transparent armour applications”, J. Eur. Ceram. Soc., 29 [2] (2009), 275-281.

24 M. F. Zawrah, A. A. El-Kheshen, "Synthesis and characterization of nanocrystalline $\mathrm{MgAl} / \mathrm{sub} 2 / \mathrm{O} / \mathrm{sub} 4 /$ ceramic powders by use of molten salts", Br. Ceram. Trans., 101 [2] (2002), 71-74. 
L. L. Shaw, Z. G. Yang, R. M. Ren, "Synthesis of nanostructured Si/sub 3/N/sub 4//SiC composite powders through high energy reaction milling”, Mater. Sci. Eng. A, 244 [1] (1998), 113-126.

26 R. N. Das, A. Pathak, P. Pramanik, "Low-temperature preparation of nanocrystalline lead zirconate titanate and lead lanthanum zirconate titanate powders using triethanolamine", J. Am. Ceram. Soc., 81 [12] (1998), 3357-3360.

27 M. Han, C. R. Vestal, Z. J. Zhang, "Quantum couplings and magnetic properties of $\mathrm{CoCr}_{\mathrm{X}} \mathrm{Fe}_{2-\mathrm{X}} \mathrm{O}_{4}(0<\mathrm{X}<1)$ spinel ferrite nanoparticles synthesized with reverse micelle method", J. Phys. Chem. B, 108 (2004), 583-587.

28 T. Yamamura, T. Hamazaki, H. Kato, "Alumina spinel castable refractories in steel teeming ladles”, Taikabutsu Overseas, 12 (1992), 21-27.

29 I. Ganesh et al., "Effect of fuel type on morphology and reactivity of combustion synthesised $\mathrm{MgAl}_{2} \mathrm{O}_{4}$ powders”, Br. Ceram. Trans., 101 (2002), 247-254.

30 I. Ganesh et al., "Microwave-assisted combustion synthesis of nanocrystalline $\mathrm{MgAl}_{2} \mathrm{O}_{4}$ powder”, Ceram. Int., 31 (2005), 67-74.

${ }^{31}$ A. K. Adak, S. K. Saha, P. Pramanik, "Synthesis and characterization of $\mathrm{MgAl}_{2} \mathrm{O}_{4}$ spinel by PVA evaporation technique”, J. Mater. Sci. Lett., 16 (1997), 234-235.

${ }^{32}$ C. Aksel, P. D. Warren, "Thermal shock parameters (R, R',' and R",') of magnesiaspinel composites”, J. Eur. Ceram. Soc., 23 [2] (2003), 301-308.

${ }^{33}$ R. D. Maschio, B. Fabbri, C. Fiori, "Industrial applications of refractories containing magnesium aluminate spinel”, Industrial Ceramics, 8 (1988), 121-126.

34 J. Szczerba et al., "Influence of raw materials morphology on properties of magnesiaspinel refractories", Journal of the European Ceramic Society, 27 [2-3] (2007), 16831689.

35 K. Hamano, S. Kanzaki, "Fabrication of transparent spinel ceramics by reactive hotpressing”, J. Ceram. Soc. Japan, 85 (1977), 225-230.

${ }^{36}$ Y. Kintaka, S. Kuretake, T. Hayashi, N. Tanaka, A. Ando, H. Takagi, "Crystal Structures and Optical Properties of Transparent Ceramics Based on $\mathrm{LaAlO}_{3}$ $\mathrm{Sr}(\mathrm{Al}, \mathrm{Ta}) \mathrm{O}_{3}$ Solid Solution”, J. Am. Ceram. Soc., 94 [12] (2011), 4399-4403.

37 Y. Kintaka, S. Kuretake, N. Tanaka, K. Kageyama, H. Takagi, "Crystal Structures and Optical Properties of Transparent Ceramics Based on Complex Perovskite 
$\mathrm{Ba}\left(\mathrm{M}^{4+}, \mathrm{B}_{1}{ }^{2+}, \mathrm{B}_{2}{ }^{5+}\right) \mathrm{O}_{3}\left(\mathrm{M}^{4+}=\mathrm{Ti}, \mathrm{Sn}, \mathrm{Zr}, \mathrm{Hf} ; \mathrm{B}_{1}{ }^{2+}=\mathrm{Mg}, \mathrm{Zn} ; \mathrm{B}_{2}{ }^{5+}=\mathrm{Ta}, \mathrm{Nb}\right)$ ”, J. Am. Ceram. Soc., 93 (2010), 1114-1119.

${ }^{38}$ P. G. Dehmar, A. J. Hsieh, P. J. Patel, J. M. Sands, "Protecting the future force: transparent materials safeguard the Army's vision”, AMPTIAC Quart, 8 [4] (2004).

39 A. Atkinson, P. Bastid, Q. Liu, "Mechanical properties of Magnesia-Spinel composites", J. Am. Ceram. Soc., 90 [8] (2007), 2489-2496.

40 D. Munz, T. Fett, "Ceramics mechanical properties, failure behaviour and materials selection”, Springer 1999, ISBN 3-540-65376-7

41 R. E. Carter, "Mechanism of solid state reaction between $\mathrm{MgO}-\mathrm{Al}_{2} \mathrm{O}_{3}$ and $\mathrm{MgO}-$ $\mathrm{Fe}_{2} \mathrm{O}_{3}$ ”, J. Am. Ceram. Soc., 44 [3] (1961), 116-120.

42 J. Beretka, T. Brown, "Effect of particle size on the kinetics of the reaction between magnesium and aluminium oxides", J. Am. Ceram. Soc., 66 [5] (1983), 383-388.

43 C. Garapan, H. Manaa, R. Moncorgé, “Absorption and fluorescence properties of $\mathrm{Cr}^{3+}$ doped nonstoichiometric green spinel”, J. Chem. Phys., 95 [8] (1991), 5501.

${ }^{44}$ H. C. Park, Y. B. Lee, K. D. Oh, F. L. Riley, "Grain growth in sintered $\mathrm{MgAl}_{2} \mathrm{O}_{4}$ spinel", Journal of materials science letters, 16 (1997), 1841-1844.

45 A. M. Alper, R. N. McNally, P. H. Ribbee, R. C. Doman, "The System MgO$\mathrm{MgAl}_{2} \mathrm{O}_{4}$ ”, J. Am. Ceram. Soc., 45 [6] (1962), 263-268.

${ }^{46}$ C. B. Huang, T. Lu, L. Lin, M. Lei, C. X. Huang, "A Study on Toughening and Strengthening of Mg-Al Spinel Transparent Ceramics”, Key Engineering Materials, 336338 (2007), 1207-1210.

47 J. F. Shackelford, R. H. Doremus, Ceramic and glass materials, Springer 2008, ISBN 978-0-387-73361-6.

${ }^{48}$ P. Shukla, A. Chernatynskiy, J. C. Nino, S. B. Sinnott, S. R. Phillpot, "Effect of inversion on thermoelastic and thermal transport properties of $\mathrm{MgAl}_{2} \mathrm{O}_{4}$ spinel by atomistic simulation", J Mater Sci., 46 (2011), 55-62.

49 S. Bhaduri, S. B. Bhaduri, "Phase and microstructural evolution of heat treated nanocrystalline powders in $\mathrm{Al}_{2} \mathrm{O}_{3}-\mathrm{MgO}$ binary system", NanoStructured Materials, 11 [4] (1999), 469-476. 
${ }^{50}$ T. J. Mroz, T. M. Hartnett, J. M. Wahl, L. M. Goldman, J. Kirsch, W. R. Lindberg, "Recent Advances in Spinel Optical Ceramic", Unclassified report, http://surmet.com/pdfs/news-and-media/

51 I. Ganesh, S. M. Olhero, A.H. Rebelo, J.M.F. Ferreira, "Formation and densification behavior of $\mathrm{MgAl}_{2} \mathrm{O}_{4}$ spinel: The influence of processing parameters", J. Am. Ceram. Soc., 91 [6] (2008), 1905-1911.

52 R. J. Bratton, "Sintering and grain-growth kinetics of $\mathrm{MgAl}_{2} \mathrm{O}_{4}$ ", J. Am. Ceram. Soc., 54 [3] (1971), 141-143.

53 D. M. Choi, H. Palmour, "Flow and fracture in spinel structured ceramics", Department of Eng. Research, North Carilona State University, 1965.

${ }^{54}$ R. O. Ritchie, C. J. Gilbert, J. M. McNaney, "Mechanics and mechanisms of fatigue damage and crack growth in advanced materials", Int. J. Solids Struc., 37 (2000), 311329.

55 G. R. Villalobos, J. S. Sanghera, I. D. Aggarwal, "Degradation of Magnesium Aluminum Spinel by Lithium Fluoride Sintering Aid”, J. Am. Ceram. Soc., 88 [5] (2005), $1321-1322$.

56 B. N. Kim, K. Hiraga, K. Morita, H. Yoshida, "Optical properties of transparent MgOdoped alumina fabricated by spark plasma sintering”, Materials Science Forum, 654-656 (2010), 2041-2044.

57 R. Apetz, M. P. B. Bruggen, “Transparent alumina: A light-scattering model”, J. Am. Ceram. Soc., 86 [3] (2003), 480-486.

${ }^{58}$ C. Aksel, B. Rand, F. L. Riley, P. D. Warren, "Mechanical properties of magnesiaspinel composites", J. of the Europ. Ceram. Soc., 22 (2002), 745-754.

59 S. Bhaduri, S. B. Bhaduri, "Microstructural and mechanical properties of nanocrystalline spinel and related composites”, Ceramics International 28 (2002), 153158.

60 Technology Assessment and Transfer, Inc, http://www.techassess.com/doc/spinel technical data.pdf, Brochure.

${ }^{61}$ Materials and Electrochemical Research Corp., http://www.mercorp.com/, Brochure.

62 R. L. Stewart, R. C. Bradt, "Fracture of polycrystalline $\mathrm{MgAl}_{2} \mathrm{O}_{4}$ ", J. Am. Ceram. Soc., 63 [11-12] (1980), 619-623. 
63 A. Ghosh, K. W. White, M. G. Jenkins, A. S. Kobayashi, R. C. Bradt, "Fracture resistance of a transparent magnesium aluminate spinel", J. Am. Ceram. Soc., 74 [7] (1991), 1624-1630.

64 J. C. Hay, K. W. White, "Grain-bridging mechanisms in monolithic alumina and spinel”, J. Am. Ceram. Soc., 76 [7] (1993), 1849-1854.

65 F. Beclin, R. Duclos, J. Crampon, F. Valin, "Microstructural superplastic deformation in $\mathrm{MgO} \cdot \mathrm{Al}_{2} \mathrm{O}_{3}$ spinel”, Acta. Metall., 43 [7] (1995), 2753-2760.

66 D. Duclos, N. Doukhan, B. Escaig, "High temperature creep behavior of nearly stoichiometric alumina spinel”, J. Mater. Sci., 13 [8] (1978), 1740-1748.

67 K. W. White, G. E. Kelkar, "Fracture Mechanisms of a Coarse-Grained, Transparent $\mathrm{MgAI}_{2} \mathrm{O}_{4}$, at Elevated Temperatures", J. Am. Ceram. Soc., 75 [12] (1992), 3440-3444.

68 J. B. Quinn, G. D. Quinn, "Indentation brittle of ceramics: A fresh approach", J. Mater. Sci., 32 (1997), 4331-4346.

69 A. Krell, "A new look at grain size and load effect in the hardness of ceramics", Materials Science and Engineering A, 245 (1998), 277-284.

70 A. Krell, "A new look at the influence of load, grain size, and grain boundaries on the room temperature hardness of ceramics", International Journal of Refractory Metals and Hard Materials, 16 (1998), 331-335.

71 P. J. Patel, J. J. Swab, M. Staley, G. D. Quinn, "Indentation Size Effect (ISE) of transparent AlON and $\mathrm{MgAl}_{2} \mathrm{O}_{4}$ ", Army Research Laboratory, ARL-TR-3852, 2006.

72 J. Gong, J. Wu, Z. Guan, "Examination of the indentation size effect in low-load Vickers hardness testing of ceramics", Journal of the European Ceramic Society, 19 (1999), 2625-2631.

73 A. Krell, A. Bales, "Grain size-dependent hardness of transparent Magnesium Aluminate Spinel”, Int. J. Appl. Ceram. Technol. 8 [5] (2011), 1108-1114.

74 A. R. G. Brown, E. Ineson, "Experimental survey of low-load hardness testing instruments”, J. Iron \& Steel Institute, 169 (1951), 376-388.

75 I. H. Bückle, "Use of the hardness test to determine other material properties", In: The Science of Hardness Testing and its Research Application, American Society for Metals, Metal Park, (1973), 453-494. 
${ }^{76}$ T. E. Wilantewicz, J. W. McCauley, "Analysis of hardness indentation size effect curves in ceramics: A new approach to determine plasticity", Advances in Ceramic Armor IV: Ceramic Engineering and Science Proceedings, 29 [6] (2009).

${ }^{77}$ F. H. Li, J. B. Li, H. Lin, C. X. Huang, M. Y. Lei, H. B. Du, "Development of transparent $\mathrm{MgAl}_{2} \mathrm{O}_{4}$ spinel ceramics", Key Engineering Materials, 434-435 (2010), 649652.

78 A. F. Dericioglu, A. R. Boccaccini, I. Dlouhy, Y. Kagawa, "Effect of chemical composition on the optical properties and fracture toughness", Materials Transactions, 46 [5] (2005), 996-1003.

79 I. Reimanis, H. J. Kleebe, “A review on the sintering and microstructure development of transparent spinel $\left(\mathrm{MgAl}_{2} \mathrm{O}_{4}\right)$ ”, J. Am. Ceram. Soc., 92 [7] (2009), 1472-1480.

80 B. N. Kim et al., "Microstructure and optical properties of transparent alumina", Acta Materialia, 57 [5] (2009), 1319-1326.

${ }^{81}$ G. Gilde, P. Patel, J. Sands P. Patterson, D. Blodgett, D. Duncan D. Hahn, "Evaluation of hot isostatic pressing parameters on the optical and ballistic properties of spinel for transparent armor", U.S. Army Research Laboratory, Attn. AMSRL-WM-MC Aberdeen Proving Ground, MD 21005.

82 A. Krell, E. Strassburger, "Discrimination of basic influences on the ballistic strength of opaque and transparent ceramics", ICACC-2012, Ceramic Armor Symposium, Daytona Beach, US.

83 R. Sarkar, S. K. Das, G. Banerjee, "Effect of attritor milling on the densification of magnesium aluminate spinel”, Ceram. Inter., 25 (1999), 485-489.

84 A. M. Alper, High Temperature oxide, Part IV, Academic Press, New York and London, 1971.

${ }^{85}$ M. Bengisu, Engineering ceramics, Springer, ISBN 3-540-67687-2

${ }^{86}$ M. Grujicic et. al, "Design and material selection guidelines and strategies for transparent armor systems", Materials \& Design, 34 (2012), 808-819.

87 DIN 50359-1 (1997-10-00), Testing of metallic materials - Universal hardness testing - Part 1: Test method, DIN Deutsches Institut für Normung e.V.

88 W. C. Oliver, G. M. Pharr, "Measurement of hardness and elastic modulus by instrumented indentation: Advances in understanding and refinements to methodology", J. Mater. Res., 19 [1] (2004), 3-21. 
89 ASTM Standard C1499-05, 2004, "Test Method for Monotonic Equibiaxial Flexural Strength of Advanced Ceramics at Ambient Temperature", ASTM International, DOI: 10.1520/C1499-05, www.astm.org.

90 A. K. Swarnakara, S. Giménezb, S. Salehic, J. Vleugelsd, O. Van der Bieste, "Recent Advances in Material Characterization using the Impulse Excitation Technique (IET)", Key Engineering Materials, 333 (2007), 235-238.

91 Y. Qiu, Y. Bao, X. Liu, X. Wang, K. Li, "Comparison and relative error of elastic modulus in glass measured by tree tests techniques”, Key Engineering Materials, 434-435 (2010), 209-213.

92 A. G. Evans, E. A. Charles, "Fracture toughness determination by indentation", J. Amer.Ceram. Soc., 59 [7-8] (1976), 371-372.

93 K. Niihara, R. Morena, D. P. H. Hasselman, "Evaluation of $\mathrm{K}_{\mathrm{IC}}$ of brittle solids by the indentation method with low crack-to-indent ratios", J. Mater. Sci. Lett., 1 (1982), 13-16.

94 G. R. Anstis, P. Chantikul, B. R. Lawn, D. B. Marshall, "A Critical Evaluation of Indentation Techniques for Measuring Fracture Toughness: I, Direct crack measurements", J. Am. Ceram. Soc. 64 (1981), 533-538.

95 B. R. Lawn, A. G. Evans, D. B. Marshall, "Elastic/Plastic indentation damage in ceramics: The median/radial crack system”, J. Am. Ceram. Soc., 63 [9-10] (1980), 574581 .

96 P. Chantikul, G. R. Anstis, B. R. Lawn, D. B. Marshall, "A Critical Evaluation of Indentation Techniques for Measuring Fracture Toughness: II, Strength methods", J. Am. Ceram. Soc., 64 (1981), 539-543.

97 M. W. Barsoum, Fundamentals of ceramics, IOP Publishing Ltd 2003, ISBN: 0-75030902-4.

98 J. M. J. den Toonder, "A general introduction to fracture mechanics and mechanical strength of materials", Unclassified report, Philips Electronics, 1998.

99 J. Lankford, "Indentation microfracture in the Palmqvist crack regime: implications for fracture toughness evaluation by the indentation method”, J. Mater. Sei. Lett., 1 [11] (1982), 493-495.

100 J. J. Petrovic, "Effect of Indenter Geometry on controlled-surface-flaw fracture toughness", J. Am. Ceram. Soc., 66 [4] (1983), 277-283. 
101 ISO 13586:2000, Plastics - Determination of fracture toughness $\left(\mathrm{G}_{\mathrm{IC}}\right.$ and $\left.\mathrm{K}_{\mathrm{IC}}\right)$ Linear elastic fracture mechanics (LEFM) approach.

102 J. E. Srawley, W. F. Brown, "Fracture toughness testing methods", ASTM STP 381 (1965), 133-145.

103 A. A. Griffith, "The phenomena of rupture and flow in solids", Philosophical Transactions of the Royal Society of London, A 221 (1921), 163-198.

104 G. Irwin, "Analysis of stresses and strains near the end of a crack traversing a plate", Journal of Applied Mechanics, 24 (1957), 361-364.

105 T. L. Anderson, Fracture mechanics: fundamentals and applications, CRC Press, 2005.

106 J. B. Wachtman, Mechanical Properties of Ceramics, Wiley, New York, 1996.

107 S. M. Weiderhorn, E. R. Fuller Jr., "Structural Reliability of Ceramic Materials", Mater. Sci. Eng., 71 (1985), 169-186.

108 W. Weibull, “A Statistical Theory of the Strength of Materials”, Proc. R. Swed. Inst. Eng. Res., 151 (1939), 1-45.

109 W. Weibull, “A Statistical Distribution Function of Wide Applicability”, J. Appl. Mech., 18 (1951), 293-297.

110 C. Lu, R. Danzer, F.D. Fischer, "Influence of threshold stress on the estimation of the Weibull statistics", J. Am. Ceram. Soc. 85 (2002), 1640-1642.

111 S. L. Fok, B. C. Mitchell, J. Smart, B.J. Marsden, "A numerical study on the application of the Weibull theory to brittle materials", Eng. Fract. Mech., 68 (2001), 1171-1179.

112 J. Smart, B. C. Mitchell, S. L. Fok, B. J. Marsden, "The effect of the threshold stress on the determination of the Weibull parameters in probabilistic failure analysis", Eng. Fract. Mech., 70 (2003), 2559-2567.

113 S. R. Choi, J. A. Salem, F. A. Holland, "Estimation of slow crack growth parameters for constant stress-rate test data of advanced ceramics and glass by the individual data and arithmetic mean methods", NASA Technical Memorandum 107369, 1997.

114 W. D. Callister Jr., Materials Science and Engineering an Introduction, John Wiley and Sons, Inc., 5th edition, 1999. ISBN 0-471-32013-7. 
115 ASTM Standard C1239-06A, 2007, "Standard practice for reporting uniaxial strength data and estimating Weibull distribution parameters for advanced ceramics", ASTM International, DOI: 10.1520/ C1239-06A, www.astm.org.

116 DIN EN 843-5: Advanced technical ceramics - Mechanical properties of monolithic ceramics at room temperature - Part 5: Statistical analysis, DIN Deutsches Institut für Normung e.V.

117 R. Danzer, T. Lube, P. Supancic, J. Pascual, "Fracture statistics of ceramics - Weibull statistics and deviations from Weibull statistics", Eng. Fract. Mech., 74 [18] (2007), 2919.

118 De With G, Structure, deformation, and integrity of materials, Vol I. Wiley, New York, 2006.

119 R. B. Abernethy, The New Weibull Handbook, Fourth Edition, 2000, ISBN 09653062-1-6

120 S. S. Pai, J. P. Gyekenyesi, "Calculation of Weibull strength parameters and Batdorf flow-density constants for volume- and surface-flaw-induced fracture in ceramics", NASA Technical Memorandum 100890, 1988.

121 J. A. Salem, L. Powers, "Guidelines for the testing of plates", Proc. 27th Int. Cocoa Beach Conf., Ceram. Eng. Sci. Proc., 24 [4] (2003), 357-364.

122 R. L. Barnett, C. L. Connors, P. C. Hermann, J. R. Wingfield, "Fracture of brittle materials under transient mechanical and thermal loading", U.S. Air Force Flight Dynamics Laboratory, AFFDL-TR-66-220, 1967.

123 K. Trustrum, A. D. Jayatila, "On estimating the Weibull modulus for a brittle material”, J. Mater. Sci. 14 (1979), 1080-1084.

124 O. M. Jadaan, A. A. Wereszczak, K. E. Johanns, W. L. Daloz, "Weibull effective area for Hertzian ring crack initiation”, Int. J. Appl. Ceram. Technol., 8 [4] (2011), 824-831.

125 Y. W. Bao, S. B. Su, J. J. Yang, L. Sun, J. H. Gong, "Nondestructively determining local strength and residual stress of glass by Hertzian indentation", Acta Mater., 50 [18] (2002), 4659-4666.

126 N. Nagabhushana, T. Nithyanantham, S. Bandopadhyay, J. Zhang, "Subcritical crack growth behavior of a Perovskite - type oxygen transport ceramic membrane", Int. J. Appl Ceram Technol, 8 [2] (2011), 390-397.

127 Barsoum M. W., Fundamentals of ceramics, McGraw-Hill, New York, 1996. 
${ }^{128}$ E. C. Teixeira, J. R. Piascik, B. R. Stoner, J. Y. Thompson, "Dynamic fatigue and strength characterization of three ceramic materials”, J Mater Sci. Mater Med, 18 (2007), 1219-1224.

129 R. W. Davidge, J. R. McLaren, G. Tappin, "Strength-probability-time (SPT) relationships in ceramics", J. Mat. Sci., 8 [12] (1973), 1699-1705.

130 J. F. Doyle, J. W. Phillips, Manual on experimental stress analysis, Fifth edition, Society for experimental mechanics, Bethel, Connecticut, 1989.

131 J. W. Phillips, "Experimental stress analysis", Unclassified report, http://www.ifsc.usp.br/ lavfis/BancoApostilasImagens/ApEfFotoelastico/photoelasticity. pdf.

132 M. I. Mendelson, "Average grain size in polycrystalline ceramics", J. Am. Ceram. Soc., 52 (1969), 443-446.

133 ASTM E 1876-01, "Standard Test Method for Dynamic Young's Modulus, Shear Modulus, and Poisson's Ratio by Impulse Excitation of Vibration", In: Annual Book of ASTM Standards, Vol. 03.01 (ASTM, West Conshohocken 1995).

134 BS/EN/ISO 1288-1, "Glazing in Building - Determination of the bending strength of glass Part 1: Fundimentals of testing glass".

135 R. W. Schmitt, K. Blank, G. Schönbrunn, "Experimentelle Spannungsanalyse zum Doppelringverfahren”, Sprechsaal, 116 (1983), 397-405.

136 R. Kao, N. Perrone, W. Capps, "Large Deflection Solution of the Coaxial-RingCircular-Glass-Plate Flexure Problem”, J. Am. Cer. Soc., 54 (1971), 566-571.

137 DIN 1288-1, 2000: "Bestimmung der Biegefestigkeit von Glas", DIN Deutsches Institut für Normung e.V.

138 J. A. Salem, G.D. Quinn, M.G. Jenkins, "Fracture resistance testing of monolithic and composite brittle materials", STP 1409, ASTM International 2002, ISBN 0-8031-2880-0.

139 DIN 51105:2010-08: "Hochleistungskeramik - Mechanische Eigenschaften monolithischer Keramik bei Raumtemperatur - Bestimmung der DoppelringBiegefestigkeit”, DIN Deutsches Institut für Normung e.V.

140 ASTM C1421 - 10, "Standard Test Methods for Determination of Fracture Toughness of Advanced Ceramics at Ambient Temperature", ASTM International, DOI: 10.1520/ C1421-10, www.astm.org. 
141 M. S. Bobji, S. K. Biswas, "Hardness of a surface containing uniformly spaced pyramidal asperities", Trib. Lett. 7 (1999), 51.

142 W. W. Gerberich et al., "Interpretation of indentation size effect", Journal of Applied Mechanics, 69 (2002), 433 - 442.

143 C. Hilton, J. McCauley, J. Swab, E. Shanholtz, "Using hardness tests to determine plasticity and predict impact performance", Proc. 36th Int. Daytona Beach Conference, 2012 .

144 D. Hallam, A. Miller, M. Robinson, P. Brown, A. Heaton, B. James, P. Smith, J. Yeomans, "An evaluation of the relationship between indentation size effect and ballistic performance in a range of ceramic materials", Proc. 36th Int. Daytona Beach Conference, 2012.

145 G.D. Quinn, R.C. Bradt, "On the Vickers indentation fracture toughness test”, J. Am. Cer. Soc., 90 [3] (2007), 673-680.

146 J. Malzbender, R. W. Steinbrech, "Threshold fracture stress of thin ceramic components", Journal of the European Ceramic Society, 28 [1] (2008), 247-252.

147 S. L. Fok, B. C. Mitchell, J. Smart, B. J. Marsden, "A numerical study on the application of the Weibull theory to brittle materials", Engineering Fracture Mechanics, 68 (2001), 1171-1179.

148 R. Danzer, P. Supancic, J. Pascual, T. Luba, "Fracture statistics of ceramics - Weibull statistics and deviations from Weibull statistics", Engineering Fracture Mechanics, 74 (2007), 2919-2932.

149 R. Riedel, Handbook of Ceramics Hard Materials, Wiley-VCH, 2000, ISBN 3-52729972-6.

${ }^{150}$ K. P. R. Reddy, A.R. Cooper, "Oxygen diffusion in magnesium aluminate spinel”, J. Am. Ceram. Soc., 64 [6] (1981), 368-371.

151 G. D. Quinn, Fractography of Ceramics and Glasses, NIST, 2007

152 D. K. Palchaev et al., "Resistance of brittle materials to slow crack growth", Steklo i Keramika, 6 (1983), 27-29.

153 J. Salem, "Slow crack growth in spinel $\left(\mathrm{MgAl}_{2} \mathrm{O}_{4}\right)$ ", Proc. 35th Int. Daytona Beach Conference, 2011. 


\section{ACKNOWLEDGMENTS}

Although only one name is listed in the author line of this thesis, its appearance would not be possible without the much-appreciated assistance of many individuals. First, I would like to express my sincere gratitude to Prof. L. Singheiser for giving me the opportunity to work in the Institute of Energy and Climate Research (IEK-2), Forschungszentrum Jülich.

Dr. J. Malzbender, Dr. R.W. Steinbrech and Prof. T. Beck are kindly acknowledged for their inestimable contribution to my research work, their instructions and constant availability to support my initiative.

I am very grateful to my colleagues from IEK-2, as well as colleagues at the partner institute IEK-1 - namely Dr. W. Fischer and Mr. M. Ziegner for the XRD investigations; Dr. E. Wessel and Dr. D. Grüner for the SEM studies; Dr. H. J. Penkalla and Ms. D. Esser for the TEM studies; Mr. J. Bartsch and Mr. V. Gutzeit for the optical microscopy and assistance with metallographic preparation; and Mr. P. Joecken, Mr. W. Dank and Mrs. M. Felden for their technical support.

Special thanks also to Dr. L. Schnetter and Ms. H. Menges from CeramTec-ETEC $\mathrm{GmbH}$, for their collaboration and valuable discussions.

I would also like to express my gratitude to Dr. M. Bläsing, Mr. K. Watermeyer and Mr. A. Yakubovsky for their assistance in the experimental and calculation portions of the thesis.

Many thanks go to all the colleagues of the Materials Mechanics Group and particularly to Mr. J. Mönch, Ms. T. Osipova, Mr. R. Küppers for their invaluable technical support; and Prof. W. Araki, Dr. M. Lipinska-Chwalek, Dr. B. X. Huang, Ms. V. Stournari and Dr. G. Pećanac for their help and fruitful dialogue.

This work would have been much more difficult without the support of my family and friends throughout these years. 
The study was financially supported by the German Federal State of Northrhine Westfalia (Project TRANAK: Transparente Nano Keramik). 

Band / Volume 202

Full-waveform inversion of surface ground penetrating radar data and coupled hydrogeophysical inversion for soil hydraulic property estimation S. Busch (2013), $112 \mathrm{pp}$

ISBN: 978-3-89336-930-0

Band / Volume 203

Politikszenarien für den Klimaschutz VI -

Treibhausgas-Emissionsszenarien bis zum Jahr 2030

Advances in Systems Analysis 5

P. Hansen, S. Gores und F. Chr. Matthes (Hrsg.)

(2013), XX, $257 \mathrm{pp}$

ISBN: 978-3-89336-932-4

Band / Volume 204

Effect of Composition, Microstructure and Component Thickness

on the Oxidation Behaviour of Laves Phase Strengthened Interconnect

Steel for Solid Oxide Fuel Cells (SOFC)

C. Asensio Jimenez (2014), 210 pp

ISBN: 978-3-89336-935-5

Band / Volume 205

Airborne VOC measurements on board the Zeppelin NT during the PEGASOS campaigns in 2012 deploying the improved Fast-GC-MSD

System

J. Jäger (2014), VIII, 182 pp

ISBN: 978-3-89336-936-2

Band / Volume 206

Pulvermetallurgische Funktionsbauteile aus NiTi- und NiTi-X

Legierungspulvern

M. Bitzer (2014), III, 144 pp

ISBN: 978-3-89336-937-9

Band / Volume 207

Zinkoxid: Einfluss von Dotierung und Legierungen auf elektro-optische Eigenschaften, auf das Ätzverhalten und auf die Tempernachbehandlung M. Warzecha (2014), 8, vii, $170 \mathrm{pp}$

ISBN: 978-3-89336-938-6

Band / Volume 208

SGSreco - Radiologische Charakterisierung von Abfallfässern

durch Segmentierte y-Scan Messungen

T. H. Krings (2014), ix, 181, XI

ISBN: 978-3-89336-945-4 
Band / Volume 209

Kühlkonzepte für Hochtemperatur-Polymerelektrolyt-BrennstoffzellenStacks

J. Supra (2014), III, 191 pp

ISBN: 978-3-89336-946-1

Band / Volume 210

Eigenschaften des Phosphorsäure-Polybenzimidazol-Systems in Hochtemperatur-Polymerelektrolyt-Brennstoffzellen

A. Majerus (2014), viii, $141 \mathrm{pp}$

ISBN: 978-3-89336-947-8

Band / Volume 211

Study on the Complex Li-N-H Hydrogen Storage System

L. Du (2014), I, 132 pp

ISBN: 978-3-89336-952-2

Band / Volume 212

Transport and Retention of Stabilized Silver Nanoparticles in Porous Media

Y. Liang (2014), IV, $109 \mathrm{pp}$

ISBN: 978-3-89336-957-7

Band / Volume 213

Effizienzoptimierte $\mathrm{CO}_{2}$-Abtrennung in IGCC-Kraftwerken mittels Wassergas-Shift-Membranreaktoren

Schiebahn, S. T. (2014), XXII, 203 pp

ISBN: 978-3-89336-958-4

Band / Volume 214

Lebensdauer und Schädigungsentwicklung martensitischer Stähle für Niederdruck-Dampfturbinenschaufeln bei Ermüdungsbeanspruchung im VHCF-Bereich

Kovacs, S. (2014), IV, 140 pp

ISBN: 978-3-89336-959-1

Band / Volume 215

Micro- and Macro- Mechanical Testing of Transparent $\mathrm{MgAl}_{2} \mathrm{O}_{4}$ Spinel Tokariev, O. (2014), X, 99 pp

ISBN: 978-3-89336-960-7

Weitere Schriften des Verlags im Forschungszentrum Jülich unter http://wwwzb1.fz-juelich.de/verlagextern1/index.asp 



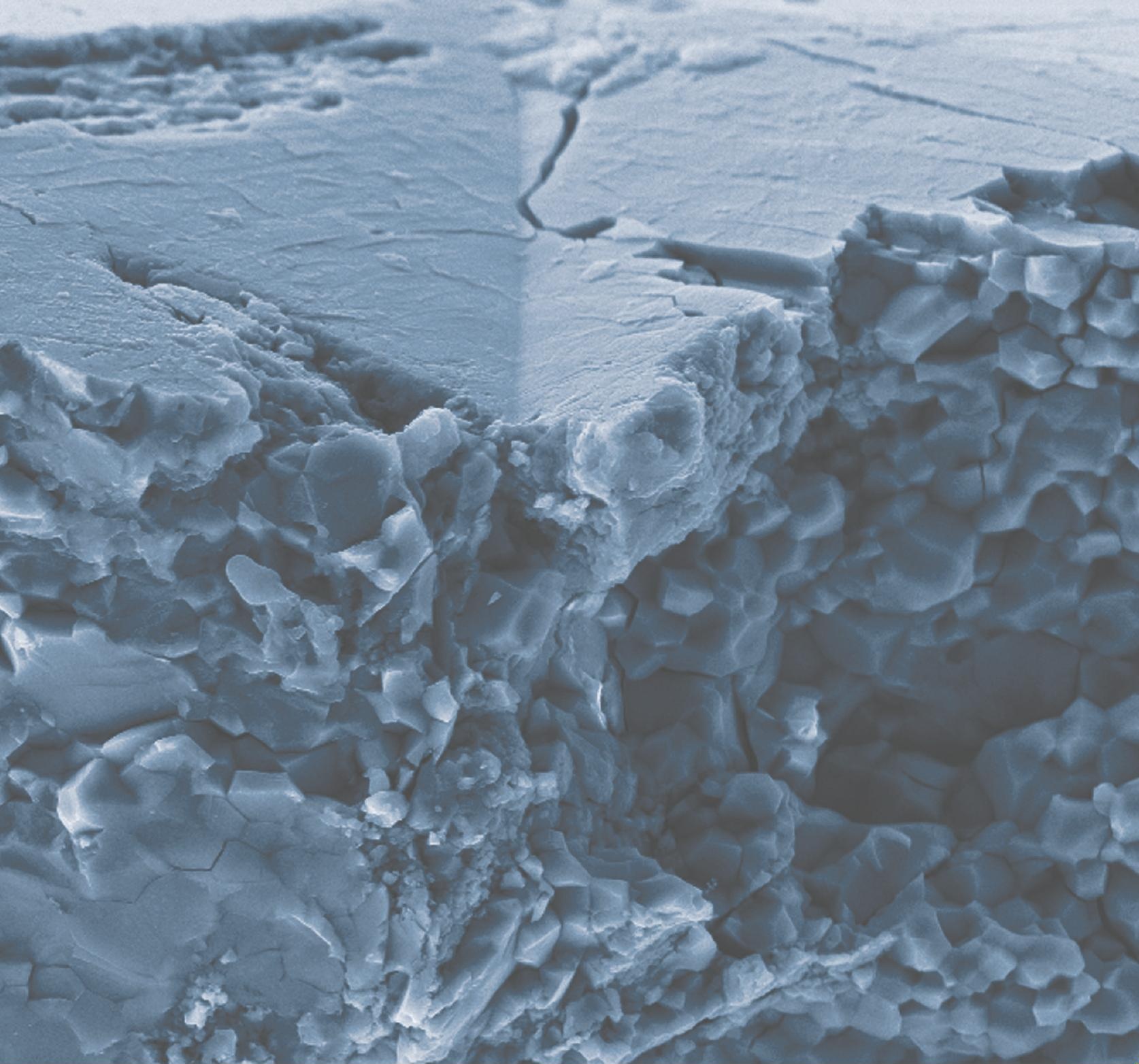

Energie \& Umwelt / Energy \& Environment

Band/Volume 215

ISBN 978-3-89336-960-7

J JöLICH 